$\begin{array}{llllllllllll}\text { B } & \text { I } & \text { B } & \text { L } & \text { I } & \text { O } & G & \text { R } & \text { A } & \text { F } & \text { I } & \text { A }\end{array}$ 
Daniel González Lagier y Juan Antonio Pérez Lledó (coords.)

\section{LA FILOSOFÍA DEL DERECHO EN ESPAÑA (1987)}

Esta sección ha sido coordinada por Daniel González Lagier y Juan Antonio Pérez Lledó. Las reseñas que no aparecen firmadas han sido elaboradas por los propios autores de los artículos o libros objetos de las mismas. 
AARNIO, Aulis.

Sobre la ambigüedad semántica en la interpretación jurídica (trad. José Pedro Ubeda).

Doxa, Alicante, núm. 4, 1987, págs. 109-117.

En el presente trabajo el autor pretende realizar una comparación teórica entre la ambigüedad semántica en textos jurídicos, por un lado, y en la literatura, por otro; y para ello toma como punto de partida un estudio de Leena Kirstinä.

En este sentido, el autor concluye: «La referencia a lo autorizado en la interpretación jurídica es la característica distintiva más significativa entre las dos. Los objetos de la interpretación jurídica son los textos promulgados oficialmente, cuya función es servir como instrumentos en el ejercicio del poder social. Por consiguiente, la interpretación jurídica está más atada que la interpretación de una novela en cuanto se refiere a las fuentes y los principios que rigen su uso. A pesar de ello, la teoría de la interpretación de una novela parece ofrecer varias ideas nuevas a la teoría jurídica. Pienso, en particular, en el análisis del proceso de interacción, que ha sido ampliamente estudiado por los eruditos de la literatura. Además, el cambio de ideas no necesita ser unilateral. Por ejemplo, en la teoría de la novela el concepto y el estatus del auditorio de la interpretación se ha demostrado problemático en muchos aspectos. En este contexto, la teoría jurídica podría tener algo que ofrecer a la teoría de la literatura. En resumen, la imprecisión semántica intencional, usada como medio estilístico en literatura, tiene mucho en común con su contrapartida jurídica, la ambigüedad semántica no pretendida en los textos jurídicos.»

(Josep Aguiló Regla)

ALARCÓN CABRERA, Carlos.

Reflexiones sobre la igualdad material. 
Anuario de Filosofía del Derecho, Madrid, núm. 4, 1987, págs. 31-42.

Tras rechazar una noción física de la igualdad, el autor analiza las dos dimensiones en que, en su opinión, puede descomponerse la igualdad material: la igualdad como punto de partida (igualdad de oportunidades) y la igualdad como punto de llegada (igualdad de resultados).

«La igualdad como punto de partida expresa no discriminación mediante obstáculos arbitrarios para alcanzar posiciones sociales y, en particular, para acceder con las mismas posibilidades que los demás a los procesos de producción y distribución de bienes o de toma de decisiones políticas.» Pero esta igualdad posee ciertos impedimentos que frenan su realización y la desvirtúan, como, por ejemplo, la existencia de circunstancias amparadas por la ley y que son determinantes del logro de un cierto puesto social.

Frente a estos inconvenientes entraría en juego la igualdad de resultados, determinada por medio de una regulación que repercute en una distribución semejante de los bienes. Un primer método para alcanzar esta igualdad podría consistir en la repartición igualitaria de los bienes primarios; pero, de acuerdo con la crítica marxista, el «derecho igual» revertiría en una acentuación de las desigualdades, que sólo podrían evitarse mediante el derecho desigual o equitativo. Ante el problema de determinar cuándo existen las diferencias suficientes que justifiquen la aplicación de un distinto tratamiento, el autor opta por el criterio según el cual la existencia de una necesidad autoriza un tratamiento diferenciado, consistente en la satisfacción de esa necesidad. La determinación de estas necesidades es muy conflictiva, sólo existiendo acuerdo respecto a aquellas necesidades básicas mínimas (salud, vivienda, educación, alimentación y cultura).

Pero esta pauta para la aplicación de un trato desigual debe completarse, en opinión del autor, con otros parámetros como son el criterio cuantitativo del rendimiento (justificado por su utilidad práctica para el crecimiento económico) y el criterio de la capacidad (que provocaría una distribución más eficaz de los empleos).

Para finalizar el autor analiza la relación existente entre la igualdad material y la libertad, no considerando estos valores en absoluto incompatibles, sino más bien al contrario: «la libertad, como opuesta a la igualdad, equivale exclusivamente a la libertad de los agraciados económicamente (...) Cuando hablamos de igualdad material entendemos por ella una misma libertad de todos, no idéntica ni para los mismos objetivos, pero sí con las mismas posibilidades».

(Isabel Lifante Vidal) 
ÁLVAREZ, Norberto.

La fuerza en el Derecho.

Anuario de Filosofía del Derecho, Madrid, núm. 4, (Nueva Época) 1987, págs. 625-638.

¿Es realmente la fuerza una nota esencial del concepto de Derecho? Para responder a esta cuestión, el autor analiza los modos en que la fuerza puede aparecer en el Derecho: como sanción (castigo $a$ posteriori por haber infringido una norma), coacción (actuación sobre el sujeto impeliéndole físicamente al cumplimiento de la norma), coercibilidad (posibilidad de acudir a la fuerza), referencia a la aplicación de la fuerza (en el sentido defendido por Ross para dar cuenta de las normas de organización) o simple vocación potencial de la norma para estar dotada de fuerza.

Un amplio sector de la doctrina, aceptando que la fuerza es elemento consustancial al Derecho, la entiende siempre como coacción, concepto que englobaría al de sanción considerando que la descripción de una conducta sancionada implícitamente supone otra conducta -la contraria a ellacoaccionada.

Ante la objeción de que la coacción (entendida como utilización actual de la fuerza) no siempre está presente en el Derecho, pues éste es cumplido en la mayoría de los casos espontáneamente, otro sector de la doctrina (Recaséns Siches) sostiene que lo esencial al Derecho es sólo la coercibilidad. Pero, en opinión del autor, si por esa razón descartamos la coacción, «considerar la coercibilidad (posibilidad de forzar) elemento esencial tampoco resulta atinado, por la misma razón, porque a veces no es posibilidad, sino realidad». Recaséns va salvando las dificultades de su tesis modificando el concepto de coercibilidad: ante la objeción de que hay casos en que la coacción resulta ineficaz (por ejemplo, cuando no es posible llegar a tiempo para evitar la comisión de un delito), Recaséns reduce dicho elemento esencial al Derecho a la posibilidad, en mayor o menor grado, de acudir a la fuerza, que, en ocasiones, es capaz de coaccionar, y en otras sólo de intentarlo. Y ante la imposibilidad de obtener por la fuerza la conducta debida cuando ésta consiste en la prestación de un servicio personalísimo (como pintar un cuadro), Recaséns señala que en tales situaciones se sustituye el primitivo contenido de la obligación por una conducta subsidiariamente obligada (por ejemplo, el pago de una indemnización), que ya es posible imponer mediante la fuerza. Pero, con todo, exigir que la norma sea coercitiva para que sea jurídica supone excluir absurdamente del dominio del Derecho -como pone de manifiesto Ross- todas las normas de competencia. La solución que Ross propone hace radicar la juridicidad de la norma, no en estar respaldada por la fuerza, sino en estar referida a la aplicación de la fuerza, abarcando así a las normas que organizan instituciones estatales que administran la fuerza. La tesis de Ross, sin embargo, nos obliga a negar el carácter jurídico de las normas del Derecho internacional. Ello se salvaría si, según propone el autor, entendemos esa «referencia de la norma a la aplicación de la fuerza» en un sentido ligeramente diferente: como referencia a una fuerza física no sólo actual, sino también potencial, es decir, «que la norma esté, al menos, pidiendo ser dotada de fuerza». Según el autor, desde esta concepción -que es más acorde con la «intuición» que a priori tenemos del Derecho, pues incluye en él a todas las normas que solemos considerar jurídicas-, la referencia mínima a la fuerza, como elemento común a la coacción, a la coercibilidad, a la sanción, a la referencia a la aplicación de la fuerza, o a la simple vocación de la norma de estar dotada de fuerza, es elemento esencial del Derecho como un todo orgánico (sin que para 
ello sea necesario que todas y cada una de sus normas conlleven tales cualidades).

Finalmente, el autor se ocupa también de las relaciones entre fuerza del Derecho y poder político-económico y entre fuerza del Derecho y legitimidad, llegando a la conclusión de que «al Derecho le es esencial una cierta legitimidad, entendida ésta como la pretensión de la norma de inspirarse en un criterio de justicia, que la diferencia de otras figuras normativas», y señalando que «desde una perspectiva sociológica, la legitimidad socialmente vigente impide que el Derecho pueda acudir a determinadas técnicas de control, siendo éstas practicadas desde los poderes fácticos y políticos sin ninguna posibilidad de justificación jurídica y de forma encubierta».

(Juan Antonio Pérez Lledó)

ATIENZA, Manuel.

Para una razonable definición de «razonable».

Doxa, Alicante, 1987, págs. 189-200.

El concepto de «razonabilidad» o de «razonable» (y de «irrazonabilidad» o «irrazonable») es de una importancia fundamental en la práctica y en la teoría de la argumentación jurídica, pero aclarar dicha noción plantea no pocos problemas. En principio, una frase como «X es razonable» podría entenderse de maneras distintas, según que se considere que $\mathrm{X}$ representa un enunciado jurídico, un agente jurídico o un acto consistente en establecer, interpretar o aplicar enunciados jurídicos. El autor se centra en el concepto de «decisión jurídica razonable», entendiendo por tal los actos consistentes en interpretar y aplicar enunciados jurídicos a casos. Parte de la siguiente definición: «Una decisión jurídica es razonable en sentido estricto si y sólo si: 1) se toma en situaciones en que no sería aceptable, o no se podría, adoptar una decisión estrictamente racional; 2) logra un equilibrio entre exigencias contrapuestas, pero que necesariamente hay que considerar en la decisión, y 3) es aceptable para la comunidad.» Y desarrolla los diversos conceptos aquí envueltos, utilizando como ilustración una reciente y polémica sentencia del Tribunal Constitucional español sobre la ley de objeción de conciencia.

ATIENZA, Manuel.

La analogía en la obra de Norberto Bobbio.

Revista de ciencias sociales, Valparaíso, núm. 30, 1987, págs. 261-280.

A lo largo de su vastísima producción, Bobbio se ha ocupado en diversas ocasiones del problema de la analogía jurídica. En este artículo se analizan las posturas de Bobbio en diversas obras de 1938, 1957, 1966 y 1968, a propósito del concepto de analogía, la estructura lógica del razonamiento por analogía, la validez lógica y el fundamento normativo de la analogía, la distinción entre interpretación 
extensiva y analogía, y entre analogía y principios generales del Derecho. La conclusión a que se llega es que -excluido el concepto de analogía- Bobbio ha defendido, en relación con los otros problemas, soluciones distintas e incompatibles entre sí que el autor resume en un cuadro sinóptico hacia el final de su trabajo.

Mientras que esta heterogeneidad de planteamientos parece deberse al carácter fragmentario y no sistemático que, en general, tiene la obra de Bobbio, las insuficiencias y obscuridades sobre la analogía jurídica podría pensarse que se deben a la utilización por Bobbio de un instrumental lógico que hoy puede considerarse como desfasado. Sin embargo, el autor del artículo concluye reconociendo que el empleo de un aparato de análisis más sofisticado no parece haber conducido tampoco a resultados mucho más fecundos: «la analogía -como Bobbio ha puesto bien de manifiesto- es uno de los problemas centrales de la teoría del Derecho, y un problema que hay que considerar como todavía no suficientemente analizado». 
BARCIA MARTÍN, Luciano.

Derecho de libertad religiosa en España después de la Constitución.

Anuario de Filosofía del Derecho, Madrid, núm. 4 (Nueva Época), 1987, págs. 433-448.

El autor llega a las siguientes conclusiones, que reproducimos literalmente:

«1. Las convicciones, las creencias, los sentimientos, especialmente aquellos que comportan una determinada dirección de vida en aspectos tenidos como fundamentales forman parte del patrimonio espiritual de una persona y como tal patrimonio unido a la persona deben ser protegidos. Cuando tienen o adquieren una dimensión religiosa, el carácter o naturaleza patrimonial son lo más íntimo, lo más ligado a la persona, por razón de su transcendencia y de la intensidad de su presencia en la vida humana.

Tal sería el principio básico que debe ser reconocido: el derecho del hombre a pensar y a expresar sus ideas religiosas, a la vez que a orientar su vida de conformidad con las convicciones.

2. El ordenamiento jurídico de un Estado debe preocuparse de la defensa de aquel patrimonio, considerándolo propio de la persona o grupo de personas que profesan la religión. Tal defensa no puede limitarse a permitir que el grupo social, la Iglesia católica, se manifieste de acuerdo con sus convicciones, sino que ha de extenderse a protegerla contra las lesiones posibles del patrimonio. Entre las características propias del mismo cabe señalar que, por razón de su carácter espiritual, es superior en valor al patrimonio económico o material.

3. Un paso importante en este reconocimiento será el de admitir que cuando se relaciona con una determinada religión, como específico de la misma, es patrimonio, en cierta manera, exclusivo, de los que profesan esa religión. (...). Tal exclusividad debe ser protegida por el Derecho positivo, también en España después de la Constitución. (...).

4. Debe protegerse, mantenerse intacto, ese patrimonio con toda su pureza y en su integridad. (...). 5. Para ser más concreto: Cristo como tal, la Virgen María... pertenecen al patrimonio de los que creen en ellos, con las características con los que los creyentes los presentan. El cambio de su figura, la presentación de los mismos como portadores de unas cualidades distintas de las que los creyentes les atribuyen, y que para éstos pueden ser tenidas como vicios, constituyen un atentado al derecho de los católicos. A ellos deben proporcionarse medios legítimos de defensa, recogidos en leyes y medios positivos, tanto de carácter normativo como de carácter jurisdiccional. La carencia de estos medios puede dar lugar a protestas justificadas, que serían expresión del Derecho de legítima defensa. (...). Considero insuficiente el contenido de los artículos 208 y 209 del vigente Código Penal (...). Haría falta expresar, al menos, que constituye escarnio de una confesión religiosa, ultraje a sus dogmas, ritos o ceremonias, acto de profanación en ofensa de los sentimientos religiosos legalmente tutelados... el hecho de desfigurar el contenido de los dogmas o el significado de las personas veneradas, dando a los mismos una apariencia contraria a la que presentan la fe y los sentimientos de los creyentes. La punibilidad de las conductas expresadas habría que justificarse pensando, no ya en que sean o no injuriosas para con Dios o con los santos, sino pensando en que son lesivas de los sentimientos, del patrimonio íntimo de un grupo de seres humanos. El mismo fundamento habría que reconocer a la punibilidad de la blasfemia.

La protección de la libertad religiosa, incluyendo la prohibición de ultrajar los sentimientos y el 
patrimonio religioso de los creyentes, dentro del Código Penal debería hacerse al determinar los delitos relativos al ejercicio de los derechos fundamentales y libertades públicas. De conformidad con el Proyecto para la reforma del Código Penal sería oportuno presentar un artículo dentro de una rúbrica en que se recogieran los «delitos contra la libertad de conciencia, contra el patrimonio y los sentimientos religiosos.»

(Daniel González Lagier)

BARCIA, Luciano.

La dignidad como derecho del hombre y como derecho cultural de la Iglesia Católica.

Persona y Derecho, Pamplona, núm. 17, 1987, págs. 115-136.

«Reflexionaré en el presente trabajo -dice el autor- contemplando en primer lugar la defensa de la dignidad y su reconocimiento en la vigente Constitución española y en varios documentos internacionales. En el segundo apartado, más extenso, por tratarse de algo específicamente buscado, prestaré atención al hecho de que la defensa de la dignidad del hombre es algo propio de la cultura cristiana.»

Se examinan, pues, el preámbulo y el artículo $10.1 .^{\circ}$ de la Constitución y las declaraciones de derechos de Virginia (1776), la Declaración de Derechos del Hombre y del Ciudadano (1789), la Carta de las Naciones Unidas (1945), la Declaración Americana de los Derechos y Deberes del Hombre (1948), el Convenio para la represión de la trata de personas y de la explotación de la prostitución ajena (1949), la Convención suplementaria sobre la abolición de la esclavitud, la trata de esclavos y las instituciones y prácticas análogas a la esclavitud (1956), la Declaración de los Derechos del Niño (1959), la Convención relativa a la lucha contra las discriminaciones en la esfera de la enseñanza (1960), la Declaración sobre la concesión de la independencia a los países y pueblos coloniales (1960), la Declaración de las Naciones Unidas sobre la eliminación de todas las formas de discriminación racial (1963), la Declaración sobre la protección de todas las personas contra la tortura y otros tratos o penas crueles, inhumanos o degradantes (1975), la Declaración sobre el progreso y desarrollo en lo social (1969), el Pacto de San José de Costa Rica y la Declaración sobre el fomento entre la juventud de los ideales de paz, respeto mutuo y comprensión entre los pueblos.

En el segundo apartado el autor desarrolla la relación entre la cultura cristiano-católica y la dignidad humana atendiendo a las dos siguientes cuestiones: a) «Es deber de justicia reconocer que el cristianismo, la Iglesia Católica, ha valorado y ensalzado la dignidad humana y afirmado fundamentos concretos.» b) «La expresión de la dignidad humana, junto con los fundamentos que le asigna como base, constituyen un valor cultural propio del cristianismo, que debe ser protegido, a la vez que reconocido, en el campo del Derecho.»

(Daniel González Laiger)

BELTRÁN, Elena. 
Nozick, la justificación de la propiedad.

Sistema, Madrid, núm, 77, 1987, págs. 131-139.

La autora desarrolla en este texto una crítica a la justificación que Nozick realiza del Derecho de propiedad tal como él lo entiende, es decir, como un derecho absoluto que marca los límites «a cualquier intervención que no sea la de su titular o esté autorizada por éste». Para ello, en primer lugar, a) describe brevemente la Teoría del Título de Nozick y su idea de la propiedad como derecho absoluto; en segundo lugar $b$ ) examina lo que Locke dice acerca del derecho de propiedad en los tratados sobre el Gobierno Civil; por último $c$ ) trata de ver hasta dónde Nozick sigue a Locke y «si realmente se llega a justificar el derecho de propiedad partiendo del principio de "justicia en la adquisición" tal y como él lo describe».

a) La Teoría del Título de Nozick distingue entre la «justicia en la adquisición», determinada por la presencia de ciertas condiciones en el momento de la apropiación, y la «justicia en las transferencias», determinada por la adecuación de las transferencias o intercambios a ciertas normas. De no cumplirse los anteriores requisitos de justicia entra en juego el principio de rectificación para restablecer las situaciones anteriores a la injusticia; pero siempre que se cumplan «se cubre exhaustivamente la cuestión de la justicia en las pertenencias de las personas». En cuanto al derecho de propiedad, Nozick lo considera un derecho absoluto frente a todos, tanto individuos como instituciones, lo que le lleva a rechazar los Estados que defienden principios finalistas o redistributivos como no legitimados moralmente.

b) La autora pretende demostrar que caben matizaciones a la extendida consideración de Locke como representante de un «individualismo posesivo» que da paso al concepto burgués de propiedad. Locke parte de la existencia de límites de derecho natural al deseo de apropiación que experimenta el hombre; así, el paso de la propiedad común a la propiedad privada se daría sólo cuando el hombre ha aportado su trabajo a la transformación de aquello de lo que se apropia («labor theory»), no cabe acumulación de cosas perecederas y en cualquier apropiación se ha de dejar tanto y de la misma calidad para que se apropien los demás. Cuando surge el dinero, sin embargo, estos límites se vuelven ineficaces y es necesario la creación de un gobierno que imponga otros límites. Y, según la autora, «en ningún caso, parece dar a entender Locke que no sea su intención limitar la propiedad individual, sino más bien al contrario, tratar de que por medio de las competencias propias de un gobierno centralizado, sea éste el que a través de una regulación legal establezca unos límites equivalentes a los que existían en el estado de naturaleza». Continuando con esta interpretación hay que tener en cuenta que Locke utiliza un concepto amplio de propiedad: «aquello que es de uno y no puede ser utilizado sin su consentimiento», definición que, dado que entiende por consentimiento el de la mayoría o el de sus representantes, puede comprenderse como «una exigencia de legitimación democrática para aquellos gobiernos que deciden interferir en las propiedades de las personas que están sujetas a su legislación». Así, «la regulación de la propiedad no es otra cosa que un medio para lograr un fin de bien público»: la conservación del género humano, que requiere que se garantice, entre otros, el derecho a «las posesiones materiales necesarias para la conservación en la sociedad política».

c) Nozick parte de la interpretación más conservadora de Locke, utilizándolo «sólo en lo que se aviene a esta concepción» -su concepción del derecho de propiedad-, según la autora. Justifica la apropiación original siguiendo a Locke (el derecho de propiedad derivaría del derecho previo a la propiedad sobre uno mismo y del derecho debido como compensación al trabajo), pero entiende la autora que no toma 
«realmente en cuenta esta vía lockeana de justificación» para centrarse en la justificación de la apropiación cuando se cumple la condición de dejar «tanto y de igual calidad para los demás». Nozick, que parece admitir esta limitación en un principio, acaba su argumentación concluyendo que es posible «empeorar» la situación de los demás (es decir, no dejarles tanto y de la misma calidad) siempre que sean compensados por ello, con lo que se aparta sensiblemente de Locke.

«En definitiva -concluye la autora-, no parece que en Anarchy State and Utopia esté expuesta una justificación moral de la adquisición originaria que pueda fundamentar un derecho de propiedad tan absoluto como el que Nozick defiende.»

(Daniel González Lagier) 
BELTRÁN, Miquel.

La falacia de los independientes: la fundamentación del Estado en Nozick.

Sistema, Madrid, núm. 78, mayo de 1987, págs. 113-120.

Este artículo es una exposición y crítica de los argumentos que esgrime Nozick para fundamentar el Estado Mínimo.

Nozick considera un individuo sujeto a la fórmula kantiana «actúa de tal modo que trates a la humanidad, ya sea en tu propia persona o en la de cualquier otro, nunca simplemente como un medio, sino al mismo tiempo como un fin» e inmerso en un estado de naturaleza lockeano en el que cada cual posee un «área o espacio moral constituido por sus derechos naturales». La intromisión en este espacio genera a favor del afectado un derecho natural a una compensación. Estos individuos se integran en asociaciones protectoras de ámbito territorial («agencias») que, a su vez, se agrupan entre sí. Nozick ha de demostrar, para fundamentar el Estado Mínimo, que forman parte del mismo cuantos residen en el territorio que éste protege, bien voluntariamente, bien obligados a ello.

Para ello introduce el «Principio de Compensación», según el cual «los perjudicados por prohibiciones de emprender acciones que únicamente podría ocurrir que dañaran a otros, tienen que ser compensados por el perjuicio que se les irroga con el fin de proporcionar seguridad a los demás». Este principio recortaría hasta tal punto las posibilidades de actuación de los «independientes» «que lo mejor que pueden hacer es convertirse en clientes de alguna agencia protectora».

Nozick propone varios argumentos en defensa de la aplicación del Principio de Compensación como única respuesta ante los actos peligrosos. Uno de ellos es el argumento de la división de beneficios del intercambio: hay dos tipos de compensación apropiada a la violación de límites; uno es la compensación plena, mediante la cual la víctima vuelve a la misma situación en la que se encontraba antes de la transgresión, pero este tipo de compensación «resuelve el problema de la distribución de beneficios (...) de un modo totalmente arbitrario» (ya que los beneficios van a parar, sin motivo, a una sola parte: quien ha creado la necesidad de dicho intercambio). El otro tipo es la compensación mercantil, por la que «se proporciona a la víctima aquello que habría recibido en el caso de que hubiera tenido lugar un acuerdo libremente negociado»; sin embargo, «entonces (...) es absurdo permitir a una persona que transgreda un límite, para que, ulteriormente, determine junto con la víctima el precio que hubieran acordado negociando libremente al respecto». De todo ello deduce Nozick que los actos peligrosos deben ser prohibidos, evitando así los problemas que plantea su permisión seguida de una compensación.

Otros argumentos son el de la provocación del temor, según el cual «si a despecho de saber que serán compensadas ulteriormente, las personas temen ser víctimas de un determinado acto, ese acto debe ser prohibido»; la afirmación de que «un sistema que permitiese la transgresión de límites seguida de compensación implicaría el uso de las personas como medios» y la consideración de que algunas intromisiones pueden no ser compensables, así como la dificultad de conocer de antemano la cuantía de la compensación.

Llegado a este punto debe demostrar también Nozick que la aplicación del Principio de Compensación es permisible aunque de hecho invada el espacio moral de los independientes, es decir, que no le es aplicable ni el argumento de la división de beneficios del intercambio ni el de la provocación del 
temor. Ahora bien, para fundamentar que este principio no produce beneficios y explicar por qué, sin embargo, los clientes se empeñan en su aplicación, Nozick afirma que «en el caso concreto de los actos peligrosos no cuentan los motivos que inducen a los independientes a su realización, siempre y cuando se pague a éstos una compensación mayor que la que les motivaría mínimamente a abstenerse de actuar en tal sentido».

Para el autor de este artículo el argumento es sumamente artificioso y, en general, la fundamentación de la integración de los independientes es contraria «a los presupuestos libertarios que se hallan en la base de la teoría». En definitiva, Nozick niega a los independientes su derecho natural a defenderse partiendo de principios de justicia fundamentados en la imparcialidad del resultado o en el bienestar de la mayoría, criterios que previamente había rechazado.

(Daniel González Lagier)

BERGALLI, Roberto.

Argentina: Cuestión militar y discurso jurídico del olvido.

Doxa, Alicante, núm. 4, 1987, págs. 381-395.

-La afirmación de que la vida política e institucional argentina ha estado en los últimos cincuenta y siete años permanentemente condicionada por lo que se denomina cuestión militar, constituye una verdad tan objetiva que merece aquí muy poca comprobación. Mas, las derivaciones que semejante condicionamiento ha provocado sobre todo en el terrenojurídico -especialmente en el tiempo más reciente- son de tal magnitud que merecen unas consideraciones particulares.

-Tales derivaciones han sido constitutivas de lo que en esta ponencia se denomina como un discurso jurídico específico. Por discurso jurídico se entiende la construcción de una doctrina oficial y de una legislaciónpeculiar que originariamente se sanciona con el objeto de determinar las responsabilidades criminales en las que han incurrido los integrantes de las Fuerzas Armadas, policiales, penitenciarias y de seguridad en general, en materia de violaciones a los derechos humanos cometidas durante el tiempo de las últimas dictaduras militares. A la consideración de este proceso de creación de normas penales y procesales, debe agregarse también la correspondiente al comportamiento observado por buena parte del cuerpo judicial en época democrática, el cual, por cierto, contrasta con el que revelaron como clase judicial durante los períodos militares de facto.

-La continuidad de una clase judicial que reconoce una antigua tradición de dependencia a las contingencias y presiones de los distintos regímenes de facto, ha servido también para condicionar una de las dos fases en que se ha articulado la elaboración oficial del discurso jurídico específico para encarar en Argentina la aludida cuestión militar.

-La observación en conjunto de esos dos aspectos del discurso jurídico específico debería hacerse teniendo en cuenta la estrategia oficial puesta en práctica desde la misma instauración del gobierno democrático, en diciembre de 1983.

-Dicha estrategia, que apoyaba en el mensaje ético enunciado por el propio Raúl Alfonsín desde la previa campaña política y se ejecutó en el marco del Estado de Derecho, poco a poco se demostró como endeble y errónea lo cual favoreció el rearme del poder militar. 
-Asimismo, semejante estrategia propició un desusado protagonismo de ciertos magistrados judiciales que, en el caso concreto del juzgamiento de la cúpula militar (sentencia de la Cámara Federal de Buenos Aires, 9 diciembre 1985) que gobernó el país entre 1976 y 1983, dio lugar a la afirmación de dos tesis jurídicas de gran ambigüedad: 1) posibilidad de proseguir o iniciar denuncias contra aquellos oficiales superiores que actuaron en «la lucha contra la subversión» y «de todos aquellos que tuvieron responsabilidad operativa en las acciones»; 2) destacar las «responsabilidades concretas» de cada comandante y de cada Fuerza, reconociendo que durante la represión militar existió un estado de «guerra revolucionaria». La ambigüedad de estas dos tesis, como se verá, confirmaron la orientación del discurso jurídico específico.

-En la ponencia se propone un análisis de todo este cuadro que refleja el discurso jurídico oficial en Argentina, desde la perspectiva disciplinaria que pretende entenderlo como orientado a cancelar de la memoria histórica lo acaecido en materia de violaciones a los derechos humanos. A partir del reconocimiento de la falta de voluntad por reconocer el propio pasado (memoria colectiva) podría entenderse la manifiesta tendencia a no sancionar como delitos, a hacerlos prescribir y a justificar o exculpar -según se entienda- ciertos comportamiento militares, lo cual atenta contra la solidaridad mecánica y el propio derecho penal (Durkheim).

-De tal modo, la manifiesta decisión de descargar responsabilidades de ejecutores y autores mediatos de aquellos graves delitos, mediante el retorcimiento de categorías jurídico-penales: la prescripción (mediante la llamada ley de «punto final») y la obediencia debida (con la ley del mismo nombre), más allá de violar acendrados principios constitucionales (el de la igualdad ante la ley), debe considerarse como propulsada por una ideología del olvido.

-Pero, las dos grandes concesiones hechas por el gobierno democrático al poder militar proponiendo el olvido y la cancelación de lo ocurrido mediante formas ocultadoras o encubridoras del discurso jurídico, no sólo van precisamente contra los alegados motivos de reconstrucción nacional en el que se apoyaron las dos leyes aludidas, sino que, además, puede llegar a condicionar las propias instituciones democráticas de Argentina.

\section{BOBBIO, Norberto.}

La teoría de las formas de gobierno en la historia del pensamiento político (trad. de José F. Fernández Santillán).

Fondo de Cultura Económica, Sección de Obras de Política y Derecho, México, 1987, 193 págs.

Este libro recoge un conjunto de lecciones del autor sobre lo que llama uno de los «temas recurrentes» de la filosofia política (entendiendo por «recurrentes» «los temas que han sido propuestos y discutidos por la mayor parte de los escritores políticos y que, por tanto, forman parte de una teoría general de la política»). Se trata de la tipología de las formas de gobierno, es decir, de las distintas maneras de organizar la vida social según los lugares y el tiempo. Como afirma el autor, «casi no hay escritor político que no haya propuesto y defendido una cierta tipología de las formas de gobierno». El autor examina, pues, algunas tipologías «particularmente significativas desde la filosofía griega hasta los umbrales de la edad contemporánea, animado -advierte- no por una exigencia histórica, sino 
conceptual.

Estas tipologías son de gran importancia, «sea porque mediante ellas han sido elaborados y continuamente discutidos algunos conceptos generales de la política, como oligarquía, democracia, despotismo, gobierno mixto, etc., sea porque ellas constituyen uno de los aspectos por medio de los cuales una teoría puede ser caracterizada y comparada mejor con otras»».

El autor sostiene una triple función de las tipologías de las formas de gobierno. Por un lado, una función descriptiva o sistemática, señalando los diversos tipos de constitución política que en la experiencia histórica se presentan a la vista del observador. Las primeras grandes clasificaciones de las formas de gobierno, corno las de Platón y Aristóteles, son de este tipo. Por otro lado, una función prescriptiva o axiológica, pues «el escritor político no se limita a describir; generalmente se plantea otro problema, que es el de indicar, de acuerdo con un criterio de selección que naturalmente puede cambiar de autor a autor, cuál de las formas de gobierno descritas es buena, cuál mala, cuál mejor y cuál peor, y eventualmente también cuál es la óptima y cuál la menos incorrecta». En los autores estudiados se observa que frente a la variedad de las formas de gobierno son posibles tres posiciones: a) todas las formas de gobierno existentes son buenas, postura propia de una filosofía relativista e historicista, sostenida, por ejemplo, por Vico; $b$ ) todas las formas son malas, postura de Platón; y $c$ ) algunas son buenas y otras son malas, que es la posición más frecuente, a la que el autor llama aristotélica. También se aprecia, por otro lado, que aquellos autores que describen un modelo de Estado óptimo o bien idealizan una forma histórica, o bien lo construyen combinando en síntesis ideal los diversos elementos positivos de todas las formas buenas (Polibio), o bien realizan una elaboración intelectual o producto de la imaginación.

Por último, las tipologías de las formas de gobierno pueden cumplir también una función histórica. El autor entiende por «uso histórico» «el que han hecho algunos autores de la tipología de las formas de gobierno para delinear una verdadera y propia filosofía de la historia; en términos simples, para trazar las líneas del desarrollo histórico que transitaría de acuerdo con un esquema que naturalmente cambia según el autor, de una forma de gobierno a otro». En los autores tratados en este libro puede observarse que en la antigüedad clásica una teoría de las formas de gobierno se resuelve en una concepción cíclica de la historia. Otro ejemplo de uso histórico de las tipologías de las formas de gobierno se encuentra en Hegel, que considera el despotismo como la forma de gobierno típica del mundo oriental, a la república del romano y a la monarquía del moderno.

Las corrientes del pensamiento y los autores estudiados en este libro son los siguientes: la reflexión de los griegos sobre los asuntos de la política en el siglo III a.C., como se refleja en las Historias de Heródoto (capítulo I), Platón (cap. II), Aristóteles (cap. III), Polibio (cap. IV), el medievo (entre la época clásica y Maquiavelo) (cap. V), Maquiavelo (cap. VI), Bodino (cap. VII), Hobbes (cap. VIII), Vico (Cap. IX), Montesquieu (cap. X), el despotismo (cap. XI), Hegel (cap. XII) y Marx (cap. XIII). El libro concluye con una reflexión sobre la dictadura (cap. XIV).

(Daniel González Lagier) 
BULYGIN, Eugenio.

Sobre el status ontológico de los derechos humanos.

Doxa, Alicante, núm. 4, 1987, págs. 79-84.

En este breve artículo, el autor, en primer lugar, da un sucinto repaso a la evolución de la fundamentación de los derechos humanos. Así, muestra algunas etapas: en la segunda mitad del siglo XVIII son derechos otorgados por el Derecho Natural, al legislador lo único que le queda es su reconocimiento; en el siglo XIX con el advenimiento del positivismo jurídico como convicción iusfilosófica dominante se tiende a verlos bajo el prisma de derechos y garantías constitucionales y la anterior fundamentación pierde terreno; en el siglo XX con la aparición de los regímenes totalitarios se siente la necesidad de dar a los derechos humanos una fundamentación más sólida que el mero Derecho positivo para protegerlos contra dichos regímenes; al final de la segunda guerra mundial aparecen de nuevo invocaciones al Derecho Natural y reacciones contra el positivismo jurídico dominante hasta entonces. Pero este renacimiento no duró mucho, «autores como Kelsen, Ross, Hart y Bobbio se encargaron de poner las cosas en su sitio». «Sin embargo, en los últimos tiempos se ha producido un nuevo renacimiento de las teorías iusnaturalistas, aunque sus protagonistas rara vez utilizan el término "derecho natural" para referirse a sus doctrinas. Este resurgimiento del Derecho natural comienza con Ronald Dworkin, quien lanzó ya en los últimos sesenta su famoso ataque al positivismo de Hart. En los últimos años se ha incrementado notoriamente el número de pensadores que cabe calificar como partidarios del Derecho natural: Rawls y Nozick en los Estados Unidos, Finnis en Inglaterra y Carlos Nino en Argentina son quizás sus representantes más notorios. Todos estos autores se ocupan de derechos y en particular de los derechos humanos. En lo que sigue me referiré en especial al libro de Nino, Ética y derechos humanos.» Finalmente, de esta discusión con Nino el autor concluye: «Por lo tanto, los derechos humanos no son algo dado, sino una exigencia o pretensión. Recién con su "positivación" por la legislación o la constitución los derechos humanos se convierten en algo tangible, en una especie de realidad, aun cuando esa realidad sea jurídica. Pero cuando un ordenjurídico positivo, sea éste nacional o internacional, incorpora los derechos humanos, cabe hablar de derechos humanos jurídicos y no ya meramente morales.

»Se me podría reprochar -continúa- que esta concepción de los derechos humanos los priva de cimientos sólidos y los deja al capricho del legislador positivo. Por lo tanto, la concepción positivista de los derechos humanos sería políticamente peligrosa. Sin embargo, no veo ventajas en cerrar los ojos a la realidad y postular un terreno firme donde no lo hay. Y para defenderme del ataque podría retrucar que es políticamente peligroso crear la ilusión de seguridad, cuando la realidad es muy otra. Si no existe un Derecho natural o una moral absoluta, entonces los derechos humanos son efectivamente muy frágiles, pero la actitud correcta no es crear sustitutos ficticios para tranquilidad de los débiles, sino afrontar la situación con decisión y coraje: si se quiere que los derechos humanos tengan vigencia efectiva hay que lograr que el legislador positivo los asegure a través de las disposiciones constitucionales correspondientes y que los hombres respeten efectivamente la Constitución.»

(Josep Aguiló Regla) 
BRUFAU PRATS, Jaime.

Hombre, vida social y Derecho.

Ed. Tecnos, Madrid, 1987, 146 págs.

En este texto se recogen cinco estudios «que miran a temas propios de lo que constituye el contenido del corpus de la filosofía jurídica». Se enfocan estos temas desde la perspectiva de un «iusnaturalismo dinámico» es decir, de una concepción de los derechos fundamentales como derechos asentados en la condición de persona que tiene el hombre por ser hombre. Se considera que tales derechos se encarnan en la peculiar situación histórica de cada momento, permaneciendo inmutable su núcleo fundamental; consiguientemente, la norma de derecho positivo justo es una concreción histórica y mudable, más o menos próxima, del Derecho natural.

Los estudios recogidos son los siguientes: Saber científico y saber filosófico. Algunas consideraciones acerca de su distinción; Algunas consideraciones acerca de la filosofía del Derecho y de sus planteamientos actuales; Normatividad jurídica y cambio social; Hombre-Naturaleza-Libertad. En torno al tema «Libertad y Derecho»; Sentido actual del derecho de propiedad en el pensamiento pontificio.

(Daniel González Lagier)

BRUFAU PRATS, Jaime.

Teoría fundamental del Derecho.

Ed. Tecnos, Madrid, 1987, 330 págs.

En este libro se recogen una serie de textos publicados con anterioridad en lengua catalana, a los que se añaden otros textos inéditos.

El contenido de la obra consta de cuatro partes: la primera, El hombre y el Derecho, «mira al ámbito antropológico-jurídico» y se compone de un solo capítulo del mismo nombre. La segunda, El Derecho y el entorno social, «se centra en la determinación sociológica del mundo del Derecho. Esta parte se compone de cuatro capítulos: Punto de partida, Desarrollo de la vida humana en el ámbito social, La regulación de la vida social y El Derecho como factor regulador de la vida del grupo. La tercera parte, El ser del Derecho, «se adentra en la realidad del derecho y en su fundamentación» y consta de los siguientes capítulos: La realidad jurídica, El fin del Derecho, El bien común, La justicia, La seguridad jurídica y La fundamentación del Derecho. Por último, la cuarta parte, El saber jurídico, «esboza una teoría del conocimiento jurídico centrada en los niveles científico y filosófico».

(Daniel González Lagier) 
CALSAMIGLIA, Albert.

\section{Eficiencia y Derecho.}

Doxa, Alicante, núm. 4, 1987, págs. 267-287.

En este artículo se reclama la utilización en los distintos quehaceres jurídicos del criterio de eficiencia aportado por la teoría económica.

El autor señala que «la preocupación fundamental de nuestra profesión jurídica ha sido -por lo menos hasta épocas muy recientes- equilibrar la seguridad jurídica con unos criterios de justicia determinados que varían con la historia. El normativismo ha supuesto un avance importante en la comprensión de la estructura normativa del Derecho, las relaciones entre las normas, la jerarquía de esas relaciones y la problemática de la interpretación. Sin embargo, el normativismo -en sus versiones más sofisticadas como las del último Kelsen o Hart- cuando se encuentra ante casos difíciles recurre a conceptos tan ambiguos como los principios jurídicos o la discreción judicial (...). La discusión de problemas difíciles es útil para la construcción de criterios y la elección entre ellos. Pero la elección no puede ser confiada a la subjetividad, a la discreción del intérprete, porque estaríamos sacrificando la previsibilidad del derecho».

Por estas razones parece necesario aceptar la propuesta de los economistas de analizar el Derecho desde el punto de vista de la eficiencia, pero con algunas precisiones. En relación con esto el autor de este artículo llega a las siguientes conclusiones:

«1. He presupuesto que el criterio de eficiencia es el que permite justificar un sistema económico. He tratado de argumentar que existen casos en los cuales el mercado libre no conduce a resultados eficientes de tal manera que no siempre está justificado el mercado libre. Por tanto, una extensión excesiva de las tesis del libre mercado es inadecuada. Las doctrinas que usan la teoría económica más allá de sus límites no se fundamentan en ella, sino que la adulteran.

2. La eficiencia -entendida como aquel criterio que maximiza la riqueza social- exige en ocasiones la intervención estatal o intervenciones externas al mercado. Por tanto, quien sea reticente a la utilización de este método no puede identificarlo con la defensa del neoconservadurismo.

3. La eficiencia es un componente de la idea de justicia pero no es el único criterio de justicia. Difícilmente podríamos calificar de justo un sistema totalmente ineficiente o una sociedad que despilfarrara recursos básicos que cubren necesidades básicas. Pero los criterios de eficiencia no son los únicos a tener en cuenta para calificar un sistema de justo. Junto a la eficiencia, los derechos y los objetivos colectivos ocupan un lugar sumamente importante. Un sistema institucional imprevisible e inseguro no puede ser calificado de justo, pero un sistema muy ineficiente tampoco.

4. Observar el fenómeno jurídico desde el punto de vista de la eficiencia puede ser especialmente útil para la construcción de una política jurídica que alcance sus objetivos. Los instrumentos jurídicos pueden ser eficientes o no. Un legislador no sólo está preocupado por establecer un modelo ideal hacia el cual debe tender sino que también está preocupado por los mejores caminos que conducen a este objetivo. Muchas veces los juristas nos olvidamos de los caminos y no llegamos a donde queremos.» 


\section{CALVO GONZÁLEZ, José.}

Giménez Fernández y el regionalismo andaluz de los años 30.

Anales de la Fundación Joaquín Costa, núm. 4, 1987, págs. 93-106.

Se detalla la participación de Manuel Giménez Fernández en el curso enunciado de los planteamientos teóricos del andalucismo en perspectiva a la estimación de los resultados obtenidos al cierre de la experiencia republicana y a las contribuciones de quienes protagonizaron más directamente la empresa de elaboración y defensa de un Estatuto regional para Andalucía. El autor estudia como preámbulo la intervención del personaje a lo largo de las sesiones de discusión promovidas por el Ateneo de Sevilla en diciembre de 1918 ante la petición de autonomía requerida al presidente del Consejo de Ministros por el Consejo permanente de la Mancomunidad Catalana. Allí su posición en torno al tema regionalista sobresale, dentro de las tendencias tradicionalistas y conservadoras en que inicialmente se inscribe, con una proyección avanzada y favorable respecto de las iniciativas autonómicas. Con todo, el interés por la idea regional y autonomista se apreciará más puntualmente durante los episodios andalucistas de la década de los 30 y en particular con ocasión de los preparativos para la celebración de la Asamblea Regional de Córdoba el año 1933. Revisando las reacciones que en la prensa local suscitó tal convocatoria, así como graduando la incidencia y aceptación alcanzada en esas fechas por la difusión de los símbolos regionales y andalucistas, analiza el autor la propuesta de acceso a la autonomía defendida por Giménez Fernández en representación del Ateneo de Sevilla, y que como tal encuentra concordancia y afinidad con la dirección del populismo italiano de Sturzo, asumida en España por las corrientes democristianas. El estudio concluye con la referencia al decaimiento y casi total abandono de la preocupación regionalista por la mayoría de sus seguidores durante la etapa central y años finales de la República, a causa unas veces del planteamiento demasiado ideal de los postulados y desideratum autonómicos andalucista, y las más por el ostracismo a que le condenarían estrategias políticas de mayor convergencia en todo el Estado, lo que aconseja a considerar y asumir la experiencia regionalista en Andalucía para la década del 30, distintamente a como a menudo se ha hecho, en un sentido pluralista y acogedor de las diferentes perspectivas ideológicas y humanas que implicó.

\section{CALVO GONZÁLEZ, José.}

Inmediatez filosófica y discontinuidad política del idealismo hegeliano en A. Benítez de Lugo.

Cuadernos Informativos de Derecho Histórico Público, Procesal y de la Navegación, núms. 6-7, 1987, págs. 1007-1024.

Se ocupa el autor de aspectos no abordados ni tratados todavía en las diversas contribuciones que se han llevado a cabo en los últimos años aportando un mejor conocimiento, dentro del ámbito filosófico-político, del movimiento neogeheliano en España a través, precisamente, de la figura de uno 
de sus más importantes representantes: Antonio Benítez de Lugo. Así, aquí se nos ofrece una pormenorizada información biográfica del personaje y el completo y ordenado índice de su producción científica, incluyendo por tanto todo lo relativo al abundante y variado contenido de los escritos u obran menores, tanto como sobre la relevancia, participación e intervenciones de Benítez de Lugo en actividades y debates organizados por los círculos culturales sevillanos krausistas, positivistas y flokloristas conectados al panorama del mundo académico e intelectual de su época, en especial la Real Academia Sevillana de Buenas Letras y Sociedad Antropológica de Sevilla. De este examen se desprende una preocupación filosófico jurídica y política que llega aproximadamente hasta 1877 yel inicio a partir de esa fecha del cultivo de temas y asuntos históricos. De la primera etapa, en lo que al pensamiento hegeliano se refiere, resulta un estado que el autor califica de inmediatez filosófica, aunque no plena identidad, anotando la escasa ambición crítica de las exposiciones. En cuanto a la dimensión filosófico-política el autor acude al término discontinuidad, de lo que harán prueba el tratamiento de cuestiones como la constitución del Estado, concepto de pueblo, soberanía popular, figura y función del monarca, etc..., donde las convicciones republicanas de Benítez de Lugo prevalecerían frente a una fidedigna exposición del sistema de Hegel. Por contra, en el área de problemas de filosofía iusprivatista la similitud es plena. Por lo que hace a los estudios históricos se recogen trabajos como el dedicado al movimiento de las Comunidades en Sevilla y los aparecidos en Revista de España. Se incluyen también noticia de la polémica entre Benítez de Lugo y M. Poley en la Sociedad Antropológica sobre naturaleza y fundamento de los derechos naturales. 


\section{CALVO GONZÁLEZ, José.}

Notas sobre criptogobierno e invisibilidad y ocultación del poder.

Cuadernos Informativos de Derecho Histórico Público, Procesal y de la Navegación, núms. 4-5, 1987, págs. 581-601.

Tomando como ocasión la obra colectiva -por Bobbio, Pontara y Veca- Crisis de la democracia, así como la recopilación de trabajos del primero de ellos presentada bajo el título de El futuro de la democracia, y luego de proceder al examen y comentario crítico de los estudios que integran ambas obras, se pasa a analizar de modo particular lo expuesto en relación al conjunto de comportamientos y actitudes que, calificadas por Bobbio como «efectos perversos», más profundamente amenazan desde su interior la vida y existencia del régimen democrático. De entre éstos -ingobernabilidad, privatización de lo público y acción del poder invisible- se elige el último que estructurado en las categorías de subgobierno, criptogobierno y poder omnividente, encuentra un desarrollo complementario al expuesto por Bobbio en el tema del poder oculto e invisible como criptogobierno y la crisis y futuro de la democracia. La dirección que en ello se sigue permite al autor aprovechar para el caso la metodología instrumental del género policíaco, del cuento o la novela «negra», caracterizada por técnicas como la observación, el empirismo lógico, el razonamiento deductivo e inductivo y la interpretación de evidencias. De esta manera, apoyado en textos de E. A. Poe y G. K. Chesterton, el eje del problema filosófico-político de la sustantividad y operatividad del poder invisible se sitúa para el autor en la cotidianidad; usufructuándola el Poder infiltra insensiblemente máximas y reglas de comportamiento, modela normas de conducta y normaliza la existencia toda recibiendo el dócil acatamiento del ciudadano. El trabajo concluye con una reflexión de carácter fantástico que en una relectura de la portada del Leviathan, sugestiva e inquietante, introduce la posibilidad de otras y desconocidas fuentes y canales de influencia del poder invisible y oculto como criptogobierno.

\section{CALVO GONZÁLEZ, José.}

Notas sobre la dimensión filosófico-politica de las metáforas epistemológicas. A propósito de laberintos y guerra nuclear (Razón fantástica versus Razón lógica).

Anuario de Filosofía del Derecho, Madrid, núm. 4 (Nueva Época), 1987, págs. 639-649.

Tomando como referencia los estudios contenidos en la obra de Bobbio El problema de la guerra y las vías de la paz y dedicando especial atención al que le da título, el autor procede a un desarrollo complementario a lo allí expuesto por Bobbio cuando (págs. 91-92), sirviéndose de un conocido pasaje de las Investigaciones filosóficas de Wittegenstein, alude a la situación del hombre frente al problema nuclear semejándola a la de alguien que esté en el interior de una botella abierta, a la de un pez atrapado en la malla de una red o, por último, a la de un ser extraviado y errante por las calles de un laberinto, considerando así que la estrategia histórica de un sucesivo juego de elecciones sobre 
caminos bloqueados ha conducido finalmente a una disyuntiva sobre los dos caminos restantes, donde uno conduce a la salida, pero el otro, en lugar de ser un camino bloqueado, termina en el abismo. El autor considera que la utilización con carácter simbólico cultural no particular de la botella, la red y el laberinto, resulta en tres figuras de una común estructura, a saber: la laberíntica. Es decir, todas constituyen aplicaciones alusivas e ilusivas de la idea de laberinto como laberinto clásico o griego, moderno o rizomático esquema Deleuze-Guattari y manierista o barroco esquema trial and error procers. A continuación reconvierte tales aplicaciones en metáforas epistemológicas de dimensión filosófico-política representando simbolizaciones de estado psico-espirituales (seguridad, salvación, fatalismo, caos, esperanza). El último modelo, que es al que Bobbio hace referencia, implica cierto optimismo por dejar a la decisión humana la solución del problema, aunque es un modelo influido por la precariedad del equilibrio y el riesgo del desequilibrio que implica la elección autàut. Esto mismo, por otra parte favorece la demora en resolver la disyuntiva conduciendo a una situación real de parálisis, lo que modificaría la fisonomía del laberinto; en concreto transfigurándose de prisión en refugio, cuya dimensión ético-religiosa y filosófico-política es tan patente como en la dialéctica amo-esclavo hegeliana. El trabajo se apoya en textos literarios de Poe y Borges.

CARACCIOLO, Ricardo Alberto.

Racionalidad objetiva y racionalidad subjetiva.

Doxa, Alicante, núm. 4, 1987, págs. 145-151.

Este artículo, partiendo de que la propiedad «predecible» suele presentarse como condición necesaria de la propiedad «racional» -al menos en la literatura sobre la racionalidad de una decisión jurídica individual-, intenta responder a la siguiente pregunta: ¿en qué medida el concepto de «racionalidad objetiva» -entendida como aquella que supone la posibilidad de predicción- es compatible con una noción de «racionalidad subjetiva» que se refiera a las condiciones de racionalidad de una decisión individual?

Para ello utiliza como instrumentos de análisis el modelo de decisión individual de Arrow y los conceptos de «acción» y de «norma» de Von Wright, llegando a las siguientes conclusiones:

a) La «racionalidad subjetiva» de una decisión es relativa a un contexto determinado de alternativas y a un sistema de valores. Es relativa a un contexto determinado de alternativas porque cualquier decisión de un individuo en una situación determinada es una elección entre dos alternativas excluyentes de acción pertenecientes a un conjunto de alternativas posibles -el contexto-, conjunto que es más o menos amplio en función del conocimiento de la situación -por tanto, del lenguaje en el que se expresa ese conocimiento-. Es relativa a un sistema de valores en la medida en que el individuo usa un sistema tal para ordenar según sus preferencias las alternativas de acción posibles de un contexto y para optar por la alternativa que es preferida a todas las demás.

b) «El contenido de un contexto de alternativas, esto es, la identificación de las acciones que un individuo puede empíricamente realizar, es una función de su conocimiento de la situación en que tiene que actuar.» "Cualquier "incremento del conocimiento" conduce a ampliar el número de "mundos 
posibles" y, por consiguiente, las alternativas de acción.»

c) Un sistema de normas generales puede ser considerado como un sistema de valores que ofrece una regla de preferencia entre alternativas de acción y determina el contenido del contexto y, con ello, el nivel del conocimiento relevante para la acción. En tal caso podría decirse que el conocimiento de un sistema de normas permite predecir una decisión individual («si el individuo X acepta el sistema constituido por Op entonces se sabe de antemano que sus alternativas son P y -P y además que, si es racional, elegirá $\mathrm{P} \gg)$.

d) No obstante, la afirmación anterior presupone que el lenguaje en el que se describen las acciones reguladas por ese sistema no es susceptible de ser enriquecido, sino que expresa el máximo nivel de conocimiento. Pero como tal lenguaje no existe «siempre es posible que el estado de cosas individual que constituya la oportunidad para la acción de un individuo X pertenezca a más de una clase de estados de cosas genéricos, lo que significa que su descripción puede ser relativa a distintos lenguajes con capacidad para expresar diversos niveles de conocimiento». Por ello «una decisiónsubjetivamente racional puede ser, no obstante, impredecible y, por tanto, objetivamente arbitraria si se adopta el sistema normativo como base para formular la predicción».

(Daniel González Lagier) 
CARPINTERO, Francisco.

La independencia y autonomía del individuo: los orígenes de la «persona jurídica».

Anuario de Filosofía del Derecho, Madrid, núm. 4 (Nueva Época), 1987, págs. 477-522.

El autor trata de dilucidar el curso doctrinal de la teoría que siguió la doctrina ética y la filosofía del Derecho en la Edad Moderna que dio como resultado que nuestra cultura jurídica y moral se fundamente y parta desde el individuo independiente, autónomo, aislado de los demás; se trata, pues, de poner de relieve una de las facetas decisivas del pensamiento jurídico y político liberal contemporáneo.

El punto de arranque del estudio es la teorización pre-kantiana a este respecto. En ella se muestra como los ilustrados entendieron que la única concepción científica posible del hombre es su consideración como un ser que naturalmente sólo depende de sí mismo y vive para sí mismo; este hombre, así concebido, sólo puede quedar obligado, como es consecuencia lógica, por el consentimiento que él libremente preste, por lo que el contractualismo o pactismo avanza al primer plano de la realidad jurídica diseñada.

Kant y su medio centenar de epígonos, que dominaron hegemónicamente en la cultura europea en el cambio de siglos, acentuaron y llevaron hasta sus límites esta exigencia, en la medida en que erigieron a cada individuo en un «fin en sí mismo», un Selbstzweck; pero el decurso que sigue la doctrina del Selbstzweck tiene poco que ver con lo que usualmente, hoy, se entiende bajo ella. En efecto, lejos de hacer posible un entendimiento más digno de la persona, el «fin en sí mismo» fue entendido como un «fin-para-sí-mismo» en que se erigía cada sujeto. De forma consecuente, la manifestación primaria y fundamental del Derecho es la exteriorización del arbitrio indeterminado, y en principio indeterminable, de cada individuo. Dado que los siglos XVII y XVIII se agotaron en reclamar tal tipo de arbitrio, resulta, finalmente, una libertad o noción del Derecho que se define ante todo por la capacidad de excluir; resulta, de esta forma, una libertad puramente formal, negativa y vacía. Por este motivo, la justicia sólo puede consistir en una actitud negativa, una omisión continuada, eine Enthaltung, en definitiva.

Esta noción del Derecho que justifica a un individuo independiente, autónomo y aislado, tropieza en el siglo XIX con la crítica de Hegel, quien -en el marco del pensamiento jurídico del Idealismo alemán- denuncia el egoísmo y la ausencia de solidaridad que encubren las teorías ilustradas, especialmente la kantiana, bajo el pretexto del afianzamiento de la «libertad».

\section{COLOMER, Josep M.}

\section{Teoría de la democracia en el utilitarismo.}

Revista de Estudios Políticos, Madrid, núm. 57, págs. 7-30.

El artículo gira en torno a una posible reconsideración de los fundamentos teóricos del utilitarismo con 
el fin de encontrar respuesta a la crisis de legitimidad que experimentan las democracias contemporáneas. En este sentido, después de realizar una introducción a la figura histórica de Bentham, se aborda el significado del principio de utilidad como método, que, basado en la observación y el análisis de los hechos, combate la tradición moralizante. El paso siguiente nos lleva al examen de la teoría de las penas y la teoría del valor, que son consecuencia de dicho principio de utilidad. Todo esto nos conduce al análisis concreto de la teoría de la democracia; Bentham parte de la necesidad de una democracia representativa radical, de lo que se deriva una postura favorable al sufragio universal y al control de los gobernantes por el pueblo. Así, aunque la democracia no ofrece la seguridad de un buen gobierno, la ausencia de la misma sí imposibilita «conseguir un buen gobierno, dada la tendencia de los mismos a actuar en su propio interés». En cuanto al dilema de dar prioridad a la seguridad o a la igualdad, Bentham, como buen liberal, subraya que el objetivo igualitario está condicionado por el mantenimiento de las garantías jurídicas. El último aspecto a tratar es la revisión del benthanismo por Stuart Mill que contribuyó por un lado a los notables éxitos políticos del radicalismo como tendencia organizada, pero también a una notable rigidez del pensamiento de Bentham al incorporar como uno de los objetivos del gobierno la mejora de las cualidades morales e intelectuales de los miembros de la sociedad y considerar con optimismo las virtudes de las minorías gobernantes, adoptando una actitud restrictiva respecto a la participación de las masas. Concluye el autor resaltando el interés que el estudio del pensamiento utilitarista tiene hoy, tanto desde un punto de vista metodológico como por su contribución a la relativización de la contraposición entre democracia como protección y democracia como participación.

(Angeles Ródenas Calatayud)

CORTINA ORTS, Adela.

La calidad moral del principio ético de universalización.

Sistema, Madrid, núm. 77, 1987, págs. 111-120.

Este artículo se inscribe en la polémica entre Felipe González Vicén y Elías Díaz -a la que se ha sumado Javier Muguerza- sobre la obediencia al Derecho. En tal debate se plantea si existe un fundamento ético para obedecer al Derecho, «siendo así que parece haber uno para desobedecerlo: la conciencia individual». La autora interviene en este debate en defensa de la ética dialógica, en su versión apeliano-habermasiana, «que Javier Muguerza trae a colación a lo largo de su réplica, más para atacarla -creo yo- que para extraer sus virtualidades».

Según la autora, Muguerza no pone en duda que el diálogo sea el procedimiento más adecuado para llegar a una legitimación de normas jurídicas, pero afirma que el discurso posee unos límites morales -que la ética discursiva no reconoce- cuya transgresión convierte en inmoral la decisión alcanzada. Este límite moral vendría dado por la segunda formulación del imperativo categórico (la del «fin en sí mismo»), que queda sacrificado por la ética discursiva al de la «universalización», según Muguerza. Para defender la ética discursiva de estas objeciones se desarrollan en este artículo los siguientes puntos:

1. «En la ética kantiana es impensable la supervivencia de cualquiera de las formulaciones del 
imperativo, desligada de las demás, de ahí que todas gocen de igual calidad moral, y que la reconstrucción de una de ellas suponga la reconstrucción de las restantes.» En este sentido se afirma que «Kant no entendió las formulaciones del imperativo como independientes entre sí (...). Cada una de las formulaciones contiene, pues, toda la sustancia de la moralidad y lleva implícitas en su seno a las restantes».

2. «La conciencia de que habla González Vicén es más existencialista que kantiana». Y ello porque este autor, al distinguir la desobediencia civil y la desobediencia ética, caracteriza al desobediente ético como aquel que no pretende fidelidad a valores comunicables a todos y aceptables por todos, sino a su propio ser individual.

3. «La ética discursiva es legítima heredera de la ética kantiana de la conciencia, aunque reformulada por medios propios de la teoría de la comunicación, y directamente aplicable por ello a la vida jurídico-política», como el medio más adecuado para legitimar tanto las normas jurídicas como su desobediencia. Con Apel y Habermas «el monólogo se convierte en diálogo; los intereses individuales constituyen la materia del test; las consecuencias de la aplicación de las normas son atendidas a la hora de decidir y han de ser aceptadas por todos los afectados por ellas.»

4. «La universalización es -a mi juicio- el único procedimiento para superar el «corporativismo y el feudalismo democráticos», nacidos de intereses individuales y grupales; es el modo más adecuado de ser progresista». Para la autora el conformismo de las sociedades actuales, que parecen «no estar interesadas en establecer normas en que se contemplen los intereses de todos», «"tiene la culpa” de que la desobediencia civil o la desobediencia ética al derecho se hagan necesarias, y no el principio de universalización, al que no hay más remedio que recurrir cuando de legitimidad -y no de mera vigencia- se trata».

(Daniel González Lagier) 
COTTA, Sergio.

El Derecho en la existencia humana (trad. Ismael Peidró Pastor).

Ed. EUNSA, Pamplona, 1987, 248 págs.

Este libro es fruto de la labor investigadora y docente del autor en la Universidad de Roma. En su presentación (octubre 1984) Cotta escribía: «Lo que caracteriza mi período romano es mi insatisfacción acerca de una interpretación del Derecho exclusivamente formal o historicista; también mi convicción de que la experiencia jurídica se clarifica mediante la comprensión de la estructura ontológica del Derecho, así como del momento existencial del hombre, tal como ambos inciden en la relación humana coexistencial» (pág. 9).

El primer capítulo sirve de introducción al desarrollo de su pensamiento. En él se traza el perfil metodológico a seguir, especialmente el análisis fenomenológico. A continuación vienen tres partes: «Génesis ontoexistencial del Derecho» (cap. II y III); «Fenomenología de las formas existenciales» (cap. IV y V); y «Dimensiones del Derecho» (cap. VI, VII, VIII, IX y X). Es de destacar en la primera parte la afirmación de Cotta de que el Derecho participa de la misma exigencia de la existencia humana. Por eso una norma jurídica no es «heterónoma», sino «sociónoma», porque es exigida comúnmente por todos los existentes (págs. 61 y 62). De ahí que el Derecho sea «una forma coexistencial», que responde a la estructura ontológica del hombre (págs. 78-79).

En la segunda parte desarrolla su pensamiento acerca de las formas coexistenciales, que clasifica en dos clases: «excluyentes» e «incluyentes». Sitúa entre las primeras a la amistad y la política. Sitúa entre las segundas al Derecho y la caridad. Las dos primeras poseen cierta afinidad. Es más, lo que la amistad representa en el plano de las relaciones interpersonales, representa la Política en el plano de las relaciones sociales (pág. 88).

En cuanto al Derecho, Cotta reconoce su relación con la política. Por eso afirma que «el Derecho es la misma política que se desarrolla bajo forma jurídica» (pág. 111), pero de la cual se diferencia por una primaria estructura: la universalidad humana, consecuencia de la paridad ontológica de los hombres (pág. 113). Asimismo, porque «mediante la norma jurídica se posibilita la cooperación y potenciación de la capacidad de los sujetos» (pág. 115).

De la tercera parte del libro podemos subrayar el pensamiento de Cotta sobre la Justicia, que basa en la paridad ontológica de los hombres en relación con el principio de su personalidad y en el hecho de su diferenciación existencial (pág. 154), lo cual origina la Justicia primaria u ontológica, que a su vez, constituye el orden global, en cuyo seno se sitúan y rectifican las formas particulares de Justicia (intersubjetiva y social) (pág. 156).

(Ismael Peidró Pastor)

COTTA, Sergio.

Justificación y obligatoriedad de las normas (trad. de Antonio Fernández Galiano). 
Ed. Ceura, Madrid, 1987, 171 págs.

En este libro se intenta «presentar una respuesta teórica al problema de la obligatoriedad de las normas que evite la solución empírico-pragmática del recurso a la inercia de la costumbre o a la fuerza de la opresión» y ofrecer «una solución a la embrollada cuestión de la relación entre Derecho natural y Derecho positivo pretendiendo superar la oposición positividad-naturalidad».

El libro consta de seis capítulos y un apéndice. En los cinco primeros capítulos se tratan las razones (lógicas y existenciales) por las que resulta indispensable la justificación de las normas y las condiciones que hacen posible una justificación objetiva de las mismas, llegando a las siguientes conclusiones, que el propio autor sintetiza:

«1. La justificación de las normas es indispensable para probar su obligatoriedad por dos razones: a) porque la norma atribuye una modalidad deóntica a un acto posible con preferencia a otros actos igualmente posibles; b) porque la propia norma constituye la posibilidad transcendental de la transgresión.

2. La justificación objetiva de las normas no debe limitarse a confirmar: a) ni la eficacia de las mismas (es decir, su observancia práctica generalizada); b) ni la eficacia de cualquier justificación (o sea la aceptación generalizada de las normas).

3. La justificación objetiva de las normas debe satisfacer dos condiciones formales: $a$ ) debe ser válida para todos los miembros del mismo universo lógico; $b$ ) no remitir a ningún presupuesto injustificado o injustificable.

4. La justificación objetiva de las normas debe probar, incluso frente ala argumentación en contrario: a) que el comportamiento prescrito es posible; b) que la atribución a tal comportamiento de una modalidad deóntica no es arbitraria o meramente subjetiva.

5. El carácter no arbitrario de tal atribución puede ser probado, o bien mediante la verificación de la relación funcional del comportamiento prescrito con: a) una situación existencial común pero particular (justificación relativa, secundum quid); la coexistencia humana (justificación funcional-estructural o absoluta, simpliciter), o bien puede probarse: c) mediante la comprobación de la atribución universal de la misma modalidad ética al comportamiento en cuestión.

6. La justificación objetiva, por tanto, hace a la norma obligatoria dentro del universo lógico considerado: a) relativamente obligatoria si éste consiste en un ámbito humano limitado; $b$ ) absolutamente obligatoria si el universo lógico es toda la humanidad.

7. La necesidad de justificación se impone tanto para las normas del Derecho "natural" como para las del positivo. Para las primeras, porque su obligatoriedad no es inmediatamente evidente, sino sólo demostrable mediante razonamiento; para las segundas, porque su obligatoriedad no es adecuadamente demostrable con argumentos meramente formales o fácticos.»

El capítulo VI trata de la obligatoriedad tanto del Derecho positivo como del Derecho natural, derivándola de una justificación que «ofrece una confirmación empírica de la paridad ontológica de los hombres y muestra cómo la juridicidad -en cuanto obligatoriedad racional- presupone tal paridad y la confirma con su propio modo de ser». En este capítulo también se defiende la existencia de un «Derecho natural vigente», expresión con la que se quiere decir que «el Derecho positivo, cuando sea jurídico en sentido propio (esto es, obligatorio por la justificación de su deonticidad) es Derecho natural» o que «todo el Derecho es natural (desde el punto de vista y en el sentido precisados) o no es Derecho». Por natural entiende el autor «puesto de modo humano, esto es, según la razón que argumenta en relación con las condiciones de real posibilidad de la existencia humana». Termina el 
libro con un apéndice en el que se critican las fundamentaciones no ontológicas del Derecho y se establecen las líneas para una fundamentación ontológica del mismo basada en la coexistencia, que aparece como «el criterio último de determinación del deber ser de toda posible relación infrahumana; y, por consiguiente, también del Derecho».

(Daniel González Lagier)

COTTA, Sergio.

Las raíces de la violencia. Una interpretación filosófica (trad. de Tomás Melendo).

Ed. EUNSA, Pamplona, 1987, 215 págs.

Advierte el autor de este libro que su propósito no es «examinar el completo universo de la violencia ni ilustrar todas las situaciones de las que puede surgir», sino que le mueven los siguientes objetivos: «El primero, sacar a la luz la estructura del obrar violento, poniendo de relieve sus características fenomenológicas (...). El segundo, trascender el cómo de la violencia, para indagar y discutir el por qué de aquello que (...) constituye el aspecto verdaderamente nuevo de la cuestión: la valoración positiva de la violencia.»

Para ello divide el libro en seis capítulos. De éstos, los dos primeros (La violencia actual, ¿Nueva o antigua? $y$ «Flujo» $y$ «reflujo» de la violencia) examinan las actitudes acerca de la violencia que se han dado a lo largo de la historia, indicando la existencia de un «flujo» contrario a la misma y un «reflujo» violento (que pueden observarse comparando los siglos XIX y XX como ejemplos de una y otra tendencia, respectivamente) y observando una novedad en la violencia contemporánea relativa no a una transformación de su esencia, «sino a un modo diverso de percibirla, de asignarle su puesto en la historia y, por consiguiente, de valorarla».

En el tercer capítulo (El acto violento y su fenomenología) el autor intenta distinguir entre fuerza y violencia, examinando $a$ ) el criterio de la «índole física o de la cualidad de la acción», según el cual la violencia se configuraría como «una intervención física intencional sobre el cuerpo, sobre las dimensiones físicas, de otros hombres»; b) el criterio institucional o de la cualificación del agente, que distingue la fuerza de la violencia en atención a su atribución o no a una autoridad o institución constituida; c) el criterio de referencia a los valores, según el cual un acto es violento cuando se lleva a cabo «por un motivo indigno, carente de valor», y es, por el contrario, un acto de fuerza si se realiza con referencia a algún valor; $d$ ) el criterio estructural, que afirmaría que la violencia presentaría unas características en su configuración que la distinguirían de la fuerza, como son la inmediatez, la discontinuidad, la desproporción respecto al fin, la falta de persistencia y la imprevisibilidad. Para el autor éste es el criterio más adecuado para diferenciar fuerza y violencia, a las que considera como dos especies del género "actividad-contra», destacando la ausencia de medida («es decir, la i-regularidad y el descomedimiento») como principal nota distintiva.

En el capítulo cuarto (De la medida al Derecho) añade el concepto de Derecho a la distinción entre fuerza y violencia. Concluye que «lo que unifica a los dos primeros -el Derecho y la fuerza-, separándolos nítidamente de la tercera -la violencia-, es la presencia plena de la medida. Pero mientras la fuerza es sólo actividad-contra mesurada (y en ello se distingue de la violencia), el 
Derecho configura según los modos de la medida también y, principalmente, su propia actividad-para. Por consiguiente, no sólo se opone a la violencia, sino que va más allá de la fuerza, más allá de la entera actividad-contra».

Los dos últimos capítulos (¿Por qué existe la violencia? I: Un derecho sin fundamento y ¿Por qué existe la violencia? II: El sujeto absoluto) buscan las causas del actual «reflujo» violento. A juicio del autor éstas se encuentran, por un lado, en el antiformalismo que domina la sociedad actual (mientras que, por el contrario, «en un clima cultural en el que el universo de la naturaleza se muestra comprensible, y el cosmos humano interpretable y edificable en términos de medida, regularidad y ley, resulta lógico que se tienda a marginar y a superar la violencia, en cuanto constituida por la i-regularidad y la falta de proporción») y en especial en una de sus manifestaciones: la actitud antijurídica y la fragilidad del Derecho de hoy, y, por otro lado, en la oposición entre los valores del «yo» y del «nosotros».

(Daniel González Lagier) 
DÍAZ, Elías.

Guerra en la guerra: Unamuno, 1936.

Saber leer. Revista crítica de libros, núm. 4, abril 1987, págs. 1-2.

Al hilo del reciente libro de Luciano González Egido Agonizar en Salamanca, Unamuno, julio-diciembre 1936, el autor reflexiona sobre los últimos meses de la vida de don Miguel de Unamuno, en los que preparaba un libro que hubiera llevado por título El resentimiento trágico de la vida, modificando significativamente el título de una de sus principales obras. Algo parecido hace el autor de este comentario al titularlo Guerra en la guerra, por contraste precisamente con la primera obra de Unamuno, Paz en la guerra. «Y entre una y otra -escribe el autor-, toda su vida, toda su obra, a replantear y repensar con una nueva conciencia y consciencia en este agónico final: ya no habrá más paz en la guerra; en la guerra sólo hay guerra, es decir, objetivamente, odio, violencia y degradación; y de la guerra, de esa guerra, ya no saldrá la paz, una auténtica paz, sino sólo la victoria impuesta por la fuerza, dogmática y totalitariamente, por unos españoles sobre otros, los vencidos. Tal es su estado de ánimo, de mente y de espíritu, a medida que se avanza hacia la conclusión de ese 1936.»

Unamuno «agoniza en Salamanca», lucha contra la muerte, contra la suya propia y la de los demás («la locura y las miserias morales de esa devastadora guerra civil-incivil que asola a España»), «pero sin que él se rinda del todo en ningún momento». En opinión del autor, Unamuno no llega a caer en el desencanto total, en el nihilismo final que siempre le había tentado. Aquí radica la principal discrepancia con el libro comentado; libro que, por otra parte, es ampliamente elogiado, tanto por los datos «totalmente fiables» que proporciona (especialmente para ayudarnos a comprender la evolución de Unamuno desde su primitiva adhesión a los sublevados hasta su crítica actitud de «alterutralidad» dialéctica, es decir, la de estar a la vez con unos y con otros impidiendo la fractura entre las dos Españas), como por la calidad literaria de una obra fundamentalmente concebida como «creación y recreación» («González Egido ha querido ser más escritor que historiador», aunque «ha sido también lo segundo»: «la ficción nunca falsea la historia, la realidad; sólo la complementa»). Pero, según el autor, González Egido construye su obra «desde la muerte de Unamuno», lo cual «condiciona en exceso la exégesis de lo que antes de ella, sobre todo en las últimas semanas, aviene» «Luciano González Egido sabe que Unamuno va a morir, y actúa en consecuencia.» «Eso es precisamente -señala críticamente Elías Díaz- lo que le permite, mejor dicho, le exige, anticipar un Unamuno que en los últimos tiempos de su vida parece estar ya totalmente acabado y no creer en nada.» «No lo veo yo del todo así», declara Elías Díaz. Aquel hombre viejo en la Salamanca de 1936 se debatía entre intentar resistir o dejarse morir. «Yo, no arbitrariamente, prefiero verlo dando prevalencia a la primera actitud: agonizar, en Unamuno, es mucho más luchar que morir (...). Unamuno, sin perder nunca su identidad, se estaba trazando un plan bastante racional de futuro trabajo y de acción intelectual y política.» «La experiencia de esta guerra -escribe don Miguel en sus notas contra El resentimiento trágico de la vida- me pone ante dos problemas: el comprender, repensar mi propia obra empezando por Paz en la guerra, y luego comprender, repensar, España.» «Una nueva, renovada, conciencia (y consciencia) estaba surgiendo en efecto -concluye Elías Díaz- a través de la guerra en el viejo Unamuno.» 
DÍAZ, Elías.

La transición a la democracia (Claves ideológicas, 1976-1986).

Eudema, Madrid, 1987, 222 págs.

Se trata de un conjunto de artículos surgidos y publicados en este decisivo decenio de la transición al hilo de algunos de los acontecimientos más significativos y, sobre todo, del sentido general de la evolución política e ideológica de nuestro país en esos tan importantes tiempos que arrancan del final de la dictadura franquista.

Como núcleo coherente de la «teoría de la transición» que en ellos subyace estaría la crítica a diversas, pero entre sí vinculadas ideologías que sobre aquélla han ido sucesivamente manifestándose en esos años:

1. ${ }^{a}$ Crítica a las ideologías esencialistas que, como rechazo, se hacen escépticas e, incluso, totalmente negativas respecto a la posibilidad de la transición tal y como, sin embargo, de hecho realmente se produjo.

2. ${ }^{a}$ Crítica a las interpretaciones contumazmente conservadoras de la Constitución de 1978 hechas, paradójicamente, desde muy diferentes e, incluso, contrapuestas ideologías y actitudes políticas.

3. ${ }^{a}$ Crítica a las ideologías del desencanto que, muy desde el principio de la transición, comienzan a imponerse masoquista y/o interesadamente; contraposición, pues, entre crítica de lo real y desencanto acrítico.

4. ${ }^{a}$ Crítica al rupturismo como ideología; es decir, consideración de la vía de la reforma pactada (o de la ruptura pactada) como el mal de males, el «mal radical» de las consecuencias e implicaciones de la transición: así, pues, teórica, ideológica, añoranza de una no habida ruptura revolucionaria.

5. ${ }^{a}$ Crítica a las interpretaciones continuistas de la transición respecto de la dictadura -nueva falacia de la identidad- hechas también desde muy diferentes e incluso, contrapuestas ideologías y actitudes políticas.

6. ${ }^{\mathrm{a}}$ Crítica a las interpretaciones funcionalistas-personalistas que ven la transición como resultado casi mecánico del desarrollo económico-tecnocrático cuando no, incluso, como fruto de la misma intencionalidad oculta del dictador o de los necesarios efectos no queridos de su política represiva. El libro -revisión, pues, de la cultura política de la transición- incluye una amplia y útil bibliografía de obras generales acerca de aquélla y, preferentemente, de sus principales aspectos políticos e ideológicos.

DÍAZ, Elías.

Legitimidad y justicia: la Constitución, zona de mediación.

Doxa, Alicante, núm. 4, 1987, págs. 349-353. 
Este texto constituye un paso adelante del autor en relación con algunas propuestas conclusivas formuladas en anteriores trabajos. La hipótesis de partida para ello será la consideración de la libertad como punto de convergencia entre una teoría de la legitimidad (democrática) y una teoría (crítica) de la justicia y, por tanto, asimismo, como posible zona de encuentro entre las denominadas legitimidad procedimental y justicia material. A partir de aquí, en busca de conclusiones más concretas, el autor sostiene que la libertad, ejerciéndose sin ataduras, se actúa a través de la soberanía popular, la cual, cuando se trata de partir de las posiciones originarias, se muestra en sus caracteres básicos como poder constituyente. De este modo, la Constitución y el poder constituyente pueden verse como zona de mediación y de convergencia de una suficiente legitimidad democrática y de una objetiva justicia material (histórico-material) en todo caso sometida, por supuesto, a pertinentes críticas y a racionales contrastaciones. Finaliza el autor afirmando que «la Constitución sin más (que incluye necesarios equilibrios, consenso realistas y presencia de minorías que pueden un día ser mayorías), garantiza ya un cierto, importante nivel de comportamiento ético, una vía bastante sólida hacia los objetivos últimos de una teoría crítica de la justicia».

(Ángeles Ródenas Calatayud) 
DÍAZ, Elías.

Ortega y la institución libre de enseñanza.

Revista de Occidente, Madrid, núm. 68, 1987, págs. 113-127.

En este trabajo se desarrolla la hipótesis de la existencia de una relación más intima e intensa de la que suele señalarse entre Ortega y los institucionalistas, rindiendo, al mismo tiempo, un homenaje a lo que uno y otros reportaron a la configuración de nuestra memoria histórica. Con este fin se efectúa un análisis de los diferentes testimonios históricos, de las relaciones entre ambas filosofías y, por último, de la acción estimuladora y aglutinante que institucionalistas y orteguianos van a desarrollar frente a las actividades absolutistas y totalitaristas tanto en la segunda república como en la oposición a la dictadura.

(Ángeles Ródenas Calatayud)

DIEGUEZ LUCENA, Antonio J.

La teoría de las ciencias morales en John Stuart Mill.

Ed. Universidad de Málaga, Málaga, 1987, 316 págs.

El autor considera que el estudio del pensamiento de John Stuart Mill es un antecedente necesario para una reflexión filosófica sobre las ciencias, por lo que intenta superar la imagen, en su opinión «parcial, estereotipada y a veces hasta errónea», que se ha dado del mismo, presentándolo no como el «inductivista y defensor a ultranza de los cánones de la investigación experimental» que se ha visto en él, sino como el constructor de «un modelo metodológico centrado en la deducción y la contrastación, y donde la invención de hipótesis tiene también un lugar destacado». Para ello divide el libro en tres partes.

En la primera de estas partes intenta describir el contexto filosófico en el que se sitúa la obra de este autor. Así, hace un breve resumen del debate sobre los métodos de las ciencias humanas, afirmando que la verdadera reflexión sobre éstos se inicia con Mill, quien en el Sistema de Lógica lleva a cabo «un análisis pormenorizado de los métodos de la investigación social que profundice en sus estructuras lógicas y los relacione con los métodos empleados en las ciencias naturales». En esta parte el autor rastrea también los antecedentes en los que Stuart Mill se fundó directa o indirectamente, haciendo especial referencia a Comte, quien si se dedicó en sus obras a la cuestión de los métodos fue sólo «al hilo de los contenidos doctrinarios que asignaba a la ciencia social y en total dependencia de ellos». En la segunda parte del libro se trata de la concepción de Mill sobre la lógica, a la que concibe como «una ciencia general de la investigación y del método científico». La lógica formal es para él sólo una pequeña parcela de la lógica ocupada de la consistencia de los enunciados, siendo la parcela más importante la que se ocupa del estudio de los procedimientos de investigación en las ciencias, tanto los cánones de la inducción como el método deductivo». Se trata también de las implicaciones 
filosóficas de esta concepción de la lógica y de la interpretación de Mill acerca de los modos deductivos e inductivos de inferencia (para Mill la inducción es el único tipo de inferencia auténtica y la deducción es un complemento de la anterior; sin embargo, la primacía de la inducción se circunscribe al orden del descubrimiento, mientras que en el orden de la construcción teórica prima la deducción). Por último abarca este apartado el concepto general de ciencia en este autor y conceptos afines como ley y causa, estudiando los métodos de la investigación científica citados por Mill.

El concepto de causa es central en el pensamiento de Mill, como se ve en la tercera parte del libro que comentamos. Para este autor «la conducta humana, como cualquier otro evento del universo obedece a causas», y de forma que las leyes de los fenómenos humanos deben ser averiguadas por el científico (éste es el fin de la investigación social, al igual que el de la investigación natural) a través de la inducción y de la deducción. La posibilidad de formular leyes sobre los fenómenos humanos y sociales es precisamente la condición fundamental de la existencia de tales ciencias. Otros aspectos tratados por el autor son el intento de conciliación en Mill de estas leyes con el libre albedrío («pues la propia voluntad del sujeto interviene en la producción del fenómeno como un factor causal más») y la definición de cada una de las disciplinas particulares que componen el conjunto de las ciencias morales. Por último, dedica un capítulo a «la dilucidación de los métodos adecuados e inadecuados en las citadas ciencias y de las razones que para Mill justifican la aceptación de unos y el rechazo de otros». Para el autor estudiado no existe gran disparidad metodológica entre las ciencias morales y las ciencias naturales, aunque sí cierta especificidad de estas últimas por su gran complejidad, siendo el «esquema de interacción deducción-experiencia» el modelo de funcionamiento para las ciencias en su estado de madurez.

(Daniel González Lagier)

DIEGO-LORA, Carmelo de.

Jueces y abogados ante la ley injusta.

Persona y Derecho, Pamplona, núm. 16, 1987, págs. 155-178.

En la primera parte de este artículo, el autor expone la doctrina católica del Derecho natural, a la que se adhiere decididamente. El Derecho natural «se deriva del orden natural de la Creación», y se entiende como «la ordenación normativa de la convivencia natural humana dentro de una comunidad y en servicio del bien común». «Este Derecho natural -continúa el autor- cuenta con una base estable, expresada en preceptos inmutables y universalmente válidos, derivados de la naturaleza constantemente igual del hombre y de la sociedad. La norma suprema de la vida humana es la misma ley divina eterna, objetiva y universal, por la que Dios ordena, dirige y gobierna el mundo. El Derecho positivo aparece entonces como garantizador de esas normas de Derecho natural, o como determinador de sus preceptos. Las leyes humanas, por consiguiente, nada pueden preceptuar contra la ley natural», y si así lo hicieran, «esas leyes humanas carece de fuerza de obligar», «dejarían de serlo, por su falta de racionalidad». «Ante ellas -concluye el autor- se hace necesario escuchar de nuevo aquella valiente afirmación que se lee en los Hechos de los Apóstoles: "es necesario obedecer a Dios antes que a los hombres".»" A continuación, el autor reacciona contra el «permisivismo moral», contra «el mero historicismo moral 
negador de que la sociedad posea valores inmutables», «camino elegido por el positivismo jurídico reinante, que enfoca la ley bajo el prisma del relativismo moral y entiende que lo que es ético o no lo es depende de lo que se piense en cada momento histórico, independientemente de la ordenación objetiva de Dios, que es olvidada e incluso despreciada a la hora del ejercicio de la potestad legislativa». «El permisivismo resulta ser el ambiente ideológico apto para que la corrupción moral se institucionalice (...). La falacia legislativa del respeto libertario individualista es fuente de incontables daños sociales.»

Por último, el autor aborda el problema de la actitud que jueces, abogados y procuradores han de adoptar ante una ley injusta. Cuando dicha ley es de carácter imperativo, que impone una conducta positiva contraria a la ley natural (por ejemplo, si prescribe el aborto para limitar la natalidad), la solución es unívoca para jueces y abogados: «el pecado exigido justifica la rebeldía de la desobediencia» (si es necesario, los jueces deberán abandonar su profesión judicial). Distinta es, según el autor, la situación ante la ley injusta permisiva, cuando esa permisión viene mediatizada -como en la ley de divorcio- por una sentencia judicial dictada en un proceso promovido a instancia de parte. Aquí, el juez se encuentra doblemente condicionado: por la pretensión de la parte, a la que debe responder, y por la norma jurídica, a la que debe obedecer. El juez se verá forzado «desde fuera» a una «cooperación material» que le libera de responsabilidad moral. Renunciar a la carrera judicial, además del sacrificio profesional y económico, significa «el sacrificio de toda posibilidad de un bien moral de índole social muy amplio, por parte de personas de recta y bien formada conciencia». Además, «ciertos bienes podrían ser obtenidos a la hora de la aplicación de esa ley injusta, que lógicamente quedará ajustada a sus límites estrictos». El caso de abogados y procuradores es aquí algo distinto. Salvo que estén en situaciones análogas a las antes descritas para los jueces (como sería el caso de un turno de oficio obligatorio), y salvo que la aplicación sólo formal de la ley de divorcio constituya una ficción judicial con la que se pretende un fin distinto al divorcio (por ejemplo, lograr efectos civiles para decisiones canónicas legítimas de nulidad o separación), la colaboración del abogado con la parte que pretende un divorcio no es aceptable moralmente, pues constituye un caso de cooperación formal o complicidad: si el abogado acepta la defensa, colabora libremente queriendo esos resultados injustos, solidarizándose de algún modo con el autor principal del mal. «Por ello, el criterio que rige para el abogado, a la hora de aceptar los asuntos, es el de la libertad profesional: para aceptar los asuntos que su cliente le lleve, si estima en justicia que merecen ser protegidos; o para rechazarlos, cuando considere esos intereses, por injustos, carentes de aquella dignidad que merezca blandir las armas del Derecho en la noble lid judicial, para que sean amparados.» 
ESCAMILLA CASTILLO, Manuel.

Utilitarismo e igualdad. El principio de igualdad en la teoría de Jeremy Bentham.

Anuario de Filosofía del Derecho, Madrid, núm. 4 (Nueva Época), 1987, págs. 153-192.

«El significado del principio de igualdad en la teoría de Jeremy Bentham resulta mal comprendido -opina el autor- entre muchos teóricos del Derecho e historiadores de las ideas jurídicas. Deduzco que se encuentra mal comprendido del hecho de que existen diversas interpretaciones sobre su sentido y alcance. Como muchas de estas diversas interpretaciones son contradictorias entre sí, gran parte de los intérpretes deben estar en el error. El objetivo del presente escrito es tratar de exponer algunas contradicciones graves que me ha parecido encontrar entre algunas teorías sobre la igualdad en Bentham y las teorías de éste, entendidas como un todo coherente y lógico, como un sistema».

Para ello, tras realizar distintas redacciones del artículo 14 de nuestra Constitución con el fin de comprender mejor su significado, examina la teoría de Bentham partiendo del principio utilitario. El autor se cuestiona su contenido, es decir, si se trata de la mayor felicidad para todos, la mayor felicidad para los menos, la mayor felicidad del mayor número o «una felicidad puramente formal». A continuación, el artículo se centra en el estudio de los principios conductores del principio utilitario y concluye afirmando que Bentham no hubiera escogido ninguna de las lecturas del artículo 14 propuestas al principio del artículo y «probablemente, ni siquiera hubiera incluido el artículo 14, ni ningún otro en que se contenga el término «igualdad» como objetivo legal, a no ser con un significado extremadamente vacío, formal».

(Daniel González Lagier)

ESCOTHADO, Antonio.

Moral y Derecho.

Sistema, Madrid, núm. 76, enero 1987, págs. 121-130.

Se analiza en este artículo la evolución que experimenta, en el Derecho Romano, la relación entre moral y Derecho. Según el autor, el Derecho Romano quiso ser un cuerpo técnico de normas y criterios adaptable a culturas dispares, donde los deberes morales no se agotan en los jurídicos y éstos conciernen a una esfera de actuación exterior, debiendo seguir una línea de máxima eficacia y mínimo apasionamiento.

Este deslinde entre eticidad y juridicidad, obvio en el Derecho civil, se complica en la esfera de las penas. Gracias al concepto racional de la norma (introducido por el pretor y la iurisprudentia), se realiza una distinción entre los crímenes estrictamente jurídicos y aquellos vinculados a intereses no siempre dictados por la ecuanimidad. Los primeros serían los perjuicios demostrables causados a la integridad física de las personas y a su patrimonio. Contra ellos se tipifican delitos universales y permanentes. Estos crímenes, con víctima real, delimitan claramente la moralidad y la juridicidad. 
En el segundo tipo de crímenes se incluyen los perjuicios al poder político y religioso, las ofensas a ciertos símbolos y entes transjurídicos y aquellos perjuicios que, desde una óptica paternal, pueden ocasionarse los individuos a sí mismos. Contra ellos se tipifican delitos particulares y transitorios, dependientes de cada sistema político y que defienden a víctimas hipotéticas o al propio acusado de sí mismo. Aquí el legislador no respeta la distinción entre moralidad y Derecho.

El contraste esencial entre los dos tipos de crímenes reside en su fundamento punitivo, que se manifiesta en una divergencia teórica entre los que piensan que la verdad sólo se difundirá cuando se le permita defenderse por sí misma y los que creen que el error debe evitarse legislativamente y que lo verdadero necesita, para subsistir, de la censura. A pesar de esta complicada discusión, en opinión del autor, no hay duda de que «el Derecho como empresa científica de justicia (...) es una reglamentación tendente a la máxima libertad individual compatible con una existencia en sociedad», por lo que concluye afirmando que se debería renunciar «a toda suerte de cruzadas contra el error y monopolios de la verdad».

Siguiendo con la evolución del Derecho Romano, afirma el autor que la lógica imperial acaba por considerar a la libertad de conciencia como un peligro permanente para el gobierno; así, en el Bajo Imperio está ya perfectamente organizada una censura social y política anónima. Para finalizar examina la aparición de una abundante «legislación para delitos sin víctima», encaminada a perseguir el error y cuyas penas sufren un gran endurecimiento, llegando incluso a condenar gravemente, no sólo a quienes atientan contra un representante del orden, sino también a quienes «lo hubiesen pensado».

(Isabel Linfante Vidal)

ESTÉVEZ ARAUJO, José Antonio.

¿Qué Schmitt se lee en los ochenta? (Dos intentos de rehabilitación de Schmitt).

Anuario de Filosofía del Derecho, Madrid, núm. 4 (Nueva Época), 1987, págs. 683-696.

El autor analiza algunos recientes intentos de rehabilitación de la obra weimariana de Carl Schmitt. En primer lugar, critica el intento de rehabilitación política de Schmitt llevado a cabo -con escaso éxito- por J. W. Bendersky, quien presenta al Schmitt anterior a 1933 como un firme defensor del orden republicano y constitucional. La interpretación schmittiana de los poderes «dictatoriales» atribuidos por la Constitución de Weimar al presidente del Reich en situaciones de excepción, su noción de soberanía y su búsqueda de un nuevo «fundamento espiritual» (una nueva legitimidad) al Parlamento, son el reflejo, según Bendersky, de un Schmitt interesado únicamente en dotar a la República de mecanismos de defensa frente a sus enemigos. Según el autor, Bendersky ofrece una visión falseada del pensamiento de Schmitt, incluso descontextualizando y manipulando citas y datos que, en realidad, permiten demostrar la tesis contraria: la actitud de Schmitt ha de entenderse como una actitud de defensa del statu quo frente a la «amenaza revolucionaria». Que ese objetivo «contrarrevolucionario» implicase la defensa de la República era algo exclusivamente coyuntural, como lo muestra el papel activo de Schmitt en el proceso de transformación del sistema parlamentario en uno presidencialista durante los últimos años del régimen republicano.

En segundo lugar, el autor critica los intentos de rehabilitación científica de Schmitt llevados a cabo 
-con algo más de éxito- en Italia (Schiera, Miglio, Portinaro), según los cuales es posible, rechazando la interpretación exclusivamente política de la obra schmittiana, aprovechar su valor científico interno, especialmente su configuración de lo político como categoría autónoma. Ello sugeriría una «fecunda» línea de investigación aún por explorar. Para el autor, tal fecundidad no existe: la teoría de lo político de Schmitt dice bien poco (simples generalidades vacías como la de que a la política subyace un enfrentamiento, o que la dinámica de lo político es una tensión entre decisión y enemistad, orden y desorden). Además, esa autonomía de lo político llega a transformarse en independencia total (la evolución política se explica por su propia dinámica, sin atender a factores sociales, económicos, técnicos, etc.), e incluso en un nuevo «centralismo» de lo político (cuya dinámica determinaría los cambios en esas otras esferas), desembocando en una visión idealista de los conflictos humanos. El autor evalúa también los recientes análisis de la obra de Schmitt efectuados desde el pensamiento de tradición marxista. En Alemania, los análisis externos de carácter político (Neumann, Seifert) muestran que Schmitt configura una teoría de la contrarrevolución, y que no es posible una «recuperación» de la teoría política de Schmitt por la izquierda, dado el trasfondo irracionalista que subyace a su decisionismo. Sin embargo, en Italia, algunos marxistas (Duso) han intentado su rehabilitación científica. Entre los dos polos de la dialéctica política schmittiana, enemistad (conflicto) y decisión (orden), y dado que en esta perspectiva la conflictividad «tiene lugar» sin que se sepa por qué, Duso se inclina hacia el elemento del orden, propugnando una reducción de la complejidad social mediante decisiones autoritarias.

Por último, el autor analiza dos recientes estudios sobre Schmitt en España (J. M. Beneyto y G. Gómez Orfanel), dentro de un panorama general de repudio a Schmitt desde los años setenta. Beneyto se centra en la «Teología Política» de Schmitt, mostrando su trasfondo idealista y su intención legitimadora de una autoridad estatal incondicionada. Gómez Orfanel pretende efectuar un análisis interno de la obra schmittiana (pero meramente descriptivo, sin buscar en ella «fecundidad» alguna), según el cual la dialéctica de lo político se articula en base a los conceptos «excepción-normalidad». Pero Gómez Orfanel también conecta la obra de Schmitt con su contexto político externo, mostrando la hostilidad de Schmitt hacia el régimen de Weimar.

En conclusión, el autor señala la imposibilidad de una rehabilitación política de Schmitt, y la necesidad de combinar el análisis interno con el externo para detectar el componente ideológico de su pensamiento. Ello permitiría identificar, con la suficiente prevención, los elementos aprovechables de la producción schmittiana.

(Juan Antonio Pérez Lledó) 
EYMAR, Carlos.

Karl Marx, crítico de los derechos humanos.

Ed. Tecnos, Madrid, 1987, 197 págs.

«En estas páginas -dice el autor- no se va a presentar a un Marx defensor de los derechos humanos, ya sea en su forma científica de instrumento, ya bajo el ropaje utópico de fin. Por el contrario, reservando para otra ocasión el análisis de aquellos intentos fundamentadores, se va a desarrollar con exclusividad su tarea crítica (...). Siguiendo cronológicamente el contenido de estas obras (de crítica a los derechos humanos), previa deliberada omisión de las primerizas, se va a concluir en el intento de ofrecer una fórmula que resuma lo esencial de su crítica a los derechos humanos.»

A lo largo de los capítulos que integran este libro (I. Los inicios de la crítica, II. La «cuestión judía» y el tema de la emancipación humana, III. Los derechos humanos en las obras de Marx posteriores a $1845, I V$. El concepto de ideología como instrumento crítico y V. Resumen sistemático de la crítica de Marx a los derechos humanos: Los derechos humanos como ideología de la burguesía) se pone de manifiesto «cómo Marx pone en cuestión la posibilidad de construcción del Estado racional por medios "racionales". Descubre cómo la racionalidad no tiene ninguna fuerza transformadora de la realidad porque ella misma es un producto de esa realidad que pretendía modificar. El estado que, al modo hegeliano, era considerado como la encarnación de la Idea, como lo racional en sí y para sí, es puesto en entredicho al descubrir la fuente de la racionalidad sobre la que se erigía. Así esta racionalidad que sustentaba y justificaba al Estado, presentándolo como la esfera de lo general, va a ser calificada por Marx de Ideología, de racionalidad parcial o de apariencia de racionalidad.» Es en este contexto teórico en el que el autor sitúa la critica de Marx a los derechos humanos, «en cuanto exigencias racionales de reconstrucción del Estado».

(Daniel González Lagier)

EZCURDIA LAVIGNE, José A.

Curso de Derecho natural. Perspectivas iusnaturalistas de los derechos humanos.

Ed. Reus, Madrid, 1987, 292 págs.

La finalidad de esta obra, según declara el autor en la presentación, es «ofrecer no un libro de investigación, sino de texto y, especialmente, para quienes inician su andadura en el estudio de las ciencias jurídicas». El autor presenta un estudio global de la problemática de los derechos humanos estructurado en cuatro partes:

I. Teoría general de los derechos humanos: concepto y denominaciones: configuración jurídica (su caracterización dentro de la categoría de los derechos subjetivos); caracteres y límites (rasgos que los distinguen de otros derechos subjetivos: inviolabilidad, imprescriptibilidad, inalienabilidad, irrenunciabilidad, universalidad y carácter no absoluto sino limitado); fundamentación (diversas 
teorías: iusnaturalistas, historicistas, positivistas, dualistas, etc.); fuentes (incluyendo las declaraciones y convenios a nivel supranacional); protección y garantías (con especial referencia al Convenio Europeo de Roma).

II. Desarrollo y formulaciones históricas: el autor hace un recorrido histórico a través de las declaraciones de derechos humanos desde la «prehistoria» del Concilio de Toledo y la Carta Magna hasta la Declaración Universal de Derechos Humanos de 1948 y los Pactos de Nueva York de 1966. III. Los derechos humanos en la Constitución española de 1978: aquí se analiza el Título I de nuestra Constitución, su contenido y directrices ideológicas, los valores superiores que lo informan, la clasificación de los derechos según sus mecanismos de garantía, su (debatida) inspiración «iusnaturalista crítica», etc.

IV. La Iglesia católica y los derechos humanos: el autor expone la contribución de la Iglesia a la formación y realización de los derechos humanos, analizando -tras hacer una breve referencia histórica- las principales Encíclicas de los Papas del siglo XX, desde Pío XI hasta Juan Pablo II. La especial atención dedicada a la doctrina católica de los derechos humanos se explica por la inspiración iusnaturalista cristiana que informa todo el libro. El propio autor, en la presentación de su obra, insiste explícitamente en «recordar la filiación iusnaturalistas del pensamiento jurídico en ella expresado. Un iusnaturalismo -añade- con todas las aportaciones, incorporaciones o matizaciones que el transcurso del tiempo ha hecho precisas; pero iusnaturalismo al fin. Un iusnaturalismo que no mixtifica ni priva de valor jurídico a la moderna teoría y al concepto mismo de los derechos humanos, sino que -lo creemos firmemente con tantos y tantos eminentes teóricos del Derecho- le presta su más sólido fundamento, su sentido y la mejor esperanza de definitiva vigencia».

(Juan Antonio Pérez Lledó)

FARREL, Martín D.

Acerca de algunas falacias de atingencia en la argumentación moral.

Doxa, Alicante, núm. 4, 1987, págs. 153-159.

El propósito del autor es demostrar cómo algunos argumentos que han sido considerados por los lógicos como falacias de atingencia (argumentos lógicamente incorrectos pero psicológicamente convincentes) no son realmente falaces dentro del contexto de la argumentación moral.

El autor examina tres tipos de falacias de atingencia: el argumento ad misericordiam y las dos variantes del argumento ad hominem (el ofensivo y el circunstancial), llegando a las siguientes conclusiones: el argumento ad misericordiam (con el cual se intenta que el sujeto actúe atendiendo a ciertas consideraciones caritativas) permite tomar en cuenta el cálculo de consecuencias, no siendo en estos casos un razonamiento falaz dentro de la argumentación moral; el argumento ad hominem ofensivo (con el cual «se trata de descalificar a quien defiende una opinión mostrando, no las deficiencias de la opinión misma, sino los defectos de quien la emite») permite en ocasiones tomar en cuenta la falta de imparcialidad o el cálculo de probabilidades, casos en los que tampoco es un argumento falaz dentro de la argumentación moral; por último, el argumento ad hominem circunstancial (con el que se trata de demostrar que la condición o circunstancia de un sujeto le impide defender una 
opinión determinada y la invalida) permite llamar la atención acerca de inconsistencias en las tesis que se afirman, no siendo tampoco en estos casos un argumento falaz dentro del razonamiento moral.

(Daniel González Lagier) 
FERNÁNDEZ, Encarnación.

Derecho social, democracia y pluralismo en G. Gurvitch.

Anuario de Sociología y Psicología Jurídicas, Barcelona, núm. 13, 1987, págs 5-17.

El artículo trata sobre la idea de derecho social elaborada por Gurvitch en sus primeras obras, las que podríamos llamar obras del «primer Gurvitch» y que son fundamentalmente L'idée du Droit Social, Le Temps présent e l'idée du Droit Social y L'Expérience juridique et la philosophie pluraliste du droit. La base filosófica de la idea de derecho social se encuentra, según pone de relieve el propio autor, en el transpersonalismo. El término transpersonalismo escogido por Gurvitch para designar su propia concepción metafísica, ética, filosófico-jurídica e incluso política, es poco afortunado y puede inducir a error a la hora de precisar el significado de su obra. Tal como él concibe el transpersonalismo éste presenta un carácter marcadamente antitotalitario y precisamente aparece como la verdadera premisa filosófica del régimen democrático. Así el derecho social es en la obra de Gurvitch el derecho de la democracia, proponiendo dicho autor la organización democrática no sólo de la vida política, sino también de la vida económica e internacional. Gurvitch concibe la democracia como un principio organizativo, es decir, un principio que atañe al modo de configurar la superestructura organizada de un grupo social. Pero la democracia no es un principio de organización exclusivamente político. El campo de acción de la democracia no necesariamente queda circunscrito al dominio de la organización política. Cualquier grupo social, de la índole que sea -político, religioso, económico, etc. puede organizarse democráticamente. En definitiva, la democracia consiste, para G. Gurvitch, en el enraizamiento de la organización en la comunidad subyacente. Las organizaciones democráticas son, desde su punto de vista, las organizaciones que se rigen por el derecho social -derecho social organizado basado en el derecho social inorganizado de la comunidad subyacente-, frente a las organizaciones no democráticas o «asociaciones de dominación» que se rigen por el derecho subordinativo, el cual implica una perversión del derecho social organizado, perversión que tiene lugar cuando el derecho de la organización se cierra a la influencia del derecho social inorganizado.

La noción de derecho social de Gurvitch es la base de un sistema de pluralismo jurídico, en el que una infinidad de grupos sociales distintos del Estado producen su propio derecho social autónomo, pluralismo jurídico que culmina con la afirmación de la supremacía del derecho social de la comunidad internacional sobre todos los demás órdenes jurídicos.

FERNÁNDEZ GARCÍA, Eusebio.

La obediencia al Derecho.

Ed. Cuadernos Cívitas, Madrid, 1987, 254 págs.

Este libro tiene el objetivo de responder a la cuestión de si existe una obligación moral de obedecer 
al Derecho y en qué circunstancias. Para ello parte de la consideración de los destinatarios del Derecho como agentes morales y de la afirmación de que un determinado sistema jurídico puede contar con razones morales a su favor, y postula como tesis central que existe una obligación moral de obedecer al Derecho justo y a las disposiciones jurídicas justas derivadas de la obligación moral más general que tienen los hombres de ser justos. A este respecto, el autor entiende «que un sistema jurídico es suficientemente justo cuando ha sido elaborado contractualmente y, además, respeta y garantiza el ejercicio de los derechos humanos fundamentales».

Para el autor «todo esto es compatible con la defensa de la postura de que existen, en algunas circunstancias, razones morales a favor de la obligación moral de desobedecer al Derecho injusto o a las disposiciones jurídicas injustas, razones morales para no obedecerlas u otras obligaciones morales más fuertes, en conflicto con ella, que invalidan la obligación moral de obedecer a un Derecho justo y a las disposiciones jurídicas justas». Por tanto, la obligación moral de obedecer al Derecho y a las disposiciones jurídicas justas se caracteriza por ser una obligación moral prima facie.

En el libro se analizan también otras posturas en torno a la pregunta acerca de la existencia de una obligación moral de obediencia al Derecho. Se estudian, entre las que responden afirmativamente la de la promoción de la justicia, el bien común y el consentimiento, de D. D. Raphael; la del deber prima facie de obedecer al Derecho, de Norbert Herster; y la del deber natural de justicia, de J. Rawls. También se incluyen las respuestas negativas de F. González Vicén y Javier Muguerza y las réplicas de M. Atienza y Elías Díaz, así como la tesis del respeto por el Derecho de J. Raz, que no es encuadrable en las dos posturas anteriores.

Finaliza este texto «con una defensa del liberalismo y de la fundamentación liberal de los derechos humanos fundamentales como la teoría y la práctica más acorde con el respeto a la dignidad, autonomía, libertad e igualdad humanas».

(Daniel González Lagier)

GARCÍA AMADO, Juan Antonio.

Derecho y racionalidad. La teoría del Derecho de Josef Esser.

Liber Amicorum. Colección de Estudios Jurídicos en Homenaje al Prof. Dr. D. José Pérez Montero, Universidad de Oviedo, Servicio de Publicaciones, 1988, págs. 549-571.

Se trata de un análisis global de la obra iusfilosófica y de teoría general del Derecho de Josef Esser. Se comienza con una breve caracterización, tendente a mostrar tres presupuestos muy generales, cuales son el realismo y orientación pragmática de la teoría de Esser, su visión esencialmente dinámica del Derecho y su constante preocupación por la racionalidad al operar con el mismo. Seguidamente, se pasa revista a aspectos concretos de la obra de Esser, referentes a cuestiones como las siguientes: idea general del Derecho, fuentes del Derecho, teoría de las normas jurídicas, Derecho judicial, principios generales, dogmática jurídica, conceptos jurídicos, instituciones, metodología jurídica y sus principales tendencias, y problemas de la racionalidad de la decisión jurídica. 
GARCÍA AMADO, Juan Antonio.

Problemas metodológicos del principio constitucional de igualdad.

Anuario de Filosofía del Derecho, Madrid, núm. 4 (Nueva Época), 1987, págs. 111-131.

El principio de igualdad ante la ley ejemplifica prototípicamente los problemas que se plantean a la metodología jurídica, en particular el de la racionalidad de la decisión jurídica. Las jurisprudencias constitucionales vienen diciendo que la desigualdad de trato legal sólo es admisible cuando no es arbitraria, cuando está avalada por razones atendibles y es razonable. ¿Pero tal juicio de razonabilidad de la desigualdad es mera expresión de preferencias subjetivas del emisor, o tiene lugar en el marco de unos márgenes que lo limitan? Esta última es la tesis que se defiende. Existen límites derivados de la función del principio de igualdad en el Derecho, de la estructura del ordenamiento, del contexto legal en que se formule el principio, de los argumentos justificatorios de la igualdad, de la estructura del proceso argumentativo, y de la racionalidad de las valoraciones de fondo. Con todo ello no se desconoce que queda un margen de libre apreciación de la justificación de la desigualdad, pero ya no es un margen total y absoluto, sino limitado.

GARCÍA AMADO, Juan Antonio.

Tópica, Derecho y método jurídico.

Doxa, Alicante, 1987, págs. 161-188.

Se examinan algunos rasgos fundamentales de la obra de Viehweg sobre la tópica jurídica y se pone ésta en relación con la problemática más actual y las principales direcciones contemporáneas de la metodología jurídica. También se hace mención de algunas de las críticas relevantes que la doctrina mencionada ha recibido. Se termina examinando si la tópica jurídica es realmente una doctrina del método jurídico y si sostiene una teoría consensual de la racionalidad jurídica. La tesis que al respecto se mantiene en el trabajo es que la tópica presupone un consenso respecto a los argumentos susceptibles de utilización como justificación de la decisión jurídica, pero no implica la idea de que sea posible justificar la opción por uno de ellos, y por la consiguiente decisión, como racional sobre la base de que sea alcanzable un consenso para tal elección.

GARCÍA SAN MIGUEL, Luis.

El pensamiento de Leopoldo Alas «Clarín».

Ed. Centro de Estudios Constitucionales, Madrid, 1987, 340 págs. 
En el presente volumen, que arranca con una breve biografía de Leopoldo Alas «Clarín», el autor se detiene a estudiar el pensamiento de éste, ocupándose particularmente de sus ideas filosóficas (gnoseología y metafísica, filosofía jurídica y moral y filosofía de la educación), religiosas, políticas y sociales. En el epílogo (del radicalismo a la moderación) el autor escribe: «En lo que hemos llamado período católico-juvenil, hemos visto un Alas católico y, al mismo tiempo, liberal y republicano en política. Un Alas, por tanto, contradictorio que, de mala manera, trataba de armonizar artificialmente dos posturas incompatibles. Vimos luego cómo esta armonía se rompe durante el período madrileño, hacia 1872, momento en el que se hace krausista y adopta, por tanto, una filosofía y religiosidad «heterodoxa», al tiempo que toma contacto con grupos republicanos y se hace simpatizante del «piymargalismo». Esto mismo puede expresarse negativamente diciendo que es militante anticatólico y antimonárquico.

[...] En el orden político, Alas cuestiona la monarquía como forma de Estado, pero no, al menos no radicalmente, el orden social establecido. No es un revolucionario, aunque en algunos aspectos se aproxima a los que lo son.

Un nuevo cambio va a producirse hacia 1880 [...] abandona el radicalismo y experimenta un cambio en su manera de pensar y de sentir [...] Comienza entonces lo que pudiéramos llamar su época reformista [...] durante los aproximadamente diez años que median entre 1880 y 1889, Clarín, sin perder sus primeros ideales, va haciéndose más contemporizador con lo existente, sin duda porque toma conciencia de la solidez que tiene y porque piensa, en consecuencia, que el cambio sólo podrá llegar a través de una lenta evolución.

[...] Hacia 1892, o quizás algo antes, comienza el que hemos llamado período místico [...] Alas es ahora, sobre todas las cosas, un hombre religioso, que quizás piense en volver al seno de la Iglesia católica a poco que ésta abandone su rígido dogmatismo. Tenía, en cierto modo, un problema parecido al de Giner: éste, años atrás, dudó mucho antes de decidirse a abandonar la Iglesia. Alas dudaba ahora antes de decidirse a entrar.»

Regla)

(Josep Aguiló 
GARZÓN VALDÉS, Ernesto.

Acerca de la tesis de la separación entre ética y política.

Sistema, Madrid, núm. 76, 1987, págs. 111-119.

«Hartmut Kliemt -escribe Ernesto Garzón-, en un sugestivo trabajo (1986), ha propuesto analizar la "tesis de la separación" entre moral y política en dos niveles: el descriptivo y el prescriptivo, estableciendo a la vez una distinción entre moral esclarecida o ética y moral positiva o mores. Me propongo analizar aquí más de cerca la "tesis de la separación", en cada una de las cuatro posibilidades de combinación presentadas por Kliemt, con el objeto de dilucidar si ella es verdadera o falsa, correcta o incorrecta.» Las cuatro alternativas son las siguientes: en el nivel descriptivo la «tesis de la separación» puede querer decir: 1) la ética no juega ningún papel en la política; o 2) la moral positiva no juega ningún papel en la política. Y a nivel prescriptivo: 3) la ética no debe jugar ningún papel en la política; o 4) la moral positiva no debe jugar ningún papel en la política.

Finalmente, tras el referido análisis, Ernesto Garzón concluye: «Es probable que, no obstante, los argumentos aquí expuestos, la "tesis de la separación" sigua teniendo un respetable número de adeptos. La razón de ello se debe no sólo a la confusión de las diversas versiones aquí presentadas y a su evaluación indiscriminada, sino también al hecho de que los políticos suelen aducir que toda decisión política importante implica fatalmente el sacrificio de algún bien vital en aras de otro. Es decir, las decisiones políticas serían "elecciones trágicas" que impiden la aplicación de criterios éticos. Este tratamiento de las "elecciones trágicas" conduce sorprendentemente a la conclusión de que una ética normativa no puede solucionar los casos de conflictos de intereses y vuelve a cometer el error de atribuir a las normas éticas carácter incondicionado.

Y, finalmente -continúa Ernesto Garzón-, hay otra razón adicional que estimula la aceptación de la "tesis de la separación": la actitud pesimista provocada por los fracasos innegables de las normas éticas en el campo de la política. De aquí suele inferirse que ellas no juegan ningún papel en la vida política. Pero esto es tan correcto como inferir de las violaciones cotidianas de la ética en la vida privada de los hombres que ella no juega o no debe jugar ningún papel en este campo.»

(Josep Aguiló Regla)

GARZÓN VALDÉS, Ernesto.

El concepto de estabilidad de los sistemas políticos.

Ed. Centro de Estudios Constitucionales (Cuadernos y debates núm. 1), Madrid, 1987, 111 págs.

Este texto se divide en dos partes; en la primera se propone una definición del concepto de estabilidad de los sistemas políticos y en la segunda se procura demostrar su plausibilidad aplicándola a casos de la historia de América Latina.

Se parte de la distinción -a veces descuidada- entre estabilidad, legitimidad y legitimación (referida 
esta última en este trabajo a «aceptación»). El primer paso para la definición de estabilidad es su calificación como «propiedad disposicional», es decir, como propiedad cuya verdad o falsedad depende de la existencia o no de cierta tendencia o propensión. Así, en un primer momento puede darse la siguiente definición (a lo largo del texto estas definiciones se van concretando): «Un determinado sistema político $\left(\mathrm{S}^{*}\right)$ es estable si y sólo si en determinadas circunstancias $(\mathrm{C})$ tiene la tendencia (disposición) a reaccionar en forma tal que logra mantener su identidad (Ri).» Para concretar el concepto de «identidad» el autor lo identifica con la regla de reconocimiento, tal como la entiende Hart. De esta forma puede decirse que «un determinado sistema político $\left(\mathrm{S}^{*}\right)$ es estable si y sólo si en determinadas circunstancias (C) tiene la tendencia (disposición) a reaccionar de forma tal que logra mantener su regla de reconocimiento $(\mathrm{Rr})$ ».

Ahora bien, no todo cambio en el sistema es contrario a su estabilidad. Aquí hay que distinguir entre explicación (aquellos cambios que desarrollan el sistema sin modificar sus fundamentos) y mutación (cuando sí se ven alterados los fundamentos mismos del sistema). Por tanto, «un determinado sistema político $\left(\mathrm{S}^{*}\right)$ es estable si y sólo si en determinadas circunstancias $(\mathrm{C})$ tiene la tendencia (disposición) a reaccionar de forma tal que sus cambios sean una explicación de su regla de reconocimiento $(\mathrm{Rr}) »$. Las circunstancias en las que el sistema tiende a reaccionar conforme a su regla de reconocimiento son aquellas vinculadas con el ejercicio institucionalizado del poder. Hay «casos límite» entre la explicación y la mutación originados desde el punto de vista interno del sistema (los que resultan de contradicciones internas de la regla de reconocimiento, los que derivan de su incapacidad para dar solución a problemas que surgen dentro del ámbito de su vigencia y aquellos que son solucionables a través de una explicación de la regla de reconocimiento) y «casos limite» originados desde el exterior; todos ellos son tratados con ejemplos por el autor.

El último problema en relación con la definición de estabilidad que aborda el autor es el del tiempo que hay que tomar en cuenta para afirmar la estabilidad de un sistema: ante la imposibilidad de señalar períodos concretos hay que referirse a factores contextuales. En definitiva, «un determinado sistema político es estable si y sólo si en los casos vinculados con el ejercicio institucionalizado del poder, sean éstos «normales» o «límites», tiene la tendencia a reaccionar de forma tal que sus cambios son una explicación eficaz de su «regla de reconocimiento» y esta tendencia se mantiene durante un lapso significativo desde el punto de vista de su contexto histórico y regional».

En el segundo apartado el autor clasifica los ejemplos analizados en sistemas 111, 110, 101 y 100 según reúnan (1) o no (0) las características de existencia, legitimidad y estabilidad, respectivamente. Se trata de ejemplos tomados del pasado y del presente de América Latina con los que fundamenta la definición propuesta e ilustra la defendida distinción entre tales tres características.

(Daniel González Lagier)

GARZÓN VALDÉS, Ernesto.

Entrevista con Ernesto Garzón Valdés (realizada por Manuel Atienza y Juan Ruiz Manero).

Doxa, Alicante, núm. 4, 1987, págs. 413-426.

En esta entrevista, realizada por Manuel Atienza y Juan Ruiz Manero, Garzón Valdés responde a ocho 
preguntas que le permiten referirse a un conjunto de cuestiones diversas que abarcan temas como las claves del importante desarrollo de la filosofía del Derecho en Argentina; temas relacionados con su biografía académica; cuestiones suscitadas por algunos de sus trabajos; su actitud, en cuanto ciudadano, respecto a los problemas políticos básicos; su valoración y comparación de la filosofía jurídica y social y de las instituciones universitarias en Alemania, España y Argentina; su opinión acerca de la situación actual de la filosofia moral y sus proyectos en el campo de la teoría ética.

(Daniel González Lagier) 


\section{GIANFORMAGGIO, Letizia.}

Lógica y argumentación en la interpretación jurídica o tomar a los juristas intérpretes en serio (trad. de Juan A. Pérez Lledó).

Doxa, Alicante, núm. 4, 1987, págs. 87-108.

La autora delimita su análisis de la interpretación jurídica en tres fases:

1. Se ocupará de la interpretación referida al significado del Derecho (de un particular segmento del Derecho, como respuesta a la pregunta «¿qué dice, o prescribe, el Derecho?», lo cual significa dar contenidos a la forma de la juridicidad), y no al significado de Derecho (como respuesta a la pregunta «¿qué es el Derecho?», que significa plantearse el problema de la juridicidad, del concepto de Derecho).

2. Se referirá a la interpretación de la ley, entendida como una de las fuentes del Derecho, como norma general escrita.

3. Se centrará en la interpretación como actividad dianoética. Junto a la habitual distinción entre «interpretación-actividad»e «interpretación-producto», la autora parte aquí de la distinción entre: a) actividad noética: una comprensión, un entender, el fenómeno mental de la atribución de un significado a un texto, cuyo resultado es un significado, lo que se ha entendido; b) acto lingüístico: una adscripción de significado; y c) actividad dianoética; un razonamiento, una justificación, cuyo resultado es una proposición del tipo «el signo $S$ ha de entenderse como $S$ '», y es la conclusión de un argumento. Según la autora, la distinción entre «contexto de descubrimiento»y «contexto de justificación» sigue siendo importante, y el examen del método o camino que siguen los juristas intérpretes (produciendo y estructurando argumentos justificativos de sus interpretaciones) ha de tomarse en serio.

Acotado así su estudio, la autora formula dos tesis:

1. De la especificación de los caracteres de la interpretación-actividad noética o de la interpretación-acto lingüístico no se puede inferir la presencia o la ausencia de esos mismos caracteres en la interpretación-actividad dianoética: así, ni de la obviedad de que la interpretación como actividad noética no es una actividad lógica, ni de la obviedad de que, al no existir significados genuinos de los signos, no existen interpretaciones como producto del acto lingüístico que sean «verdaderas», se puede inferir que la justificación interpretativa (actividad dianoética) no es lógica, sino simplemente retórica.

2. Nada se puede inferir, en cuanto a los caracteres propios de una argumentación interpretativa, de los caracteres propios de la relación signo/significado. Y ello porque las argumentaciones interpretativas no pueden tener signos como premisas y significados como conclusiones. Tanto el punto de partida como el de llegada de un trayecto argumentativo son «enunciados interpretados», signos significantes. La conclusión de un argumento interpretativo no es el significado del signo que se quiere interpretar, sino una tesis interpretativa, según la cual un signo (texto) se puede sustituir por otro, porque ambos tienen el mismo significado. De lo anterior se sigue que el hecho de que una relación signo/significado no tenga carácter lógico nada dice acerca del carácter lógico o no de una argumentación interpretativa.

Las dos tesis «negativas» anteriores dejan todavía intacta la plausibilidad de la extendida tesis de que los argumentos interpretativos no son lógicos sino retóricos. Y aquí la autora sólo pretende deshacer 
algunos equívocos derivados de la ambigüedad del término «argumento» en estos contextos: como cadena completa de argumentación (logos) o sólo como premisa del razonamiento (topos). Del argumento como topos sólo es predicable su bondad o fuerza retórica, no su validez, lógica. Del argumento como logos es predicable su validez lógica, y también su fuerza, pero esto último sólo en sentido figurado, por sinécdoque: porque su argumento-premisa es retóricamente persuasivo. Lo que carece de sentido, es decir, de los argumentos en general que no son válidos sino fuertes, mientras no explicitemos el sentido en que estamos utilizando el término «argumento».

Por último, la autora pone a prueba sus anteriores consideraciones analizando un caso práctico de argumentación interpretativa.

(Juan Antonio Pérez Lledó)

GIL CREMADES, Juan José.

Filosofía del Derecho y compromiso político: Alfredo Mendizábal (1897-1981).

Anuario de Filosofía del Derecho, Madrid, núm. 4 (Nueva Época), 1987, págs. 563-587.

Este artículo tiene el propósito de aportar algunos datos relativos a la historia de la Filosofía del Derecho española durante el siglo XX, en concreto datos referentes a la vida y la obra de Alfredo Mendizábal.

Para ello, en un primer apartado ( EEdad de plata» de la ciencia jurídica en España) se describe el panorama que presentan las ciencias jurídicas en los años veinte y treinta de este siglo, señalando las instituciones, las publicaciones, las corrientes intelectuales y las figuras más sobresalientes de la época. En los siguientes apartados (Formación paterna: el Derecho natural católico, El compromiso político: la II República y La guerra, en el exilio, el olvido) el autor se centra en la figura de Alfredo Mendizábal, señalando los momentos más relevantes de su formación y de su carrera universitaria, las influencias recibidas, sus obras, su compromiso político con la II República y su exilio durante la dictadura de Franco.

(Daniel González Lagier)

\section{GONZÁLEZ VICÉN, Felipe.}

Ludwig Feuerbach y los orígenes filosóficos del marxismo.

Sistema, Madrid, núm. 76, 1987, págs. 33-47.

«La conciencia revolucionaria -escribe Don Felipe- va a ser lo que, en último término separa a Marx de Feuerbach. De principios sustancialmente iguales se van a extraer consecuencias contrapuestas. Ya Marx había escrito una vez: "Los aforismos de Feuerbach no acaban de satisfacerme, porque se refiere demasiado a la naturaleza y muy poco a la política. Y, sin embargo, esta última alianza es la única por 
virtud de la cual la filosofia actual puede hacerse verdad." Esta admonición a Feuerbach, esta alusión a la práctica, va a ser el motivo determinante en las relaciones entre Marx y Feuerbach...» (pág. 42). «Lo que Marx nos ofrece en contradicción con Feuerbach es un universo de objetos y relaciones, y en el centro de este universo, el hombre como demiurgo, como praxis y acción creadora. No hay un objeto ni una relación humana que no tenga como origen la praxis, la actividad del hombre [...] La actividad humana, y no sólo la intelectual y abstracta propia del racionalismo moderno, sino como praxis y trabajo en su sentido más inmediato, es lo que hace al hombre el creador de su mundo de objetos. El no haberlo entendido así es el gran reproche que Marx hace a Feuerbach...» (págs. 46 y 47).

«Pero el hecho de que el hombre intervenga constantemente en la creación y articulación de la realidad le abre el camino también para la rectificación o destrucción de esta realidad. $\mathrm{O}$, en otras palabras, hace al hombre sujeto no sólo de una praxis constructiva sino también de una praxis revolucionaria [...] El hombre, empero, actor y sujeto de la historia, puede descubrir y descubre en ocasiones la incongruencia de la idea, porque la realidad no es realidad verdadera, "tal y como debe ser". Es entonces cuando la praxis se hace revolucionaria, y si no reconoce como realidad lo que se da fácticamente en la historia, la cambia y la sustituye por otra, ésta, sí, verdadera.

Y así la contraposición entre Feuerbach y Marx puede expresarse con las palabras de la última Tesis de Marx: "Los filósofos sólo han interpretado el mundo de distinta manera; de lo que se trata es de cambiarlo.”» (Pág. 47.)

(Josep Aguiló Regla) 
GONZÁLEZ VICÉN, Felipe.

Rudolf von Jhering y el problema del método jurídico.

Anuario de Filosofía del Derecho, Madrid, núm. 4 (Nueva Época), 1987, págs. 223-248.

«Ninguna obra refleja más exactamente la gran controversia metodológica del último siglo dentro de la ciencia del Derecho que la obra de Rudolf von Jhering. Ni en ninguna otra puede seguirse como en ella paso a paso el proceso que lleva al resultado último de esta controversia, es decir, al tránsito de un concepto formal a un concepto social y sustantivo del derecho.

Con su radicalismo congénito, Jhering va a constituir, en la primera fase de su obra, la versión más extrema del formalismo jurídico. La "jurisprudencia conceptual”, como él mismo iba a bautizar a la dirección, la reducción a conceptos de las proposiciones y relaciones jurídicas, su enlazamiento formal y su constitución en sistema, va a encontrar en Jhering el valedor más tenaz y decidido durante un cuarto de siglo. Tan tenaz y decidida como va a ser su crítica aniquiladora de este mismo conceptualismo en la segunda mitad de su vida. Todos los motivos que animan la crítica al formalismo jurídico hacia mediados del siglo parecen darse cita en su obra, del mismo modo que ella señala también la dirección general que va a seguir, después de él, el pensamiento jurídico. En este sentido, la obra de Jhering tiene, puede decirse un valor paradigmático. Otros juristas calaron más hondo en la crítica del conceptualismo jurídico, y no hay duda de que en Jhering la mordacidad cáustica apenas si oculta en ocasiones la inconsistencia de sus argumentos. No obstante lo cual, en vano se buscaría una obra que, en un conjunto, mejor nos muestre la transformación experimentada por la ciencia jurídica europea desde que se apagan los ecos de la Escuela histórica y pasan al olvido las últimas grandes construcciones jusnaturalistas.»

(Josep Aguiló Regla)

GUIBOURG, Ricardo A.

El fenómeno normativo.

Ed. Astrea, Buenos Aires, 1987, 202 págs.

Se trata de un libro en el que se recoge un material «escrito en diversas épocas y en su mayoría publicado bajo forma de artículos o ponencias» que tiene como denominador común el tratarse de un acercamiento al fenómeno normativo a la luz de nuevas líneas metodológicas «y de cara a la conciencia del tiempo actual».

El punto de partida (capítulo I) es el concepto de acción humana, que puede considerarse como el objeto del fenómeno normativo. Esta se define como un conjunto de dos acontecimientos tales que el primero es un cambio físico o mental o un conjunto de cambios físicos o mentales de un ser humano o de un grupo de seres humanos, y el segundo un acontecimiento o situación que es idéntico al primero o integra una cadena causal a partir de éste; la relación entre ambos acontecimientos se representa 
lingüísticamente con la atribución del segundo acontecimiento al sujeto del primero. Se ocupa también el autor en este capítulo de la descripción de acciones y del tratamiento de la omisión. Otro enfoque (capítulo II) es el realizado desde una teoría de las normas y una lógica normativa (que incluya una lógica de la acción). En este punto el autor se centra en la obra de Von Wright, tratando del concepto de norma, las lógicas del cambio, de la acción y deóntica, del análisis y clasificación de las normas, de las normas de orden superior (aquellas cuyo contenido es otra prescripción) y concluyendo el capítulo con una referencia a las condiciones extrasistemáticas de la lógica deóntica. Pero la lógica deóntica requiere para su utilidad una relación de isomorfismo con el sector de la realidad que pretende analizar. Para ello el autor propone (en el capítulo III) una formalización de los conceptos jurídicos redefiniendo las palabras del lenguaje del jurista «con un toque de observación empírica, dependiente de la aplicación de sanciones o del resultado de los procesos».

A continuación (capítulo IV) se examinan los distintos fenómenos que son objeto del interés de los juristas, para diferenciarlos y asignar a uno de ellos el título de «fenómeno jurídico»; se estudia la «técnica de poder» de las lagunas, así como otros criterios de decisión, explícitos, como los contenidos en las normas positivas o los principios generales, o implícitos, como la equidad (capítulo V); y se dedica un apartado a la «revolución informático-jurídica» (capítulo VI) y a una reflexión acerca de la estructura del sistema normativo de cara a la construcción de sistemas expertos (capítulo VII). En esta reflexión se propone sustituir el "antiguo concepto de norma», por «un modelo de secuencia condicional integrada en un sistema más amplio y dependiente de éste»; en definitiva, «el modelo a proponer (...) ordenará las secuencias que componen un sistema en distintos niveles indicativos de la función que aquéllas cumplan en el razonamiento decisorio; pero, aparte de estos niveles intersecuenciales (o clasificatorios de consecuencias), distinguiremos otros niveles (los intrasecuenciales) que corresponden a otra dimensión normativa. Aquella en la que se mide la profundidad del análisis de cada secuencia»; estas distinciones permiten, según el autor, «apreciar y ordenar funciones que en el esquema tradicional son casi inasibles, dar un lugar en el sistema normativo a las definiciones y a los criterios sobre apreciación de pruebas tanto como a las disposiciones sobre competencia o reenvío (...)».

El libro concluye con algunas consideraciones acerca de la Ciencia Jurídica (capítulo VIII), su situación actual y su futuro.

(Daniel González Lagier)

GUIBOURG. Ricardo A.

El papel de la norma en la despersonalización del poder.

Doxa, Alicante, núm. 4, 1987, págs. 119-129.

Este artículo trata de poner de manifiesto cómo los gobiernos de facto se apresuran a dotarse de instrumentos normativos que les permitan presentarse a sí mismos como gobiernos regulares y a sus actos como ejercicio no de un poder desnudo sino de facultades normativamente conferidas. En este sentido, el autor estudia el modo de proceder de diferentes gobiernos resultantes de un golpe de Estado en la reciente historia argentina (a los que denomina «modelo 1955», «modelo 1962», «modelo 1966» 
y «modelo 1976»), concluyendo que, «aun por encima de las diferencias o semejanzas que puedan observarse de un modelo a otro, se advierte una constante en la relación entre poder y norma. En efecto, quien ejerce el poder se siente desnudo frente a sus súbditos si no tienen alguna norma que ampare sus acciones. Por tanto, o bien invoca normas anteriores, acaso con cierto auxilio religioso (modelo 1955), o finge que su poder es el mismo que ejercían sus predecesores (modelo 1962), o da rápida expresión normativa a su poder y se apoya luego en esas normas, como si quisiera olvidar que fue él mismo quien las dictó (modelos 1966 y 1976)».

En definitiva, la norma proporciona la coartada justificativa de las acciones y conductas que el gobernante impone a sus súbditos (aludiendo a aquélla). No obstante, «la necesidad de justificación y, en especial, la búsqueda de esta justificación en la invocación de normas generales es precisamente el flanco débil del despotismo», pues el ordenamiento jurídico se convierte, en manos del gobernado, en un medio de control, limitación y moderación de la arbitrariedad de unos gobernantes «que no se sienten a gusto cuando se les sorprende incursos en acciones opuestas a las normas y a los valores en los que intentan justificar su poder». Además, «en nuestros tiempos es posible incluso prever una evolución favorable a partir del actual disimulo, ya que la arbitrariedad tiende a hacerse técnicamente insostenible».

(Angélica Such) 
GUISAN, Esperanza.

Igualdad, imparcialidad y bienestar en la ética contemporánea.

Anuario de Filosofia del Derecho, núm. 4, 1987, págs 9-29.

El presente artículo trata de demostrar con relación al principio de igualdad «los dos puntos siguientes a) las éticas teleológicas en su variedad de éticas del bienestar, contienen principios relativos a la igualdad o imparcialidad; b) el principio del bienestar es el punto de referencia que da sentido y contenido a cualquier teoría de la justicia que pretenda defender la igualdad de trato».

En primer lugar, la autora revisa la idea de imparcialidad en la metaética contemporánea analizando las posturas de Albert, Baier, Toulmin, Brand y Hare, para pasar a continuación a revisar las ideas de imparcialidad y bienestar en la ética normativa contemporánea. Aquí la autora explica cómo las éticas de la «felicidad no sólo no rechazan sino que destacan los principios de igualdad de trato entre las personas, o imparcialidad en la consideración de todo el mundo por igual, y que presentan además un elemento de interés adicional respecto a las éticas de principios, a saber: una definición sustantiva de la justicia, un punto de contraste y referencia que da sentido a los principios de igualdad, equidad e imparcialidad, o como quiera que deseemos denominarlos». Puede resultar cierto como señala la autora, que la expresión «bienestar» sin mayores especificaciones o cualificaciones, pudiera dar lugar a conservadurismos, por cuanto las preferencias de los hombres son fruto de la socialización a que han sido sometidos. Sin embargo, «cuando se cualifica el bienestar, las preferencias y los intereses, conforme a los requisitos de ilustración, imparcialidad, libertad y coherencia con los principios adoptados, se percibe inmediatamente que una teoría que pretenda defender adecuadamente el derecho al trato igual si no quiere convertirse en puro misticismo, verborrea demagógica o panfleto, ha de buscar sus raíces en una ética normativa y una metaética que engloben por igual los tres vértices del triángulo ético: racionalidad práctica, imparcialidad y bienestar».

López Ruiz)

(Francisco

\section{GUISAN, Esperanza.}

Las repercusiones prácticas de la metaética o la relevancia ética de la metaética.

Sistema, Madrid, núm. 78, 1987.

Este trabajo «pretende ser una breve declaración de principios a favor de la necesidad de dedicar tiempo y espacio a la metaética» en cuanto que ésta es «la fuente de legitimación de la praxis cotidiana».

El artículo se divide en dos partes. En la primera se tratan las diversas ramas de la Teoría Ética, distinguiendo entre ética descriptiva, ética normativa o prescriptiva, metaética o ética crítica y ética 
práctica o aplicada. En concreto la autora entiende que «la ética crítica o metaética no se reduce (...) a "analizar" los términos éticos. Sus metas, resulta evidente, no son en ningún caso lingüísticas, sino epistemológicas, fundamentalmente. Se trata de una teoría del conocimiento moral, cuya pretensión es, ni más ni menos, que la de indagar acerca de la posibilidad y forma de la justificación de los enunciados de la ética prescriptiva o normativa». En este apartado se ocupa también de las relaciones entre estas cuatro fases: «La ética normativa reflexiona sobre la descriptiva. La ética crítica o metaética se ocupa de la ética descriptiva fundamentándola, validándola y/o invalidándola. $\mathrm{O}$, lo que es igual, el punto de partida son los hechos brutos de la moralidad (ED) sobre los cuales delibera y arbitra normas y principios pertinentes la ética normativa (EN), la cual, a su vez, precisa ser sancionada, para justificar el acierto o desacierto de sus decisiones, por una ética crítica (EC) o metaética (ME) adecuada. Cuando los principios de la EN reciben el respaldo de la EC, la teoría filosófica vuelve a engarzarse con el mundo de experiencia cotidiana para dictaminar acerca de la corrección o incorrección de las opciones políticas, sociales, etcétera, diversas (EP).»

La segunda parte del artículo se centra en las relaciones entre la metaética y la praxis. Para la autora la metaética tiene la función de introducir en la práctica mayor racionalidad e indica que «podría decirse que se requieren dos tipos de esclarecimientos previos a fin de que la discusión sobre los temas de la ética aplicada resulte racionalmente provechosa: a) La explicitación de los privilegios o valores a tenor de los cuales se aprueba una práctica social $(. .$.$) ; b) La explicitación de los principios$ en virtud de los cuales uno ha asumido los principios regulativos o valores primeros de su ética normativa». Continúa este apartado con un breve comentario de las diversas concepciones metaéticas que más impacto han causado en la filosofía contemporánea, destacando que «de una actitud claramente no racionalista, cuando no rayando en el irracionalismo, se han ido quemando sucesivamente etapas en una línea tendente a la afirmación de la posibilidad de legitimar determinados principios en base a argumentos racionales», lo que incide en gran medida en la ética práctica.

(Daniel González Lagier)

HERNÁNDEZ GIL, Antonio.

Bobbio y el positivismo lógico.

Revista de Ciencias Sociales, Valparaíso, núm. 30, 1987, págs. 135-145.

Este artículo se estructura en cuatro apartados. En el primero de ellos («La tesis de Bobbio. Alcance de su adscripción al positivismo lógico») el autor sostiene que la atención prestada por Bobbio al positivismo lógico «no permite considerarle integrado en su seno de manera completa ni siquiera esencialmente significativa. Ello es así, de un lado, en cuanto dota a la ciencia -señaladamente a la jurídica- de cometidos que exceden ampliamente de tal doctrina».

De otro lado, por lo que sostiene respecto a la lógica: «Bobbio, con un pluralismo tan marcado como él insinúa, propende a una lógica material. No parece que tal pluralismo quede exclusivamente referido a las posibilidades de una lógica no circunscrita a los criterios de verdad y falsedad, como acontece en la lógica deóntica y en la modal.» Si el pluralismo de la lógica radica, en cambio, en el carácter convencional de las proposiciones primitivas, hay que decir que la convención, de suyo, no es lógica, 
ni todas las proposiciones «primitivas» han de considerarse exclusivamente convencionales. El positivismo lógico, en cuanto positivismo, descansa en una base empírica.

En el segundo apartado («Rigor discursivo y lenguaje. Apreciaciones críticas») se sostiene una más clara situación de Bobbio en el ámbito de ciertos aspectos del positivismo lógico cuando encarece el entendimiento de la verdad como rigor propiciando más una uniformidad de las investigaciones lógicas que un pluralismo. Bobbio identifica discurso riguroso y lenguaje riguroso, que se manifiesta en la formación de las proposiciones y en la transformación. Para Bobbio la investigación del jurista tiene como principal objeto el lenguaje del legislador a fin de construir un lenguaje jurídico como lenguaje riguroso, si bien, al explicar la obtención de este lenguaje riguroso «nos parece que no discrimina suficientemente las operaciones y los criterios utilizados por la ciencia jurídica tradicional de signo racionalista... de los propios y específicos del moderno análisis del lenguaje». El mérito de Bobbio descansa en haberse percatado del valor del positivismo lógico y el análisis del lenguaje para la investigación jurídica más que en la realización de ciencia jurídica (lógica o filosofía del lenguaje) bajo el signo de estas corrientes.

A continuación («Conceptualismo y positivismo lógico en Bobbio») se nos plantea hasta qué punto lo que Bobbio concibe como lenguaje riguroso en el tratamiento del Derecho es proyección del positivismo lógico o simple perfeccionamiento del método tradicional conceptual. En el primer caso la palabra es definida mediante su uso, en el segundo es medio de expresión y de definición; no obstante, cabe plantearse si en el conceptualismo se contienen algunas anticipaciones de lo que puede ser el positivismo lógico.

Por último («Particular significado del lenguaje en el Derecho y en la ciencia jurídica»), el autor hace constar que en el planteamiento hecho por Bobbio del tema del lenguaje se echa de menos el particular significado que ofrece en la ciencia jurídica la consideración del lenguaje. La ciencia jurídica recae sobre algo que precientíficamente es ya lenguaje; ello se traduce en limitaciones para el propio lenguaje científico, siendo sólo en cierto modo un metalenguaje normativo, ya que el logro de un lenguaje riguroso se centra no tanto en el lenguaje cuanto en el metalenguaje. «Si el positivismo lógico admite que los sistemas semánticos corrigen la convención, esto acontece con toda claridad en lo jurídico.»

(Ángeles Ródenas Calatayud) 
HERNÁNDEZ MARÍN, Rafael.

La obligatoriedad del Derecho.

Anuario de Filosofía del Derecho, Madrid, núm. 4 (Nueva Época), 1987, págs. 619-623.

El texto analiza los diversos significados del enunciado «la disposición jurídica d es obligatoria». Se estudian las dos siguientes acepciones: (1) «La disposición jurídica d tiene fuerza obligatoria» (entendiendo a [1] como una aserción); (2) «Es obligatorio obedecer la disposición jurídica d».

Respecto a (1) el autor llega a la conclusión de que es falsa, suscribiendo la posición de Olivecrona de que «la fuerza obligatoria» del Derecho sólo es en realidad una idea de la mente humana.

Respecto a (2) distingue aún tres sentidos: (2. 1) «Obligatorio obedecer la disposición jurídica (prescriptiva) d»; (2. 2) «Existe un precepto, jurídico o moral no positivo (no establecido por el hombre), según el cual es obligatorio obedecer la disposición jurídica (positiva) d»; (2.3) «Existe un precepto ético positivo (establecido por el hombre), según el cual es obligatorio obedecer la disposición jurídica (positiva) d».

El autor considera que (2.1) es una prescripción -y, por tanto, carece de valor de verdad o falsedady es, además, repetitiva, pues no dice nada que no diga ya la propia disposición jurídica d. A la aserción (2. 2) la considera una aserción falsa, ya que el autor rechaza la existencia de preceptos no positivos (en el sentido de no establecidos por el hombre). Por el contrario, (2. 3) es una aserción verdadera.

El autor concluye este breve artículo reflexionando acerca de la polémica entre F. González Vicén y E. Díaz sobre la obediencia al Derecho. En este sentido opina que «el desacuerdo entre González Vicén y E. Díaz se debe, más que al hecho de que ambos hablan de conciencias individuales distintas, al hecho de que han elegido distintos conjuntos de preceptos éticos como patrón de las disposiciones jurídicas positivas o a que sustentan concepciones distintas acerca de las disposiciones jurídicas.

(Juan Sala Puche)

HERRERA FLORES, Joaquín.

Cuestiones básicas para la fundamentación de los valores jurídicos.

Anuario de Filosofía del Derecho, Madrid, núm. 4 (Nueva Época), 1987, págs. 403-431.

Ante la existencia de, por un lado, investigaciones dirigidas a concretar el fundamento o fundamentos posibles «de nuestra tabla de valores jurídicos y, en un sentido más general, del conjunto de derechos humanos», y, por otro, «de opiniones y trabajos que parten de la base de que dichos esfuerzos fundamentadores no conducen a nada positivo, o bien confunden más que aclaran el objeto de su estudio», el autor cree necesario afrontar una serie de cuestiones previas acerca del concepto de fundamentación y «de la estructura formal que dicha fundamentación debe tomar como base procedimental de su desarrollo material». 
Tras un apartado de introducción, el autor contrapone en el segundo apartado (Fundamentalismo versus fundamentación) los conceptos de fundamentación y fundamentalismo, agrupando bajo esta última denominación todas las perspectivas absolutistas en la tarea de justificación de valores. Afirma que «intentar fundamentar la moral en principios generales es aceptar que sólo hay una moral que los posea -con lo que se incurriría en fundamentalismo-; hacer referencia al conjunto de necesidades y valores que se encuentran en la base de la fundamentación, conlleva el reconocimiento de la pluralidad y diversidad de los mismos en función de los diferentes contextos en que aparecen y en los que encuentran su posibilidad de satisfacción».

En el apartado III (Radicalidad y suficiencia de la fundamentación de los valores) el autor opina que ha de optarse no por una fundamentación absoluta y necesaria, sino por «una fundamentación suficiente que, por un lado, parta de la evidencia material de la relación entre la experiencia y los valores jurídicos o tendentes al reconocimiento constitucional, en función de las exigencias expresadas a través del conjunto de necesidades humanas con relevancia moral; y, por otro, de una propuesta teórica y metodológica que reivindique la racionalidad crítica e intersubjetiva y la posibilidad de aplicar esa racionalidad discursiva y práctica al estudio de los valores básicos». Tal fundamentación, afirma el autor, no se limitaría al mero plano del discurso racional, porque la racionalidad vendría concretada por la conexión entre hechos y valores y por la contextualización de estas objetivizaciones en la «historia conceptual» (es decir, en la historia como «proceso de constante discusión, crítica y revisión fáctica de los significados de los términos y de las producciones culturales»).

Tras hacer en el apartado IV (Delimitación y clarificaciones de la estructura formal de la fundamentación) una síntesis crítica del ensayo de Norberto Bobbio L'illusion du fondament absolu, el autor plantea en el último apartado del artículo (Conclusiones) una estructura formal de fundamentación que reúna los caracteres de racionalidad, teleología e intersubjetividad. La racionalidad vendría dada, por un lado, a través del consenso social acerca de las instituciones normativas existentes y, por otro, por la constatación de la pluralidad de órdenes normativos que postulan metas alternativas al estado de cosas dominante. Su carácter teleológico derivaría de la necesidad de «postular como fines y objetivos los valores que conforman el inacabado proyecto ilustrado de modernidad». Por último, la intersubjetividad vendría dada por el reconocimiento formal de las necesidades y expectativas individuales o grupales a través del «consenso» o «diálogo racional».

(Daniel González Lagier)

HERRERA FLORES, Joaquín.

Reflexiones teóricas sobre el uso contemporáneo del Derecho natural como método.

Doxa, Alicante, núm. 4, 1987, págs. 289-326.

El presente texto se estructura en tres apartados: I. Introducción; II. El Derecho natural contemporáneo como resto formal y metódico, subdividido a su vez en dos apartados: II. 1 Derecho natural como método. II. 2 Derecho natural ¿concepto histórico o formal? y III. Condiciones de aplicación del Derecho natural en la teoría jurídica contemporánea, subdividido en tres apartados: 
III. 1 Superación de lo natural. III. 2 Concepción activa y crítica de la racionalidad. III. 3 La experiencia jurídica como «totality approach».

El autor asume de forma crítica la tradición iusnaturalista: el Derecho natural se centra en la oposición entre lo real y lo racional; el proyecto ilustrado debe entenderse como un intento de acabar con esta tensión entre «lo que es» $\mathrm{y}$ «lo que debe ser». En consecuencia, si bien dicho intento debe considerarse inalcanzado, posee virtualidad en cuanto pauta desde la que enjuiciar críticamente la realidad.

El autor propone entender el Derecho natural como «resto» formal y metódico consistente en una metaética de lo jurídico, «como método de acercamiento a los valores, y a la normatividad en general (...) y, por otro lado, como el modelo teórico que permite la interconexión de los diferentes momentos que componen cualquier objetivación cultural».

Esta concepción metodológica hace necesario abordar los tres momentos siguientes: 1. la superación de lo natural, entendida como «rechazo de considerar a cualquier ley como un enunciado veritativo» y admitiendo «como única ley natural la del constante cambio y mutación de lo real en todas sus vertientes»; 2. la concepción de la racionalidad, ya que ésta es el instrumento por medio del cual opera el Derecho natural. Así, ser racional no es sólo la actuación conforme a determinadas reglas (racionalidad pasiva), sino que la asunción de los valores como normas universalizables hace posible la crítica a dicho comportamiento (racionalidad activa), 3. la experiencia jurídica como «protensión» a la totalidad del fenómeno jurídico.

En conclusión, la idea central del texto, en palabras del autor, consiste en la propuesta «de un Derecho natural como método en el sentido moderno de autotematización de la ciencia desde los tres supuestos reseñados con anterioridad, es decir, la superación de lo natural, la racionalidad crítica y la experiencia jurídica como «protensión» a la totalidad del fenómeno jurídico, y todo ello, desde el punto de inflexión de la praxis de la ciencia jurídica en cuanto ciencia, es decir, desde el punto de vista de la plausibilidad de sus resultados en función de la legitimidad de los mismos».

(Juan Sala Puche) 
HERVADA, Javier.

Historia de la ciencia del Derecho natural.

Ed. EUNSA (Manuales de la Colección Jurídica), Pamplona, 1987, 340 págs.

Agotada en pocos años la edición del «Compendio de Derecho natural», escrito por el autor en colaboración con el ilustre Prof. D. Miguel Sancho Izquierdo, la avanzada edad de este último ha impedido seguir la obra de colaboración de ambos autores. Aprovechando lo escrito entonces, el autor ha reelaborado los materiales y ha añadido lo oportuno para sacar un nuevo manual.

No es este manual una historia de la filosofía del Derecho. Poco después del surgimiento del pensamiento idealista y como consecuencia del cambio que operó Kant en la concepción del Derecho natural, la filosofía del Derecho y la ciencia del Derecho natural comenzaron a ser entendidas como una sola disciplina, o bien enteramente la misma, o bien la segunda como una parte de la primera. Hervada rechaza esta identificación y entiende que se trata de dos disciplinas distintas, por lo que ciñe su exposición a la evolución histórica de la ciencia del Derecho natural. Se trata de un manual dirigido a los alumnos de primer curso de la licenciatura en Derecho y, en razón de algunos de sus desarrollos y del aparato bibliográfico, a quienes comienzan a especializarse en la disciplina.

Después de una introducción para fijar brevemente el concepto de Derecho natural, el libro se estructura en diez capítulos y un epílogo.

El capítulo I, dedicado a la Antigüedad, expone la concepción del Derecho natural, desde sus orígenes en Grecia hasta la caída del imperio romano de Occidente: sofistas, Aristóteles; estoicismo, Cicerón, Séneca; los juristas romanos, la Biblia y la Patrística, con especial mención de San Agustín, son los temas abordados.

El capítulo II trata de la doctrina medieval, desde la compilación justinianea hasta el auge de la Escolástica (Isidoro de Sevilla, Irnerio y Graciano, los glosadores, los decretistas y la Escolástica hasta Tomás de Aquino). Por su especial relevancia este último autor es objeto de exposición en el capítulo III.

El capítulo IV comprende de la Escolástica al Renacimiento (Duns Escoto, Guillermo de Ockham, etc.). Se ocupa el capítulo V del Renacimiento y la Reforma (el humanismo jurídico, Lutero, Calvino, Melanchton y primeros tratados protestantes de Derecho natural).

El capítulo VI tiene por título «La escuela española del Derecho natural» y comenzando por Vitoria, expone a Soto, Molina, Vázquez y Suárez para terminar con Fernando Vázquez de Menchaca.

El capítulo VII contiene una exposición de los rasgos generales del iusnaturalismo moderno y de Grocio, Hobbes y Spinoza. Pufendorf, Thomasio y Wolff, así como sus discípulos y comentadores, son el objeto principal del capítulo VIII.

De Kant se ocupa el capítulo IX y con el capítulo X, que analiza el siglo XIX, se termina propiamente la exposición histórica. El libro se cierra con un epílogo en el que se da una breve panorámica de las doctrinas iusnaturalistas del siglo actual.

INNERARITY, Daniel. 
La Ilustración sociológica de Niklas Luhmann.

Persona y Derecho, Pamplona, núm. 17, 1987, págs. 11-29.

La sociedad contemporánea se caracteriza por su gran complejidad, el proceso mismo de civilización no es sino complicación. «Esta es la clave -dice el autor- del intento teórico de Luhmann: despejar la incertidumbre que una realidad compleja provoca, convertir la perplejidad en certeza, elaborar una nueva soziologische Aufklärung». «Complejidad quiere decir un "exceso de posibilidades de mundo", respecto de lo cual la elección es, fundamentalmente, exclusión de otras posibilidades», es decir, contingencia y riesgo. En este marco, los sistemas tienen por función «captar y reducir la complejidad», mediando entre «la extremada complejidad del mundo y la limitada capacidad del hombre para la asimilación y tratamiento de experiencias. La formación de sistemas es el verdadero proceso de racionalización»».

Por ello, es preciso para Luhmann que se abra paso una nueva Ilustración «en clave social», que sustituya el funcionalismo científico-causal por el «funcionalismo de equivalencia»: «la atención no se concentra sobre la causa y el efecto, sino sobre un género de fenómenos cuya característica común es la de producir un mismo efecto». La viabilidad de un sistema social dependería de su capacidad de producir y seleccionar soluciones equivalentes. «La sociedad como sistema no aparece como conjunto de hombres, sino como un entramado de acciones, que deben ser interpretadas funcionalmente.» La noción de individuo produce hoy «desilusióny alteraciones sociales», pues pertenece a la complejidad que hay que reducir. En cambio, la institucionalización de la libertad individual (su «absorción sistémica») «protege al individuo de sí mismo, al ahorrarle decisiones»: el hombre se pliega a los valores establecidos, a la seguridad de las estructuras jurídicas y burocráticas. «En este sentido -señala el autor- la Ilustración sociológica representa un cambio en el centro de atención: del individuo a la sociedad, de los deseos y valoraciones singulares a las exigencias funcionales y los criterios de racionalidad del sistema.»

Según Luhmann, las teorías jurídicas y políticas de la época moderna son inadecuadas para comprender nuestra sociedad y resolver sus problemas de ingobernabilidad, porque un sistema empeñado en fundamentar la legitimidad de las normas en convicciones morales no es capaz de reconocer el problema social básico: que los sistemas complejos de acción se encuentran bajo el imperativo de la selectividad. Con su positivación, el Derecho deviene contingente, su validezdepende de decisiones adoptadas en el sistema político. «La reducción de la legitimidad a la legalidad se debe a que el factor de legitimación no es el contenido normativo, sino los procedimientos de producción del Derecho», entendiéndose por procedimiento «el proceso de participación de los destinatarios no en las decisiones mismas, sino a través del reconocimiento generalizado de competencia decisional para la instancia política correspondiente». Ello supone, según señala críticamente el autor, un reconocimiento «acrítico e institucional» de la legitimidad de la pura legalidad. Además de una «neutralización ética del orden social», la concepción de Luhmann conlleva un cambio en la idea tradicional de democracia: «la democracia, entendida como participación, comporta un aumento de complejidad no reducible y desilusión. Por el contrario, la capacidad de un sistema político en relación a su función específica de adoptar decisiones vinculantes debe crecer en la medida en que aumenta la complejidad del sistema social». «La nueva legitimación ha de reposar sobre la aceptación mecánica de decisiones burocráticas, y no sobre la tradición, la convicción o el consenso.» El artículo concluye desarrollando estas críticas que el autor dirige contra Luhmann. Su decisionismo 
conduce a la arbitrariedad (además, «en un escenario así, sin referencias objetivas, decidirse no es estabilizar una certeza, sino continuar en la perplejidad»). Su rechazo de la validez objetiva de los valores de dignidad y libertad humana conduce a una «disolución funcional del hombre». «El funcionalismo, pese a su autocomplacencia racional, se muestra finalmente como un nuevo Fausto que se rinde al mecanismo administrativo.» «La sociedad -concluye el autor- no puede ser entendida exclusivamente como un sistema de autoconservación. También en un panorama de elevada complejidad puede mantenerse la esperanza de que las cosas funcionen... bien.»

(Juan Antonio Pérez Lledó)

ITURRALDE SESMA, Victoria.

Una aproximación al tema de las antinomias normativas: problemas relativos a la identificación de las mismas.

Anuario de Filosofía del Derecho, Madrid, núm. 4 (Nueva Época), 1987, págs. 331-353.

En la preocupación por establecer el carácter sistemático de los ordenamientos jurídicos no son infrecuentes los estudios dedicados al examen de los medios aptos para superar los problemas de inconsistencia e incompletitud de aquéllos. Ahora bien, en la mayoría de los casos se omite una labor previa, cual es la de determinación de las condiciones en las cuales podemos afirmar que un determinado ordenamiento jurídico (o parte del mismo) es antinómico (o inconsistente) o incompleto. Pues, bien, este trabajo, limitado al primero de estos problemas, tiene como objeto poner de relieve las condiciones que tienen que estar presentes para que podamos hablar de la existencia de una antinomia normativa en una parte del ordenamiento jurídico.

El trabajo comienza con una referencia a los diversos conceptos de la expresión «antinomia normativa» que giran, unos, en torno al concepto de incompatibilidad deóntica y, otros, en torno al de imposibilidad de aplicación y/o de cumplimiento. Nosotros optamos por hacer gravitar el concepto de antinomia normativa alternativamente sobre ambos; distinguiendo así los conceptos de antinomia deóntica y antinomia no deóntica. Nuestro estudio se limita a las primeras.

Partiendo de que todo enunciado deóntico puede representarse como compuesto de un antecedente deóntico, una relación deóntica y un consecuente deóntico, establecemos que para que podamos hablar de antinomia deóntica entre dos enunciados tiene que existir: 1) una identidad de los antecedentes deónticos de ambos enunciados, y 2) una incompatibilidad entre sus relaciones deónticas.

El antecedente deóntico de un enunciado normativo incluye, además de la condición de aplicación en sentido estricto, otra serie de circunstancias (a menudo no incluidas expresamente en el mismo enunciado pero sí en otros adyacentes) como son: el o los sujetos, el tiempo y el territorio de aplicación.

La determinación de cuándo se produce una incompatibilidad de relaciones deónticas en el lenguaje legal presenta algunos problemas. En una primera aproximación parece poder zanjarse la cuestión tomando como referencia el hexágono de las relaciones deónticas y estableciendo que una antinomia deóntica tiene lugar en los casos de contrariedad y contradicción. Ahora bien, la naturaleza del lenguaje legal pone de manifiesto que para comprobar dichas relaciones de contrariedad y 
contradicción se hace necesaria una labor de traducción del lenguaje legislativo al lenguaje deóntico, es decir, pasar de la estructura superficial de los enunciados normativos a su estructura profunda. Y en este terreno se plantean problemas debido, de un lado, a que a una misma relación deóntica suele corresponder en el lenguaje legal más de una forma gramatical y, de otra, a que los términos deónticos de que se sirve el lenguaje legal son ambiguos. 


\section{LAPORTA, Francisco.}

\section{Sobre el concepto de derechos humanos.}

Doxa, Alicante, núm. 4, 1987, págs. 23-46.

El presente trabajo constituye una investigación conceptual sobre los derechos humanos que comienza y concluye mostrando la posible incompatibilidad entre la multiplicación del catálogo de los derechos humanos, por un lado, y el conferir a éstos una particular fuerza justificatoria o motivacional, es decir, considerarlos como los «escalones últimos y más poderosos de los sistemas morales y jurídicos, expresión de exigencias éticas y políticas tan fundamentales que no son susceptibles de negociación o trueque», por otro lado.

El artículo se estructura en dos partes: a) análisis de los problemas conceptuales que surgen en torno a la idea genérica de «tener un derecho» $\mathrm{o}$ a las expresiones del género «A tiene un derecho a $\mathrm{X}$ », pues -como dice el autor- «para hablar con fundamento de "derechos humanos" tenemos antes que saber hablar de "derechos" sin más»; y b) análisis de los rasgos estructurales y formales que suelen atribuirse a la idea de derechos humanos. Así, en la primera parte, tras criticar tanto a las corrientes que han pretendido situar los derechos fuera del ámbito de los lenguajes normativos (por considerar que se dan ciertos derechos antes de que existan normas), como aquellas otras que si bien sostienen que sólo cabe hablar de derechos en el contexto de los lenguajes normativos, pero que tienden o a reducir los derechos a deberes, o a confundir los tipos de derechos con los tipos de protección normativa que se dispensa a los derechos, el autor trata de mostrar que los derechos se comprenden mejor cuando se los entiende en el contexto de los lenguajes normativos y se los aprecia «como algo que está antes que las acciones, pretensiones o exigencias, antes que los poderes normativos y antes que las inmunidades de status. Se entienden mejor cuando se les concibe como el título que subyace a todas esas técnicas de protección, es decir, cuando se les concibe como el justificante de la puesta en marcha de tales técnicas». A continuación, después de mostrar algunas consecuencias de esta aproximación, presenta una propuesta de noción de derecho (referida a los derechos-núcleo, no a los derechos-derivados) cuyos componentes aislados serían los siguientes: a) La adscripción a todos y cada uno de los miembros individuales de una clase de...b) ....una posición, situación, aspecto, estado de cosas, etc... que se considera por el sistema normativo un (...que bien tal que constituye una razón fuerte... d) ...para articular una protección normativa en su favor a través de la imposición de deberes u obligaciones, la atribución de poderes e inmunidades... etc.

En la segunda parte, tras recordar la tesis sostenida en la primera de que la «idea de "tener un derecho" puede hallarse en cualquier sistema normativo dotado de un cierto grado de complejidad interna» y apartándose, así, de quienes creen que sólo puede hablarse de "derechos" en el marco del sistema jurídico, el autor se ocupa de «analizar las más típicas características formales que suelen adscribirse a los derechos humanos en el lenguaje ético, jurídico y político sobre el telón de fondo de la idea genérica de "tener un derecho"». Estos rasgos son la universalidad, el carácter de absolutos y la idea de inalienabilidad. Finalmente, concluye diciendo: «Si pensamos en la significación de los tres rasgos formales que he analizado: la universalidad de su adscripción, su carácter de criterio superior de decisión moral y lo inalienable de su presencia en los individuos, no podemos por menos que llegar a la convicción de que los derechos humanos tratan de configurarse como una forma de expresión de 
los propios rasgos constitutivos de la moralidad interindividual [...] Si ello es así haríamos bien en no trivializarlos apelando a ellos sin ton ni son o extendiendo los catálogos y las "generaciones" arbitrariamente. De ello puede depender no sólo el que sean reconocidos, sino sobre todo el que sean efectivamente realizados en algún momento de la historia de la especie humana.»

(Josep Aguiló Regla)

LAPORTA, Francisco J.; RUIZ MIGUEL, Alfonso; ZAPATERO, Virgilio; SOLANA, Javier.

Los orígenes culturales de la Junta para Ampliación de Estudios.

Arbor, 1. ${ }^{\text {a }}$ parte núm. 493, CXXVI, 1987, págs. 17-87; 2. a parte, núm. 499-500, CXXVII, 1987, págs. 9-137.

1. El trabajo pretende llenar la laguna de un estudio detallado sobre la Junta para la Ampliación de Estudios e Investigaciones Científicas (JAE).

Los orígenes de la JAE están en las preocupaciones de la «inteligencia» española del último tercio del siglo XIX frente al atraso científico, técnico y sociocultural. La idea de «europeizar» España, iniciada de hecho con la beca a Alemania de Sanz del Río, enraíza en el 98, en el regeneracionismo y en la Institución Libre de Enseñanza como una alternativa global. Fue Giner de los Ríos el gran impulsor de la idea de enviar jóvenes a estudiar al extranjero.

Tras distintos antecedentes legislativos a lo largo del siglo XIX y principios del XX, la JAE se crea en enero de 1907 superando algunas deficiencias anteriores, en especial mediante la dirección y apoyo de los becarios y la dotación de infraestructuras de investigación en el propio país.

Entre los inspiradores de la JAE, se destacan algunos rasgos biográficos de Francisco Giner de los Ríos, Santiago Ramón y Cajal y José Castillejo. La primera parte concluye con una referencia a la composición de la JAE a lo largo de su historia.

II. La creación y primeros pasos de la JAE, y hasta su historia entera, estuvieron plagados de dificultades, sobre todo por obra de los gobiernos conservadores, bien por afán de influencia política, bien por desconfianza hacia la inspiración institucionista del organismo.

Tras un trienio de control político, la JAE se consolida a partir de 1910, cuando se consigue volver a la fórmula de autonomía establecida en su origen, creándose en su rededor instituciones como el Centro de Estudios Históricos, la Residencia de Estudiantes o el instituto Nacional de Ciencias Físico-Naturales.

Durante el período de la primera guerra mundial se revitalizaron los centros y actividades dentro de España, creándose en 1918 el Instituto-Escuela, como ensayo educativo para la segunda enseñanza en la línea de la Institución Libre de Enseñanza. Ello levantó no poca polémica, al igual que la influencia y rasgos de la JAE, que suscitó encendidos debates en las Cortes.

Durante la dictadura de Primo de Rivera, la JAE pudo proseguir su marcha, aunque no sin ataques de la derecha católica ni sin control político sobre el nombramiento de sus vocales. Es en este período cuando se consolida la relación de la JAE con la Fundación Rockefeller en materia sanitaria y educativa.

En el período de la República cobrará auge el Patronato de Estudiantes, como oficina de información 
y ayuda para estancias e intercambios estudiantiles en el extranjero. Recibiendo todavía algún significado ataque de la derecha clerical, la JAE mantuvo una exquisita neutralidad ante la situación política.

Durante la guerra civil, la mayoría de los intelectuales ligados a la JAE se integraron en la Casa de la Cultura, creada en Valencia en apoyo del gobierno republicano. Entre tanto, en la zona nacional, a la vez que se creaba el Instituto de España, se disolvía la JAE, cuyo hueco pretendió llenar dos años después el Consejo Superior de Investigaciones Científicas, de talante y balance diferentes.

\section{LÓPEZ HERNÁNDEZ, José.}

El problema del Derecho natural en J.-J. Rousseau.

Anuario de Filosofía del Derecho, Madrid, núm. 4 (Nueva Época), 1987, págs. 539-562.

Existe unanimidad en afirmar la importancia que el pensamiento de Rousseau tuvo en la crisis del Derecho natural moderno; las divergencias aparecen a la hora de determinar si su posición implica una ruptura con la tradición iusnaturalista o si, por el contrario, mantiene el núcleo esencial de esta tradición; y es precisamente en torno a este debate donde se sitúa el artículo.

En primer lugar el autor analiza las diversas posturas que, respecto a esta discusión, se han adoptado hasta nuestros días; a continuación pasa a estudiar las concepciones que, sobre el Derecho natural, mantuvieron los predecesores de Rousseau (Hobbes, Grocio, Pufendorf, Locke, etc.) y en qué medida éstas influyeron en su pensamiento.

Tras analizar las múltiples referencias de la obra de Rousseau al problema del Derecho natural, el autor afirma que es necesario descartar su adhesión al iusnaturalismo clásico y a su concepto de ley natural, al considerar que antes del pacto social no hay justicia, ya que ésta deriva sólo de la ley política; en el estado de naturaleza el hombre vive aislado, por lo que no caben ni lazos jurídicos ni morales. De este modo sus alusiones al Derecho natural y a la ley, caracterizados de forma positiva como anteriores y superiores al orden político, se refieren a los principios de tipo psicológico inscritos en la naturaleza humana, no existiendo ni derecho ni ley en sentido propio; admitir la autoridad de Dios y de la ley natural no indica -en opinión del autor- que estas fuentes sean asequibles directamente al conocimiento humano como para poder convertirse en norma legislativa.

«Su originalidad -concluye el autor- radica, pues, en negar la preexistencia del Derecho antes del pacto social y, sin embargo, concebir la naturaleza humana y sus impulsos naturales como modelo al que debe ajustarse el pacto fundamental, origen del Derecho y de la justicia.» 


\section{LOSANO, Mario G.}

Curso de informática jurídica (trad. de M. Atienza, J. Ruiz Manero y J. Aguiló Regla).

Ed. Tecnos, Madrid, 1987, 263 págs.

Este manual, que se estructura en cinco partes y diecinueve capítulos, trata de suministrar un cuadro completo de los temas que debe conocer el científico social o el jurista que entra en contacto con la informática.

En la primera parte, Tratamiento electrónico y nuevas metodologías jurídicas, el autor se detiene fundamentalmente en mostrar la génesis («la cibernética»), la evolución («de la jurimetría a la iuscibernética») y la estructura («modelística e informática jurídica») de esta nueva disciplina que él denomina «iuscibernética».

En la segunda parte, La formalización del lenguaje, estudia el paso del lenguaje natural al lenguaje lógico y muestra las correspondencias existentes entre la lógica simbólica, la teoría de conjuntos y el álgebra de los circuitos con interruptores. Asimismo, en esta parte, estudia también el sistema numérico binario.

La tercera parte está dedicada a La estructura del ordenador electrónico y en ella se da un repaso a la historia (evolución) de las máquinas de cálculo y a las informaciones (datos e instrucciones) a tratar. Asimismo, se da un repaso a los componentes más importantes de un ordenador: unidades de entrada, unidad central, memorias externas, unidades de salida, terminales, etc.

La cuarta parte, Principios de programación, contiene un análisis de las distintas fases de preparación de un programa así como de los diferentes lenguajes de programación. Todo ello desemboca en un estudio sobre el origen, la evolución y la estructura de los bancos de datos.

En la quinta parte, Informática jurídica: la construcción de bancos de datos jurídicos, se realiza un análisis pormenorizado de las técnicas de la informática jurídica entendida como recuperación automática de textos jurídicos, esto es, de legislación, jurisprudencia y doctrina.

Finalmente, el libro concluye con una extensa e importante bibliografia que reproduce la estructura de los capítulos y parágrafos del libro.

(Josep Aguiló Regla)

LUCAS, Javier de.

Nota sobre libertad de expresión y democracia en la obra de Spinoza.

Doxa, Alicante, núm. 4, 1987, págs. 355-363.

Este artículo pretende ofrecer una interpretación y comentario de algunos textos de Spinoza sobre la vinculación entre orden político y libertad de pensamiento y expresión(fundamentalmente, el Tractatus Theologicus-Politicus y el Tractatus Politicus).

El autor parte de una breve exposición de los principios básicos del sistema filosófico de Spinoza (y, 
más concretamente, de su antropología). Según Spinoza, el hombre, en cuanto parte de la naturaleza, está sujeto a la causalidad de sus pasiones, instintos y deseos («egoísmo biológico»), pero también a la razón, que (sin ser contraria a la naturaleza) exige que cada cual busque su utilidad propia («utilitarismo racional»), y conduce al hombre a un fin supremo, el conocimiento («intelectualismo»). La noción de «imitación de afectos» (exigencia de la razón, mediante la cual todos los intereses concuerdan) es el resorte del que derivan las relaciones humanas y la sociedad misma, como vía para salvar -por la guía de la razón- el estado «miserable» de deseo y violencia.

Para garantizar que todos sigan los dictámenes de la razón, surge el orden político, que debe ser democrático. La soberana potestad «no está obligada por ninguna ley, y todos deben obedecerla en todo». Se plantea aquí el problema de la libertad, pues lo anterior podría llevar a pensar que hacemos a los súbditos «siervos e inútiles para sí». Según Spinoza, esto no es así, por tres razones: a) no es libre quien obra arrastrado por sus deseos, sino quien «con ánimo íntegro sirve según las reglas de la razón»; b) esta situación no es asimilable ni a la dependencia del siervo respecto al amo ni a la del niño respecto a su padre; y c) es casi imposible que la mayoría de una asamblea numerosa convenga en un absurdo. Pero Spinoza introduce un importante matiz: si la razón del pacto es la utilidad, y la razón del Estado, la utilidad común, «aquel que detenta el poder soberano no puede, sin crimen, cumplir sus promesas con daño del Estado mismo». En consecuencia, en el orden social y político hay un criterio objetivo de justicia que emana de la voluntad de todos, presumiéndose la exclusión de la disidencia. Refiriéndose específicamente a la libertad de pensamiento y expresión, Spinoza sostiene que: a) es una necesidad y un derecho: cada uno es dueño de su pensamiento y no hay poder capaz de impedirlo, la tendencia de los hombres a comunicarse es irreprimible, y esa libertad es condición de progreso de las ciencias y de las artes. b) Es compatible con la autoridad. Más aún, las leyes contrarias a ella no sólo son violencia, sino además, inútiles, y originan dos efectos perversos: la corrupción de la sociedad y la eliminación de los hombres honrados y libres (los disidentes), tan importantes para la sociedad. Y c) libertad de pensamiento y poder soberano del pueblo son compatibles: en el gobierno democrático el pacto obliga a todos a obrar según la voluntad común, pero no a pensar de ese modo; precisamente porque los hombres no pueden pensar todos del mismo modo, pactan que tenga fuerza de ley la de la mayoría. Pero la opinión mayoritaria puede cambiar, y garantizar el derecho a pensar y expresarse de forma distinta a la de la mayoría (con tal de que la obedezcan) es una de las vías por las que puede cambiar esa opinión mayoritaria.

Sin embargo, el análisis de Spinoza queda lastrado por importantes matizaciones posteriores (en el Tractatus Politicus), reforzándose -como señala el autor- el carácter incontestable de la voluntad del soberano, la «lectura fuerte» de la expresión una veluti mente ducitur. Coherentemente con el reconocimiento de que el fin de la sociedad y del Estado, más que la libertad, es la seguridad y la paz, Spinoza sostiene aquí -como Rousseau- el carácter justo de la voluntad de la República, «que es tenida por la voluntad de todos», y defiende el derecho a obligar a los ciudadanos a vivir según razón.

(Juan Antonio Pérez Lledó)

MALEM SEÑA, Jorge.

Ernesto Garzón Valdés: apuntes biográficos y reseña bibliográfica. 
Doxa, Alicante, núm. 4, 1987, págs. 399-411.

En este texto se suministran unos apuntes biográficos sobre Ernesto Garzón Valdés en los que se incluye su actividad intelectual y su personalidad humana, así como una relación de sus publicaciones (libros, artículos y traducciones).

(Daniel González Lagier) 
MARTÍNEZ GARCÍA, Jesús Ignacio.

\section{Justicia e igualdad en Luhmann.}

Anuario de Filosofía del Derecho, Madrid, núm. 4 (Nueva Época), 1987, págs. 43-87.

Presenta este artículo «un análisis de los planteamientos de Luhmann en torno a los problemas de la justicia y los derechos fundamentales» guiado por el interés hacia un examen del principio de igualdad. Dado que el conocimiento del marco teórico del que parte Luhmann en estas cuestiones, de su concepción del Derecho y de sus presupuestos metodológicos son esenciales para llevar a cabo tal análisis, el autor del artículo dedica una primera parte del mismo a estas cuestiones previas.

Uno de los conceptos de la obra de Luhmann que es necesario conocer es el de sistema; Luhmann define a los sistemas como «identidades que se conservan en un ambiente complejo y cambiante por medio de la estabilización de una diferencia de los planos interior y exterior». Si entendemos por acción «todo comportamiento orientado con sentido y dotado de repercusión exterior», puede decirse que los sistemas «se componen de acciones concretas de una o varias personas y que se delimitan con respecto a un ambiente por medio de relaciones de sentido entre estas acciones» (familias, empresas, sociedades, Estados serían ejemplos de sistemas). Puesto que «la capacidad de la razón humana para comprender y reducir por sí sola la complejidad del mundo es limitadísima» surgen los sistemas con «la función de presentar el mundo reducido a fragmentos accesibles a la experiencia humana».

Otro aspecto a tener en cuenta es la sustitución en Luhmann de la «ilustración de la razón» por la «ilustración sociológica», es decir, el paso de una racionalidad entendida como una propiedad ontológica del sujeto individual a una racionalidad sistémica, entendida como «la capacidad del sistema para regular sus propias transformaciones en un contexto inestable». Ya no se trata de la búsqueda de verdades universales, sino de la búsqueda de soluciones a los problemas cambiantes, reduciendo complejidad. Esta racionalidad «tiene una de sus mayores virtualidades en la detección de funciones latentes», lo que nos permite descubrir que «los derechos fundamentales no son derechos humanos, derechos basados en atributos del hombre en cuanto portador de unas exigencias metafísicas, sino mecanismos jurídicos positivos, perfectamente explicables en la lógica de los sistemas, sin recurrir a un trasfondo ético».

En esta teoría el Derecho constituye un «sistema autorreferencial»o «autopoiético» (es decir, un sistema que en todas sus operaciones se refiere siempre a sí mismo, en el que toda referencia externa implica autorreferencia y en el que todos sus componentes se reproducen a sí mismos a través de los elementos de los que se componen) cuya función es «la congruente generalización de las expectativas normativas de conducta». Generalizar expectativas es inmunizarlas contra lo contingente, estabilizarlas; ello ha de hacerse en tres dimensiones: temporal, social y material.

El sentido de los derechos fundamentales será el de mantener la «propia operatividad, seguridad y supervivencia de un Derecho que aspire a desenvolverse en una sociedad compleja y altamente diferenciada». Lo que defienden «no es un mundo ideal de valores, un horizonte iusnaturalista (...), sino un sistema social evolucionado e independiente que es frágil y corre peligro de regresión». Esta función protectora se desarrolla en cuatro direcciones: la constitución social de la personalidad, la formación de expectativas generalizadas de comportamiento, la satisfacción de necesidades económicas y la elaboración de decisiones vinculantes. 
La justicia, desde esta nueva perspectiva, ha de ser redefinida como «la adecuada complejidad del sistema jurídico»; el concepto de «adecuada complejidad» hace referencia «a la capacidad del sistema para producir decisiones coherentes, a su operatividad, y no directamente a la adecuación del Derecho con la sociedad»; supone, por tanto, un enfoque intrasistémico y global (la justicia no se refiere a normas o acciones aisladas).

El principio de igualdad, por último, no se dirige a la acción de los ciudadanos, sino a la acción del Estado. Está relacionada con la justicia en que sólo a través de la justicia tal como aquí se entiende se garantiza el principio de economía decisoria de que casos iguales se decidan de manera igual.

(Daniel González Lagier)

MASSINI, Carlos I.

Individualismo y derechos humanos.

Persona y Derecho, Pamplona, núm. 16, 1987, págs. 13-37.

El texto se puede resumir en los siguientes puntos: 1. Existe toda una corriente de ideas, originaria del mundo anglosajón, que defiende una particular concepción de los «derechos», que tiene una problemática propia y en la que se desarrollan activos debates internos. 2. «La nota fundamental de esta dirección de pensamiento es su decidido individualismo, que le lleva a negar la existencia de cualquier bien general, abocando a una serie de aporías de difícil resolución dentro de la misma corriente, tanto por su repulsa a encarar una serie de temas filosóficos fundamentales, como por su estrecho nominalismo y subjetivismo de base.» 3. También se caracteriza esta orientación por su «concepción de la ética como una mera creación o invento del hombre... Esto desemboca en un relativismo subjetivista que resulta poco adecuado para otorgar un fundamento firme a los derechos humanos». 4. Esta corriente de ideas no logra explicar toda una serie de cuestiones «tales como las relaciones entre los derechos básicos y las normas, el fundamento y alcance de las obligaciones correlativas de los derechos y las soluciones a los inevitables conflictos entre derechos». 5. La ausencia de una fundamentación trascendente de los derechos «otorga a las concepciones de esta línea de ideas una notable debilidad interna, sobre todo si lo que se persigue es justificar el carácter absoluto de ciertos derechos, aun frente a las aparentemente más justificadas exigencias del poder». 6. «No obstante lo apuntado, del estudio de las obras de varios pensadores enrolables en esta corriente surgen toda una serie de sugerencias para los estudiosos de la filosofía práctica, la más relevante de las cuales nos parece su intención de encontrar bases y límites éticos para la legislación positiva, superando, de este modo, los estrechos planteos de los positivistas a ultranza. También merece destacarse su a veces acertada crítica al utilitarismo.» 7. La conclusión de este estudio sería «la necesidad de responder, por parte de las restantes corrientes filosóficas y en especial del realismo intelectualista, a los desafíos lanzados por los pensadores analizados» desarrollando y precisando todo lo referente a los fundamentos -aun a los fundamentos últimos- de los derechos humanos.

(Ángeles Ródenas Calatayud) 
MONZÓN ARAZO, August.

\section{El derecho en Joan Lluís Vives.}

Ed. Universidad de Valencia, Valencia, 1987 (publicación en microficha).

La tesis se propone analizar el planteamiento de Joan Lluís Vives (ca. 1492-1540) con respecto al derecho, con el objeto de establecer la significación histórica y la relevancia filosófica de dicho planteamiento.

Para la realización de este análisis se ha asumido el enfoque hermenéutico propio de la «Filosofía de la experiencia jurídica», y se ha tenido en cuenta la investigación bio-bibliográfica más reciente (C. Matheeussen, E. González). El estudio constituye en algunos puntos una confrontación con las conclusiones expuestas por C. G. Noreña en su síntesis Juan Luis Vives (1970), situándose, por otro lado, en continuidad con los principales estudios dedicados a la génesis -del derecho y el pensamiento jurídico modernos (F. Wieacker, D. Maffei, M. Villey).

En la primera parte se expone el estado de la cuestión de la investigación vivista en general, así como el de los estudios (parciales) realizados en torno a Vives y el derecho, y se ofrece por primera vez una descripción cronológicamente ordenada de la totalidad de los escritos vivesianos de tema jurídico. La parte central de la tesis está dedicada al examen del pensamiento filosófico-jurídico de Vives. En primer lugar se intenta determinar la perspectiva a partir de la cual Vives abordó el fenómeno jurídico, así como la posición que adoptó en las polémicas contemporáneas acerca del derecho. Seguidamente se procede a considerar con detenimiento los temas mayores del tratamiento vivesiano del derecho: relación derecho-filosofía y fundamentos del derecho; concepción de la equidad; proyecto de reforma del derecho.

La tercera y última parte del trabajo, de intención filosófico-constructiva, trata de valorar el legado de Vives en relación con el pensamiento moderno y con la posible superación de los planteamientos reduccionistas de éste a partir de una antropología integral.

El estudio pone de manifiesto la alineación decidida de Vives con los planteamientos del humanismo jurídico, así como algunos rasgos diferenciales significativos con respecto a éste: perspectiva filosófica y no científico-jurídica; ausencia de sentido crítico en la evaluación de la ciencia jurídica medieval. Estos datos son indicio de reduccionismo filosofizante y muestran que el interés de Vives por el derecho posee sobre todo significación política (responde a la preocupación burguesa por la transformación del sistema feudal) y que ha de ser conectado con las ideas y perspectivas del iusnaturalismo racionalista.

La consideración de Vives como precedente del derecho natural racionalista viene confirmada por el estudio de sus fuentes y de su tratamiento de la equidad y de la reforma del derecho, que revelan una significativa oposición a las soluciones escolásticas. El pensamiento filosófico-jurídico vivesiano, en fin, manifiesta una concepción del hombre al mismo tiempo naturalista y moralista, característicamente moderna y alejada de la antropología cristiana original.

MUGUERZA, Javier. 
Sobre el exceso de obediencia y otros excesos. (Un anticipo).

Doxa, Alicante, núm. 4, 1987, págs. 343-347.

Este texto, comenta el autor, es un anticipo de lo que «podría ser» su respuesta a Adela Cortina y Eusebio Fernández frente a las objeciones suscitadas por su intervención en la polémica entre González Vicén y Elías Díaz sobre la cuestión de la obediencia al Derecho.

En primer lugar el autor resume los términos de la discusión, recogiendo las posturas de González Vicén y Elías Díaz y la suya propia, que viene a ser un apoyo a González Vicén pero sin llegar tan lejos, ya que, a diferencia de éste, Muguerza afirma que sí existe un fundamento ético para la obediencia al Derecho y que es de índole contractual; en concreto este fundamento se encontraría en la reformulación que Habermas realiza del imperativo categórico kantiano que prescribe obrar sólo según una máxima tal que se pueda querer al mismo tiempo que se torne en ley universal. Por el contrario, otra formulación del imperativo categórico («obra de tal modo que tomes a la humanidad, tanto en tu persona como en la de cualquier otro, como un fin al mismo tiempo y nunca como un medio») serviría de fundamento para la desobediencia al Derecho en el caso del fanático dispuesto a querer como ley universal aquella que le perjudicaría. A continuación avanza la contestación a Adela Cortina y Eusebio Fernández. La primera le objetaba contraponer las dos versiones del imperativo categórico kantiano, puesto que Kant las consideraba «idénticas en el fondo»; frente a esto el autor sostiene que son dos versiones con distinto alcance y peso. A Eusebio Fernández -que le reprochaba haber utilizado a Kant para fundamentar la posibilidad de desobediencia ética al Derecho, puesto que éste rechazaba esta desobediencia- el autor le contesta que «la actitud de Kant ante el (mal) llamado derecho de resistencia constituye -como el propio González Vicén ha recordado- una vexata quaestio de la filosofía jurídica y política de Kant, quien -junto al repudio de aquel supuesto derecho- no vaciló en expresar su entusiasmo por los levantamientos y rebeliones de Irlanda y los Estados Unidos y, por supuesto, por la revolución francesa.

(Daniel González Lagier)

MUGUERZA, Javier.

Ética y comunicación.

Revista de Estudios Políticos, Madrid, núm. 56, 1987, págs, 7-63.

En este artículo el autor analiza la dimensión ético-política del pensamiento de J. Habermas, partiendo de «Conocimiento e interés» hasta sus últimos escritos.

La primera parte del artículo tiene un doble objetivo: de un lado, analizar el presunto «marxismo» de Habermas, de otro, mostrar sus conexiones con el «contractualismo». Por lo que al primer punto se refiere, el autor examina las conexiones de Habermas con la teoría crítica de la escuela de Frankfurt. Habermas muestra los puntos débiles de la teoría crítica y propone una reinterpretación del paradigma weberiano de la acción social y de la racionalidad, distinta de la interpretación de la teoría crítica. A continuación el autor se introduce en el presunto contractualismo habermasiano tomando como hilo 
conductor de su argumentación su teoría de los intereses del conocimiento.

En la segunda parte del artículo, partiendo del «giro lingüístico» del pensamiento de Habermas, examina los presupuestos lógico-lingüísticos que sirven de base a la ética discursiva en la que se va adentrando poco a poco, analizando primero la teoría de los «intereses generalizables» para pasar a continuación a analizar la ética discursiva como dos etapas en el desarrollo de la ética habermasiana. La tercera y última parte del artículo constituye un análisis de la teoría «de la acción comunicativa», que para el autor es más bien una elaboración de una teoría de la sociedad, en la que «Habermas se aventura a lanzar lo que alguien llamaría una "mirada hacia adelante"» y «lo hace también parapetándose en la acristalada seguridad de las gafas del teórico social». Pero en esta obra, a juicio del autor, existe un déficit de reflexión ética, «la reflexión trascendental se inclinaría a sustituirla por una suerte de «reconstrucción racional» del desarrollo moral cuya estación terminal no sería otra que la ética comunicativa».

(Francisco López Ruiz)

NAVARRO, Pablo E.

Eficacia, tiempo y cumplimiento.

Doxa, núm. 4, Alicante, 1987, págs. 257-266.

Como aportación al análisis del cumplimiento de las normas expone el autor en este artículo dos acepciones del término «eficacia», sugiere «trabajar el problema de la eficacia de las normas a partir de parámetros definidos» y muestra «algunas dificultades teóricas vinculadas a esta noción».

Así, distingue entre eficacia como relación (E1) eficacia como propiedad (E2). Respecto de la eficacia como relación se dice que «una norma (n) es eficaz cuando un estado de cosas (generalmente el resultado de una acción) se adecua al contenido normativo de (n)... Para un conjunto finito de estados de cosas que deben realizarse de acuerdo a (n), la norma será eficaz cuando se establezca una relación de identidad entre la «conducta debida» y la «conducta producida». Por otro lado, «la norma (n) es eficaz (E2) cuando es posible afirmar verdaderamente que existen un número indeterminado de actos de cumplimiento de la norma (n)». Estos dos sentidos de eficacia se encuentran relacionados, de forma que «para que sea posible afirmar verdaderamente que la norma (n) es eficaz (E2) es necesario poder afirmar que la norma (n) es eficaz (E1)».

A continuación introduce el autor el concepto de «tiempo de cumplimiento», atendiendo a que cumplir una norma requiere «un consumo de tiempo proporcional a la complejidad de la acción exigida». La extensión del «tiempo de cumplimiento» depende de la naturaleza de la acción y la estructura de la norma. No obstante, la medición del mismo plantea problemas en el caso concreto de las «reglas de ser» o «reglas ideales» (cuyo cumplimiento consiste en la ejecución de «una serie de actos de los que conforman los elementos de la serie de actos prescritos») y, en general, exige «contar con un aparato conceptual que permita determinar: (i) los sujetos normativos (ii) las características de las acciones debidas y (iii) el tiempo en que deben ejecutarse».

Entiende el autor que afirmaciones como la de que una norma es eficaz «cuando la mayoría de los sujetos en la mayoría de las ocasiones obedecen las normas» se vuelven circulares si se carece de 
parámetros adecuados, parámetros que pueden ser de naturaleza espacial, personal o temporal. Utilizando gráficos para representar el cumplimiento de una norma por un determinado sujeto en un determinado tiempo puede concluirse que la pregunta sobre la eficacia (E2) de una norma depende de los sistemas normativos o segmentos temporales que se tomen en cuenta.

Por último, el autor opina que quizá «sea conveniente poner más énfasis en la eficacia (E1) como un dato del funcionamiento del sistema más que un requisito de pertenencia. En esta perspectiva, la división del tiempo en segmentos permite relativizar la importancia de la eficacia como propiedad y señala marcos relevantes para el análisis de las causas de la acción humana, poniendo el acento en la eficacia como relación; o mejor dicho, en la problemática del cumplimiento de las normas».

(Daniel González Lagier) 
NINO, Carlos S.

\section{El cuatritema del consecuencialismo.}

Doxa, Alicante, núm. 4, 1987, págs. 365-366.

En este breve artículo el autor argumenta que el consecuencialismo «no puede ser una teoría moral adecuada» porque plantea el siguiente cuatrilema: «o bien es un esclavo de la moral positiva por aberrante que ella sea, o se transforma en una posición deontológica, o es circular, o tiene consecuencias altamente contraintuitivas»,

(Daniel González Lagier)

OLIVE, León.

Racionalidad y legitimación política.

Doxa, Alicante, núm. 4, 1987, págs. 131-144.

«En este trabajo -dice el autor- discuto una distinción entre los conceptos de "legitimidad" y "legitimación" en relación con los sistemas políticos. La distinción que propongo se basa sobre interpretaciones de los conceptos de "objetividad", "verdad" y "racionalidad", que se analizan en términos de conceptos epistémicos y sociales. La idea es entender cómo es posible que un sistema político y/o social esté legitimado de una manera que pueda llamarse auténticamente racional, mientras que el mismo sistema pueda ser criticado desde fuera, por sujetos racionales provenientes de algún otro sistema $y$, más aún, que el primero pueda ser juzgado como injusto o incluso como irracional. Esto significa que hay una auténtica manera racional de producir lo que llamaré "legitimación", aun si el sistema mismo puede ser criticado justificadamente desde fuera como irracional y puede por consiguiente carecer de lo que llamaré "legitimidad".

Para lograr lo anterior -continúa el autor- discutiré los conceptos de "objetividad" y de "verdad", los cuales a la vez presuponen el de "racionalidad"... Los conceptos mencionados deberían analizarse sobre la base de nociones epistémicas y sociales, idea que no implica que la racionalidad o que la verdad sean relativas a comunidades, sociedades o marcos conceptuales, pero que en cambio considera que la objetividad es relativa a los marcos conceptuales».

(Ángeles Ródenas Calatayud)

OLLERO TASSARA, Andrés.

La Constitución: entre el normativismo y la axiología. 
Anuario de Filosofía del Derecho, Madrid, 1987, núm. 4 (Nueva Época), págs. 389-402.

El artículo comienza preguntándose qué son los valores superiores, a la luz de las referencias que la Constitución española de 1978 hace a los mismos. A este respecto, plantea el autor la posibilidad de considerarlos como normas y llega a la conclusión -tras observar que se sitúan entre el Derecho positivo (y «su moral legalizada») y una «moralidad crítica»- de que "puede quedar claro que los valores superiores son auténticas normas, aunque sólo a condición de que renunciemos a tener tan claro qué sea una norma. El nítido perfil que le atribuyó el positivismo jurídico se ha abandonado, con lo cual sin duda hemos ganado en "realismo": nos hemos acercado más a lo que "realmente" es».

Si el Derecho se considera no como «substancia» o «cosa» -y así es, según el autor, como lo considera el positivismo- sino como juicio de valor, es decir, como «una actividad humana que, inevitablemente se refiere a valores (más o menos "superiores")», la relación entre principios y normas se «desdramatiza», descubriéndose que principios y normas son dos elementos imprescindibles en toda actividad jurídica: «el principio sin norma lleva a un casuismo arbitrario, imprevisible e irreversible, que acabaría por convertirse en norma particular ajena a todo sistema. La norma sin principios no puede actuar; el normativista se condena a dejar, voluntariamente o no, sus principios en la penumbra, ahorrándose su fundamentación y sustrayéndolos a toda crítica». Pues bien, en este marco los valores actúan primordialmente como principios, pero los valores «recogidos en un texto adecuado, funcionarán como normas en la medida en que su formulación permita fundamentar en ellos decisiones, hacerlas previsibles o dar paso a su posterior revisión. Si, por la apertura de su formulación, todo ello no es posible, funcionarán como principios, sin ser menos jurídicos por ello».

También se ocupa el autor de la fundamentación de los valores. «A nuestro modo de ver, y de modo forzosamente simplificado, sólo caben -afirma- dos modelos básicos. El que llamaremos "modelo A" entiende que tienen un fundamento real: que existe una realidad valiosa en sí misma, de la que derivan unas exigencias para la actividad humana, capaz de dictaminar que es más o menos correcta (...). En segundo lugar, considera que cabe un conocimiento racional (...) de dicha realidad. En el que llamaremos "modelo B" se rechaza la existencia de realidad alguna valiosa. El valor no es una característica real, que quepa conocer racionalmente, sino que expresa simplemente una opción de la voluntad.» Estos dos modelos olvidan la importancia de la existencia de un consenso suficiente en un momento histórico determinado respecto a los valores. Para el autor, sin embargo, caben «planteamientos que, compartiendo los dos elementos básicos del "modelo A" -la existencia de una realidad respecto a los valores superiores y la susceptibilidad de esta realidad de ser conocida racionalmente-, den al segundo un avance muy diverso», en el sentido de resaltar su carácter problemático, de relativizarlo; de esta forma, la existencia de un consenso histórico puede ser considerada como un «síntoma» (no como fundamento), y aparece como prudente la formulación de vías procedimentales que propicien «la transparencia argumental, el consenso intersubjetivo, la igualdad de trato y la revisión crítica».

El autor concluye que sólo dentro del «modelo A» conserva nuestra Constitución los aspectos favorables que se atribuyen a su apelación a los valores, lo que significa afirmar que existe en ella un transfondo iusnaturalista. A la luz de estos planteamientos el artículo finaliza con un análisis del artículo 1. 1. de la Constitución.

(Daniel González Lagier) 
OTERO PARGA, Milagros M.

La Filosofía del Derecho Penal en la Universidad de Santiago, 1800-1970.

Ed. Trivium, Madrid, 1987, 303 págs.

Esta obra realiza un estudio histórico sobre la enseñanza del Derecho Penal en la Universidad de Santiago de Compostela durante 170 años.

En ella pueden observarse dos partes perfectamente diferenciadas. La primera se titula Estudio de las fuentes, y la segunda Estudio de las ideas.

A su vez, cada una de estas partes genéricas presenta distintas subdivisiones internas que aclaran el contenido de la obra.

En primer lugar, y dentro del estudio de las fuentes, el primer epígrafe se titula Los catedráticos de Derecho Penal en la Universidad de Santiago de Compostela. En él se realiza un estudio bibliográfico de los doce catedráticos que sucesivamente ocuparon la cátedra de Derecho Penal en la Universidad gallega.

También dentro de este mismo epígrafe se hace mención de aquellos otros profesores que, sin ser catedráticos, se ocuparon de la enseñanza de la materia objeto de estudio, en las aulas compostelanas. Para terminar, se realiza una breve reseña de la situación actual del departamento.

El segundo epígrafe, dentro de esta parte primera dedicada al estudio de las fuentes, se ocupa de aportar la bibliografía por orden cronológico de todas las obras escritas por los catedráticos de Derecho Penal de la Universidad de Santiago de Compostela en el periodo estudiado.

La segunda parte del libro se refiere al estudio de las ideas. En ella se estudian, desde el punto de vista de la Filosofía del Derecho, una serie de tópicos sobre los cuales, los autores reseñados se habían manifestado en su tiempo.

En efecto, un subepígrafe se ocupa del Derecho Penal, otro de lo que denominamos Parafernalia del concepto, otro de la Pena, y, el último, del delito.

Cada uno de estos subepígrafes, a su vez se subdividen en otros que van proporcionando los datos suficientes para poder determinar con bastante exactitud lo que pensaban estos autores sobre las distintas ideas estudiadas. Finaliza este trabajo con una serie de conclusiones, en las que de una forma amplia y detallada se van exponiendo los puntos a los que ha conducido el trabajo realizado.

PECES BARBA, Gregorio; HIERRO, Liborio; ÍÑIGUEZ DE ONZOÑO, Santiago; LLAMAS, Ángel.

Derecho positivo de los derechos humanos.

Ed. Debate, Madrid, 1987, 430 págs.

Se trata de una recopilación de textos de derechos humanos desde su prehistoria hasta su regulación internacional en nuestros días. Además de una introducción general, cada parte, cada capítulo y cada 
texto seleccionado lleva también una introducción, lo que permite al lector «situarse en el momento histórico y en las condiciones de la evolución en su conjunto, en sus diversos momentos y en la producción normativa» (las introducciones a los textos concretos se inician con los que, en el tránsito a la modernidad, suponen el comienzo de la historia de los derechos humanos).

Los textos recogidos son los siguientes: 1. Prehistoria de los derechos fundamentales: Deuteronomio, VI Concilio de Toledo (638), VIII Concilio de Toledo (653), Carta del Convenio entre el rey Alfonso I de Aragón y los moros de Tudela (1119), Decretos de la curia de León (1188), Carta de Neuchâtel (1214), Carta Magna de Juan sin Tierra (1215), Carta jurada del rey Teobaldo II, reconociendo las libertades de Navarra (1253), El principio o regla de libertad (Las Siete Partidas), Partida séptima, Ley 34, reglas 1. ${ }^{\mathrm{a}}$ y 2. ${ }^{\mathrm{a}}$ ( (iglo XIII), Disposiciones de Oxford (1258), Pacto del 1 de agosto (Origen de la confederación Suiza) (1291), Ordenanza núm. 29 (Gran Bretaña) (1311), Código de Magnus Erikson (Suecia) (1350), Constitución Neminem captivabimus del rey Wladislav Jagiello (Polonia) (1430), Pragmática de los Reyes Católicos declarando la libertad de residencia (1480); 2. Historia de los derechos fundamentales, textos jurídicos nacionales: Textos jurídicos de la colonización española en América, Introducción de los Reyes Católicos a Nicolás Ovando, gobernador de las Indias (1501), Leyes de Burgos (1512), Cédula concedida por Fernando el Católico (1514), Decreto de Carlos I sobre la esclavitud en Indias (1526), Bula Sublimis Deus concedida por Paulo III (1537), Leyes nuevas de Indias (1542), Edicto de Nantes, Petición de derechos (1628), Cuerpo de libertades de la bahía de Massachusets (1641), Acta de tolerancia de Maryland (1649), Normas fundamentales de Carolina (1669-1670), Concesiones y acuerdos de West New Jersey (1677), Acta de habeas corpus (1679), Bill of Rights (1688), Carta de privilegios de Pennsylvania (1701), Declaración de derechos del buen pueblo de Virginia (1776), Declaración de independencia de los Estados Unidos (1776), Declaración de derechos y normas fundamentales de Delaware (1776), Declaración de los derechos del hombre y del ciudadano (1789), Declaración de derechos de Estados Unidos, enmiendas números 1 al 10 a la Constitución (1791), La Constitución política de la monarquía española (1812), La Constitución belga de 1831, la Constitución francesa de 1848, Enmiendas a la Constitución de los Estados Unidos, Constitución de la monarquía española (1869), Constitución española de 1876, Ley de asociaciones de 10 de junio de 1887, La Constitución mexicana de 1917, Declaración de los derechos del pueblo trabajador y explotado (1918), La Constitución del Reich alemán(1919), Enmiendas a la Constitución de los Estados Unidos, Constitución de la República Española (1931), La Constitución italiana (1947), Ley fundamental de la República Federal de Alemania ( 1949), Preámbulos de las Constituciones francesa de 1958 y 1946, Constitución portuguesa de 1976, revisada por ley constitucional 1/82, Constitución española de 1978; 3. Textos internacionales: Declaración americana de los derechos y deberes del hombre (1948), Declaración Universal de Derechos Humanos (1948), Convenio europeo para la protección de los derechos humanos, Documentos de la organización de las Naciones Unidas relativos a los derechos de la mujer, Declaración de los derechos del niño (1959), La Carta social europea (1961), Convenio internacional sobre la eliminación de todas las formas de discriminación racial ( 1963), Estatutos de la comisión interamericana de derechos humanos (1965), Pacto internacional de derechos civiles y políticos (1966), Pacto internacional de derechos económicos, sociales y culturales (1966), Protocolo facultativo del Pacto internacional de derechos civiles y políticos ( 1966), Convención americana sobre derechos humanos (1970).

(Daniel González Lagier) 
PECES BARBA MARTÍNEZ, Gregorio.

Los deberes fundamentales.

Doxa, Alicante, núm. 4, 1987, págs. 329-341.

Este artículo se divide en tres apartados. El primero: El origen histórico, trata del origen del concepto de deber. Este surge con una fuerte dimensión religiosa y no alcanza influencia decisiva en el Derecho hasta la modernidad, produciéndose en el siglo XVII su trasvase del ámbito moral al jurídico. El autor repasa la evolución del concepto desde la Roma clásica, destacando las transformaciones que experimenta con el iusnaturalismo racionalista y su tratamiento por autores como Hobbes y Kant, señalando cómo a partir del siglo XIX empieza a tomar cuerpo la idea de que los deberes jurídicos dependen de la existencia de una norma jurídica que los establezca y reflejando su positivación en las declaraciones de derechos y constituciones.

El segundo apartado: Concepto de deberes fundamentales, parte del concepto de deber jurídico como primer paso para determinar el concepto de deberes fundamentales. Se descartan «aquellas posiciones, como las del realismo escandinavo, que desvalorizan el concepto de deber jurídico» y se pretende estipular un uso para este concepto que sea válido para cualquier ordenamiento jurídico. Tras estudiar las definiciones de Bentham, Holmes, Kelsen y Hart el autor propone un concepto que reúna las siguientes notas:

1. «El deber jurídico existe con independencia de que el deber de que se trata haya tenido previamente o no una dimensión moral.»

2. «El deber jurídico tiene que estar reconocido por una norma perteneciente al Ordenamiento.»

3. «Normalmente los deberes jurídicos llevan aparejada una sanción en caso de incumplimiento y ésta consiste en una pena o en la ejecución forzosa a cargo de quien tiene ese deber (en el supuesto de que sea posible) o una indemnización en otro caso.»

4. «En la Teoría del Derecho a partir de Hohfeld, deber jurídico es correlativo de Derecho subjetivo y opuesto a libertad.»

Con todo ello, cabe estipular que los deberes fundamentales son «aquellos deberes jurídicos que se refieren a dimensiones básicas de la vida del hombre en sociedad, a bienes de primordial importancia, a la satisfacción de necesidades básicas o que afecten a sectores especialmente importantes para la organización y el funcionamiento de las instituciones públicas, o al ejercicio de derechos fundamentales, generalmente en el ámbito constitucional». Hay que destacar que «a diferencia de los derechos fundamentales, cuya raíz ética previa (la moralidad de los derechos fundamentales) es evidente, los deberes fundamentales son, en ocasiones, consecuencia de la convención y del ejercicio del poder soberano, titular de la producción normativa».

Por último, en el tercer apartado: El contenido de los deberes fundamentales, se examinan algunos: los deberes del poder político, instituciones y operadores jurídicos de salvaguardar la libertad y la igualdad y el deber de los ciudadanos de obedecer al Derecho (deberes recíprocos que pueden fundamentarse en una construcción racional desde posturas contractualistas, según el autor); los deberes «que se basan en razones de organización del Estado para subvenir en la satisfacción de necesidades o para la realización de funciones públicas, y que por su importancia son recogidos en la Constitución o en leyes que encuentran su fundamento en una norma de producción recogida en la Constitución» (son los deberes de función, como los de función de jurado y el deber de voto, y los 
deberes de prestación general y prestación especial, como los de servicio militar y los derivados de los cargos de funcionario, juez, etc., respectivamente); y los deberes fundamentales de los ciudadanos o de los poderes públicos que son correlativos con la existencia de derechos subjetivos (como el de respeto por los derechos fundamentales).

González Lagier)

(Daniel 
PECES-BARBA MARTÍNEZ, Gregorio.

Los valores superiores.

Anuario de Filosofía del Derecho, Madrid, núm. 4 (Nueva Época), 1987, págs. 373-388.

El presente texto se estructura en cuatro apartados. El primero nos introduce en la materia que será desarrollada en los apartados siguientes: nos plantea el problema de la integración de los valores en normas que parece realizar nuestra Constitución y propone un análisis del artículo 1.1.

El apartado II estudia el contenido del artículo 1.1. de la Constitución española, destacando las siguientes notas del mismo: la justificación pactista del poder; la configuración del poder como «Estado social y democrático de Derecho»; la plasmación de un sistema de valores (libertad, justicia, igualdad y pluralismo político); la consideración del sistema jurídico como técnica de realización de tales valores.

Considera el autor que el artículo 1.1. de nuestra Constitución hace compatible «el punto de vista normativista sistemático y el de los criterios de moralidad o de justicia, en la tarea de acotar y de independizar el fenómeno jurídico». En este sentido este artículo supone:

«1. Una teoría de la justicia no iusnaturalista, sino que propugna la positivización de una moralidad, con un fundamento histórico y racional suficiente en el mundo moderno y que se concentra en los valores superiores.

2. Una teoría de la justicia no positivista, puesto que no deja en libertad al órgano supremo de producción del Derecho para la construcción voluntarista de un sistema de valores del Ordenamiento jurídico.

3. Una teoría del Derecho basada en el sistema, pero que no reduce el sistema a su dimensión formal -modelo kelseniano-, sino que incorpora elementos materiales como básicos para la construcción de ese sistema.

4. Una teoría del Derecho que incorpora principios, pero que no tiene que ser tópica y problemática, sino que puede ser sistemática.»

El apartado III estudia también este artículo desde la perspectiva de norma localizada en el conjunto del ordenamiento jurídico, llegando a las siguientes conclusiones:

a) En cuanto norma pueden hacerse las afirmaciones siguientes: el lenguaje que utiliza es descriptivo, no prescriptivo; se trata de una norma que define los contenidos del Derecho español (es una norma definitoria, según la clasificación de Von Wrihgt); supone la positivización de los fundamentos éticos de un sistema político a través de su ordenamiento jurídico; posee una relación de totalidad en relación con el sistema jurídico.

b) Desde el punto de vista sistemático y global el autor califica la filosofía jurídica que subyace en el artículo 1.1. de normativismo corregido, porque incorpora una dimensión material a la norma básica del ordenamiento, con lo que supera al normativismo formalista.

En el apartado IV se estudia el problema de la interpretación de los valores superiores. El autor sostiene que los valores superiores poseen un núcleo central fruto de la tradición histórica y de la reflexión racional y que «en la interpretación de los valores superiores en el proceso de creación y aplicación del Derecho, deberá contar con ese núcleo central de sentido, tanto en el Derecho legal como en el Derecho judicial». Partiendo de esto, señala «algunas de las dimensiones más relevantes 
de la interpretación de los valores superiores del artículo 1.1.».

(Juan Sala Puche)

PEIDRÓ PASTOR, Ismael.

Aplicación al campo jurídico de las ideas de persona, personeidad y personalidad de Zubiri.

Anuario de Filosofía del Derecho, Madrid, núm. 4 (Nueva Época), 1987, págs. 523-537.

Sólo desde la perspectiva filosófica es posible llegar a un concepto unitario de la persona y de la personalidad jurídica, así individual como colectiva. Es el objetivo de este trabajo. Es más, sólo desde esa perspectiva cabe explicar la evolución de los distintos sistemas jurídicos vigentes en orden a la regulación de la personalidad de los entes colectivos. En el campo de la Ciencia jurídica las diversas teorías que se ofrecen para explicar la realidad de estos últimos, no han hecho otra cosa que destacar alguno de sus aspectos, pero no han llegado a descubrir la esencia de esa «realidad social viva», que es la persona colectiva.

Desde el punto de vista de su «inteligencia sentiente», síntesis del sentir y del razonar del hombre, Javier Zubiri ha configurado al hombre como un animal que aprehende lo real como real y siente lo real en impresión. «Aprensión sentiente y aprehensión intelectiva -dice- son momentos de un solo acto de aprehensión sentiente de lo real.» Por otra parte el hombre vive por sí y se siente un «autós», es alguien que se «autoposee». Por esto es «persona», es decir, una «suidad real», con dos momentos: a) el de realidad de suyo; $\mathrm{y} b$ ) el de contenido autonomizado. Aspectos interno y externo de la persona, respectivamente. La persona es una «realitas in essendo». Como tal realidad, cabe considerarla en sí misma desde su origen hasta su final, y es lo que Zubiri denomina «personeidad»; y también cabe considerarla como realidad que va siendo a lo largo de su existencia, que Zubiri llama «personalidad». Y así, dice este filósofo, como personeidad siempre soy el mismo, pero como personalidad no siempre soy lo mismo. Depende de mis decisiones en el campo de mi actuación social.

Si como sostiene hoy buena parte de la doctrina jurídica, el Derecho es un «elemento personalizante», porque en la vida social consolida la continuidad de la persona; y por otro lado, no existe mejor base para fundamentar los derechos humanos que el reconocimiento jurídico de la dignidad de la persona, es obvio que interesa llegar a una concepción unitaria del problema de la personalidad jurídica, en base a estas dos cuestiones: primera, ¿quién es persona jurídica?; segunda, ¿por qué es persona jurídica un ente colectivo? A desarrollar ambas cuestiones se dedica este trabajo, no sólo desde el punto de vista doctrinal, sino también con referencia al Derecho vigente español y europeo que se citan.

(Ismael Peidró Pastor)

PÉREZ LUÑO, Antonio Enrique.

El Defensor del Pueblo en Andalucía. 
En el vol. col. El parlamento de Andalucía, ed. Tecnos, Madrid, 1987, págs. 295-334.

Pese a que el trabajo persigue como finalidad principal el dar cuenta del marco normativo y de la actividad desarrollada (law in action) por el Defensor del Pueblo Andaluz, tal análisis se encuadra en una visión global sobre los orígenes, estructura y funciones de Ombudsman. Fiel a este planteamiento general se traza una aproximación histórica a los precedentes hispanos de la institución, con especial referencia a sus presuntas concomitancias con el Justicia Mayor de Aragón y con diversas magistraturas de Al-Andalus en la etapa musulmana. Asimismo, se enjuician los avatares que contribuyeron a la formación histórica del Ombudsman en el Derecho sueco. El estudio pone también de relieve la importancia actual de los Ombudsmen existentes en el Derecho comparado con competencias ratione loci (internacionales, nacionales, regionales y locales) y ratione materiae (judiciales, militares, de los consumidores, antitrust, defensores del administrado frente a abusos informáticos... ). Se pone, de este modo, de relieve la importancia de la institución como cláusula de garantía de las libertades y se avanza un balance prospectivo de su futura relevancia como mecanismo de tutela de los derechos fundamentales en España y, en particular, en la Comunidad Autónoma Andaluza. 
PÉREZ LUÑO, Antonio Enrique.

Implicaciones socio-jurídicas de las tecnologías de la información.

En el vol. col. IV Encuentro sobre implicaciones socio-jurídicas de las tecnologías de la información, Fundación Citema, Madrid, 1987, págs. 139-156.

Las repercusiones de las nuevas tecnologías de la información van mucho más allá del plano teórico de la interacción entre los modelos o sistemas operativos de la cibernética y explicativos de la sociedad. Es evidente que el aspecto que hoy suscita mayores expectativas, pero también mayores recelos, es el referido al impacto de las modernas tecnologías en los aspectos más directamente relacionados con la praxis humana.

La preocupación prioritaria de nuestra época se centra, por tanto, en los denominados «análisis de impacto social»o «evaluación de costes y beneficios de la tecnología» expresiones equivalentes a la ya popular terminología anglosajona del technology assessment, o de sus versiones germanas de la Evaluationsforschung o de la Wirkunsgsforschung. En realidad lo que se conoce bajo tales denominaciones no pasa de ser una amalgama heterogénea de iniciativas aisladas que obedecen a métodos de análisis y objetivos muy dispares. Resulta, por ello, perentorio un análisis global y totalizador de los fundamentos teóricos y prácticos de esa actividad evaluatoria.

Acotar los campos en los que se hace patente el impacto tecnológico es tarea ardua, porque prácticamente son todos los sectores del quehacer humano individual y social los que se hallan, en mayor o menor medida, afectados. Además resulta también difícil cuantificar la intensidad de esas repercusiones en sectores diferenciados, por su propio carácter global e interdependiente. No en vano la Revolución tecnológica ha convertido a la sociedad humana en un sistema mundial integrado que depende vitalmente de una trama orgánica de interconexiones e interdependencias.

En este trabajo se analizan estas cuestiones desde dos planos: las aportaciones que del impacto de las nuevas tecnologías se derivan en los planos ecológico, económico, político y socio-jurídico; y correlativamente sus riesgos y medios para prevenirlos o resolverlos.

(Carmelo Gómez Torres)

PÉREZ LUÑO, Antonio Enrique.

Informática y derechos fundamentales.

En el vol. col. Derecho Informático (Actas de las Primeras Jornadas Nacionales), Asociación de Escribanos del Uruguay \& Colegio de Abogados del Uruguay, Montevideo, 1987, págs. 119-136.

Las amenazas que se derivan de determinados abusos en la utilización de la tecnología informática han propiciado un movimiento de la doctrina jurídica y de la jurisprudencia de los países más avanzados tendente a la consagración de la libertad informática o del derecho a la autodeterminación informativa. 
Tales derechos se presentan como una respuesta al fenómeno de la «contaminación de las libertades», término con el que algunos sectores de la teoría social anglosajona aluden a la erosión y degradación que aqueja a los derechos fundamentales ante determinadas agresiones de las nuevas tecnologías. En este trabajo se analizan las disposiciones normativas, decisiones jurisprudenciales y aportaciones de la doctrina más recientes que permiten trazar las pautas generales de la estrategia jurídica actual de tutela de las libertades frente a las injerencias informáticas. Se esbozan, al propio tiempo, propuestas para una equilibrada coexistencia del progreso tecnológico y la protección de los derechos fundamentales.

PÉREZ LUÑO, Antonio Enrique.

La tutela jurídica del «software».

Novática. Revista de la Asociación de Técnicos de Informática, vol. XIII, núm. 71, 1987, págs. 7-11.

De entre los nuevos problemas que la informática plantea al jurista tienen hoy especial importancia los que hacen referencia a la protección del soporte lógico o software. En este trabajo se analizan los distintos instrumentos aportados para conformar el marco jurídico regulador del soporte lógico. Se analizan, en primer término, los mecanismos de protección jurídica genéricos: responsabilidad civil extracontractual, normas sobre la competencia desleal, o sobre la tutela del secreto industrial. Se exponen a continuación las ventajas e inconvenientes de la protección a través del derecho de patentes. Sucesivamente se alude a la proyección del régimen jurídico de la propiedad intelectual y, de modo particular, se hace una exégesis de las «Disposiciones tipo para la protección del software» promulgadas por la Organización Mundial de la Propiedad Intelectual en Ginebra en el año 1978. 
PÉREZ LUÑO, Antonio Enrique.

Rechtsphilosophie und Rechtstheorie in Spanien.

Rechtstheorie, núm. 3, 1987, págs. 313-334.

Este trabajo supone una reelaboración ampliada de la conferencia sobre el tema: La filosofia e la teoria del diritto in Spagna, pronunciada por el autor en la Universidad de Bolonia y que fue publicada por la «Rivista Trimestrale di Diritto e Procedura Civile», 1982, núm. 3, págs. 926-945. El texto actual parte de una exposición sobre los orígenes doctrinales e institucionales de los estudios de Derecho natural y filosofía del Derecho en las Universidades españolas. Se analizan, de forma más detenida, los avatares y principales corrientes de pensamiento que marcan el devenir de estos estudios en el siglo pasado. El artículo se concluye con una panorámica de las principales tendencias teóricas y de investigación que se han ido sucediendo en los últimos años. Se enjuician en este último apartado las principales manifestaciones del iusnaturalismo y el positivismo jurídico elaboradas en nuestro país, así como las más recientes orientaciones que pretenden situar el estudio de la filosofía del Derecho en los parámetros actuales que delimitan, a escala internacional, el status científico de la disciplina. La conclusión a que se arriba propende a un equilibrio entre las nuevas orientaciones y la tarea de reconstrucción de los aspectos más válidos de la tradición iusfilosófica hispana.

PÉREZ LUÑO, Antonio Enrique.

Sobre la igualdad en la Constitución española.

Anuario de Filosofía del Derecho, Madrid, núm. 4 (Nueva Época), 1987, págs. 133-151.

La igualdad es una de las piezas clave informadoras de la Constitución española de 1978. Sin embargo, el hecho de que la igualdad haya sido una de las categorías invocadas con mayor frecuencia en nuestra incipiente experiencia jurídico-constitucional no implica que exista acuerdo pacífico sobre su significado y alcance. En este trabajo se intenta precisar el sentido de la igualdad a partir de su relación con la idea de la justicia; examinándose asimismo el papel de la igualdad como regla y contrarregla y sus acepciones inmanente y trascendente. Se pasa luego revista al significado normativo de la igualdad en el texto de la Constitución española de 1978. Se analizan aquí sucesivamente los cometidos de la igualdad en cuanto valor constitucional, principio del ordenamiento jurídico y norma específica concretada en el derecho fundamental a la igualdad. En relación con este último papel asumido por la igualdad, en este artículo se opta decididamente por la admisión de la igualdad como derecho, frente a las tesis que impugnan tal posibilidad.

PÉREZ LUÑO, Antonio Enrique. 
Concepto y concepción de los derechos humanos. (Acotaciones a la ponencia de Francisco Laporta.)

ATIENZA, Manuel, y RUIZ MANERO, Juan.

A propósito del concepto de derechos humanos de Francisco Laporta.

LAPORTA, Francisco.

Respuesta a Pérez Luño, Atienza y Ruiz Manero.

Doxa, Alicante, núm. 4, 1987, págs. 47-77.

Este conjunto de artículos recogen una polémica suscitada a propósito del trabajo de F. Laporta Sobre el concepto de derechos humanos (ver reseña en el núm. 5 de Doxa).

El artículo de Pérez Luño se estructura en torno a la distinción de Dworkin entre concepto (que alude al significado teórico y general de un término) y concepción (que hace referencia a la forma de llevar a la práctica un concepto). Así, en primer lugar, el autor, tras realizar un cuadro de las distintas vías de acceso posibles a la delimitación conceptual de los derechos humanos, pone de manifiesto que la ponencia entraña una definición explicativa. En segundo lugar, se detiene en la concepción de los derechos humanos que se trasluce en la Ponencia. Por un lado, alude a la inspiración en el modelo iusnaturalista que se hace patente en las siguientes ideas: $a$ ) la afirmación de que no hay que confundir los tipos de derechos con los tipos de protección normativa; b) la idea de que los derechos son algo anterior a las normas; y $c$ ) el distanciamiento de quienes mantienen que sólo puede hablarse de derechos en el marco de un sistema jurídico. Si bien Laporta no se sitúa a sí mismo dentro de la teoría iusnaturalista, sino en la órbita de los derechos morales, Pérez Luño considera que la tesis de los derechos morales supone una denominación nueva para aludir a las exigencias éticas implícitas en la noción de los derechos humanos, tal como tradicionalmente han sido entendidos desde la óptica iusnaturalista. En cuanto al método seguido por Laporta, escribe Pérez Luño: «Si respecto a la inspiración genérica de la Ponencia no tengo inconveniente en declarar mi conformidad sin reservas, éstas me comienzan a surgir al analizar el método a través del cual se vehicula su concepción de los derechos humanos. Pienso al respecto que para el acceso a esas instancias éticas previas el Derecho positivo el ponente se sitúa, consciente o incosncientemente, en un enfoque iusnaturalista duro o maximalista de marcada orientación eleática. Se trata, en efecto, de una orientación metódica que prima la dimensión sincrónica respecto a la diacronía de los derechos humanos, a los que pretende emancipar de sus condicionamientos históricos e institucionales.»

Las críticas de Atienza y Ruiz Manero se centran en torno a tres cuestiones: 1. el rechazo de Laporta a definir los derechos en términos deónticos; 2. algunas inconsistencias que se derivan de la posición adoptada por Laporta a propósito de la relación entre los derechos y los sistemas normativos; y 3 . las dificultades con que se encuentran algunos de los derechos humanos usualmente considerados como más básicos para satisfacer las exigencias de la concepción de Laporta.

Finalmente, Francisco Laporta replica, al tiempo que realiza algunas precisiones a su propia ponencia, a las criticas apuntadas en los artículos anteriores. 
PÉREZ LUÑO, Antonio Enrique.

Nuevas tecnologías, sociedad y Derecho. El impacto socio-jurídico de las N. T de la información.

Fundesco, Madrid, 1987, 154 págs.

En este libro se plantean sucesivamente diferentes cuestiones básicas relacionadas con el impacto socio-jurídico de las nuevas tecnologías:

¿Qué repercusiones mediatas o inmediatas van a derivarse de las nuevas tecnologías de la información en los sectores medioambiental, económico, social, cultural y político? ¿A través de qué instrumentos epistemológicos puede abordarse la conceptuación de la incidencia socio-jurídica de las nuevas tecnologías? ¿Cuál puede ser la influencia de las nuevas tecnologías en el procesamiento de la documentación de las ciencias sociales y de las fuentes de conocimiento jurídico? ¿Existen cauces jurídico-políticos que permitan orientar el proceso tecnológico hacia objetivos que conjuguen el progreso con la libertad? Los cuatro apartados que configuran el volumen constituyen otros tantos empeños encaminados si no a la solución sí, al menos, a propiciar un marco adecuado de análisis para estas apremiantes cuestiones.

La tarea de tasación crítica de las nuevas tecnologías se está realizando con interés creciente en los países más evolucionados. En España esta labor asume ahora el signo de un desafío inaplazable si queremos que la revolución tecnológica avance por derroteros propios de una sociedad libre y democrática. Sin embargo, el eco despertado entre nosotros por estas cuestiones ha sido escaso, lo que se ha traducido en un panorama bibliográfico con amplias oquedades que apremia colmar. Este libro se propone contribuir a ese empeño.

PÉREZ LUÑO, Antonio Enrique (editor).

Problemas actuales de la documentación y la informática jurídica.

(Actas del Coloquio Internacional celebrado en la Universidad de Sevilla, 5 y 6 de marzo de 1986), Tecnos \& Fundación Cultural Enrique Luño Peña, Madrid, 1987, 295 págs.

Esta obra se halla dividida en tres partes, que responden a los respectivos núcleos temáticos que sucesivamente se abordan:

1. La primera recoge las contribuciones más directamente vinculadas con el argumento central del Coloquio, o sea, con la problemática de los sistemas automatizados de documentación jurídica. Tras un planteamiento general sobre las aportaciones de la informática para la superación de la crisis de la documentación jurídica y la exposición de los principales sistemas (Antonio Enrique Pérez Luño), se estudian los problemas jurídicos de la información y la documentación(Vittorio Frosini), así como las implicaciones políticas de los sistemas automatizados de documentación jurídica (Spiros Simitis). Se exponen, a continuación, contribuciones referentes a algunas experiencias operativas tales como: la del Instituto para la Documentación Jurídica de Florencia (Costantino Ciampi); la Legal 
Philosophical Library (Enrico Pattaro y Giovanni Sartor); el sistema SABIBI(Ernesto García Camero) y el sistema UNAM-IURE de México (Enrique Cáceres Nieto). La sección se cierra con dos estudios centrados en la Universidad de Sevilla, referidos, respectivamente, a la problemática de la Biblioteca de la Facultad de Derecho (Arcadio Castillejo) y al soporte informático con el que se cuenta para acometer su informatización (Felipe Tudela).

2. La segunda parte del libro se halla integrada por trabajos que versan sobre cuestiones referentes a la informática jurídica y sus presupuestos lógicos. Se recogen aquí, dos importantes contribuciones lógicas, referida la primera a las relaciones entre filosofia del Derecho y lógica deóntica (Georges Kalinowski), en tanto que la segunda constituye una completa y rigurosa formulación de una metodología general para el análisis de la estructura lógica de los sistemas normativos, como presupuesto para su informatización (Miguel Sánchez-Mazas). Se insertan también aquí dos investigaciones iusinformáticas sobre: la informática jurídica legislativa (Josep Aguiló), y la propuesta de un thesaurus informatizado de la Constitución española (Rafael González-Tablas). Esta panorámica se completa con una sugerente exposición prospectiva sobre la organización del estudio de la informática en las Facultades de Derecho (Manuel Atienza).

3. Los trabajos que conforman la tercera parte abordan cuestiones de Derecho de la informática. Se insertan aquí una reflexión sobre el impacto jurídico de las nuevas tecnologías, con especial hincapié en el Derecho laboral (Wolfgang Däubler); un análisis de las nuevas categorías jurídicas innovadas por el Derecho informático, como el derecho a la autodeterminación informativa (Erhard Denninger); y un estudio sobre recientes proyectos de ley italianos para la defensa de datos personales (Mario Losano).

PÉREZ LUÑO, Antonio Enrique.

Razón e historia en la experiencia filosófica y jurídica de Guido Fassò.

Reason in Law, Milán, vol. I, 1987, págs. 47-61.

La reconstrucción del pensamiento de Guido Fassò se lleva a cabo a partir de su planteamiento de las relaciones entre la razón y la historia. Para ello, se parte de la tesis de que la concepción iusfilosófica del profesor Fassò se inserta en los esfuerzos rehabilitadores de la razón práctica que han caracterizado algunas de las más interesantes aportaciones teóricas de la filosofía actual.

$\mathrm{Al}$ propio tiempo se sostiene en esta monografía que una de las más valiosas contribuciones de Fassò a la historiografía de la filosofía jurídica es la de haber elucidado el papel de la función histórica del Derecho natural, en cuanto criterio básico de racionalidad práctica de la experiencia jurídica. Los escritos de madurez de Guido Fassò reflejan una preocupación constante por superar los prejuicios y lugares comunes que, en la cultura filosófica y jurídica contemporánea, han ensombrecido u ocultado el significado ético y la función política del iusnaturalismo; es decir, su valor permanente como exigencia para supeditar el mito, el arbitrio y el poder a la racionalidad. 
PÉREZ RUIZ, Carlos.

La argumentación moral del Tribunal Supremo (1940-1975). (Prólogo de Antonio E. Pérez Luño.)

Ed. Tecnos, Madrid, 1987, 310 págs.

Esta obra constituye un estudio crítico sobre las argumentaciones morales empleadas por el Tribunal Supremo durante el período franquista. El autor, tomando como base para su investigación el examen de 1.126 sentencias producidas por dicho órgano judicial durante tan dilatada etapa, realiza un riguroso análisis lingüístico y hermenéutico de esta importante documentación, indagando aquellos principios explícitos o subyacentes en un posible sistema moral que afecta tanto a las conductas públicas (políticas, económicas, laborales) como privadas (religiosas, familiares, sexuales) de los ciudadanos. El estudio, prologado por el profesor Pérez Luño, quien dirigió el trabajo de investigación que sobre esta misma temática presentó el autor para la colación del grado de doctor, aparece estructurado en ocho capítulos en los que, tras una breve introducción en la que expone la problemática general filosófico-jurídica que sirve de referencia para dicho estudio, trata de delimitar el objeto concreto de su investigación no sólo desde el punto de vista temático, sino también cronológico, adoptando como técnica de trabajo un método que es a la vez descriptivo, inductivo y analítico. A continuación, aborda en profundidad las argumentaciones morales, en relación con las conductas religiosas; con la actividad política, económica y laboral; en las relaciones jurídico-privadas; en relación con la conducta sexual y en relación con la familia. Por último, nos ofrece una síntesis de sus conclusiones más relevantes y culmina su documentado trabajo con un amplio índice de sentencias de jurisprudencia penal, contencioso-administrativa, civil y laboral, añadiendo asimismo una extensa bibliografía sobre el tema.

(Antonio Ruiz de la Cuesta)

PRIETO SANCHÍS, Luis.

\section{Ideología e interpretación jurídica.}

Ed. Tecnos, Madrid, 1987, 146 págs.

Como sugiere su título, esta obra tiene por objeto analizar la naturaleza que presentan las labores de interpretación y aplicación del Derecho y, en particular, constatar y reflexionar sobre la presencia de ingredientes morales, políticos y, en suma, ideológicos en la actividad de los juristas, especialmente de los llamados operadores jurídicos. El propio autor lo indica en la nota preliminar: «Ya nadie cree en la racionalidad de un legislador sin pasiones y, sin embargo, sorprende todavía la confianza que suelen tener los juristas en su ciencia y los jueces en su neutralidad.»

Tras una Introducción que pretende aclarar el significado que en la propia obra se atribuye a ciertas expresiones corrientes, como la de que «los jueces producen Derecho», ilustradas incluso con algún ejemplo, los dos primeros capítulos constituyen una aproximación crítica a lo que los propios juristas han pensado acerca de su trabajo. En concreto, el capítulo inicial describe el status del conocimiento 
y de la interpretación jurídica desde el iusnaturalismo racionalista hasta las corrientes irracionalistas de los años treinta: la escisión del horizonte jurídico entre un Derecho racional y un Derecho histórico en el siglo XVII; la incidencia del contractualismo y de la formación del Estado en ese esquema iusnaturalista; la casi perfecta unión entre voluntad y razóndel iluminismo; el paulatino desplazamiento del modelo racional desde la creación a la aplicación del Derecho que, a juicio del autor, señala el tránsito del iusnaturalismo al positivismo; las consecuencias del romanticismo jurídico; el deslizamiento irracionalista y voluntarista desde la escuela de Derecho libre a la teoría jurídica nacionalsocialista, etc.

El capítulo II presenta un carácter análogo, pero centrado en el pensamiento jurídico contemporáneo a partir de 1945. Un estudio crítico de las corrientes tópica, hermenéutica y retórica, a las que el autor quiere emparentar con el juez Hércules de Dworkin, se contrapone a la teoría de la interpretación del normativismo. El libro muestra sus simpatías por este último, si bien propone algunas correcciones. Seguidamente, la obra se adentra en el estudio de las «circunstancias y supuestos de la creación judicial del Derecho», que pretende ser una disección del razonamiento judicial típico, desde la cualificación provisional de los hechos e individualización de la norma hasta la decisión o fallo, pasando por la atribución de significado, los llamados métodos de interpretación, etc.

A la vista de los resultados, el capítulo IV propone una reformulación de la posición institucional del juez en el marco de un Estado de Derecho. Concebido como un «órgano de producción jurídica», se interroga acerca de sus diferencias con el legislador, de la legitimidad de sus decisiones y de los hipotéticos medios de control y crítica.

Por último, el capítulo V constituye una reflexión sobre «creación judicial, norma hipotética y regla de reconocimiento», es decir, sobre la posibilidad de mantener una imagen sistemática, y no necesariamente hermética, del orden jurídico una vez constatada la presencia de elementos morales o valorativos en el proceso de interpretación del Derecho; todo ello en diálogo con los planteamientos de Kelsen y Hart.

PRIETO SANCHÍS, Luis.

Sabuco y los pleitos (La crítica al derecho de un médico humanista de finales del siglo XVI).

Revista Al-Basit, Albacete, núm. 22 (segunda época, año XIII), 1987, págs. 169-176.

El trabajo forma parte de un número monográfico dedicado por la Revista Al-Basit a la figura de Miguel Sabuco, médico humanista natural de Alcaraz (Albacete) y autor de una curiosa «Nueva filosofía de la naturaleza del hombre, no conocida ni alcanzada por los grandes filósofos antiguos, la cual mejora la vida y la salud humana». La obra, en forma de diálogo entre tres pastores, se inscribe en la corriente educativa, preilustrada, antimonástica y antropológicamente optimista de muchos humanistas españoles, abordando las más diversas áreas del conocimiento y de la acción humanas, desde la naturaleza física y psíquica del hombre a los métodos agrícolas, pasando por la política, el Derecho y, sobre todo, la medicina.

El trabajo de L. Prieto pretende ser una breve introducción al conocimiento de un autor casi olvidado y, por lo demás, no excesivamente relevante en el ámbito de la filosofía jurídica del humanismo, cuyo 
tratamiento representa una mínima parte de la obra. Las ideas de Sabuco tampoco parecen muy originales ni desarrolladas, al menos en lo referente al Derecho, por lo que el estudio se centra de modo principal en una comparación entre el pensamiento del autor de Alcaraz y las aportaciones mucho más sólidas y elaboradas de Erasmo y Vives. Desde esta perspectiva, Prieto repasa brevemente la crítica humanista al Derecho Romano y a una ciencia jurídica esclerotizada, la polémica de la época acerca del honor y de los estatutos de limpieza de sangre, los deseos humanistas de modernización y simplificación del Derecho y de la práctica forense, su lucha en favor de la sustitución del latín por la lengua romance, etc. Por último, el estudio finaliza con una valoración general del humanismo jurídico de Sabuco desde la perspectiva de la filosofía jurídica contemporánea, indicando su relación con la tópica o la hermenéutica de nuestros días. 
PRIETO SANCHÍS, Luis.

Un punto de vista sobre la filosofía del Derecho.

Anuario de Filosofía del Derecho, Madrid, núm. 4 (Nueva Época), 1987, págs. 591-617.

El presente trabajo recoge con algunas modificaciones uno de los epígrafes de la «Memoria» en su día preparada por el autor para el concurso a la cátedra de filosofía del Derecho, y esta finalidad se aprecia inevitablemente tanto en el contenido como en la forma. En síntesis, pues, se trata de una reflexión sobre el sentido que en nuestra cultura jurídica y en la Universidad actual puede tener la disciplina de filosofía del Derecho, así como sobre las tareas que debe asumir.

En relación con el primer aspecto, se constatan las dificultades que ha de encontrar una asignatura crítica y de las tradicionalmente llamadas formativas en un ambiente de creciente tecnificación y abandono de la discusión ideológica, si bien, al mismo tiempo, se defiende su necesidad como contrapunto al carácter dogmático de los estudios jurídicos. Con todo, la filosofía jurídica no debe proponerse como objetivo lesionar el modelo de jurista técnico y operativo que hoy parece requerir el «mercado». Más bien al contrario, la reflexión filosófica ha de encontrar en ese modelo su punto de partida a fin de poner de relieve las insuficiencias, condicionamientos e implicaciones del trabajo dogmático y del mismo Derecho positivo.

Asumiendo esa dimensión crítica, tal vez la tarea más evidente e indiscutible consiste precisamente en la crítica de la dogmática, es decir, del modelo de conocimiento jurídico $\mathrm{y}$, estrechamente conectado, de la forma de aplicación del propio Derecho. No cabe duda que esta tarea de crítica del lenguaje puede aportar una cierta terapéutica de la que el saber jurídico parece estar necesitado. En este sentido, no se pretende deslegitimar la actividad del jurista, pero sí mostrar su auténtico carácter, obligándole a salir del confortable refugio de la justificación técnica y a buscar la posición que le corresponde entre los titulares de un poder de decisión.

Este lenguaje de segundo grado sobre el lenguaje de la ciencia del Derecho constituye, en opinión del autor, el primer capítulo de una tarea más amplia, la teoría del Derecho, cuya competencia se extiende a todo el lenguaje jurídico, desde el legislativo al doctrinal. Al margen de polémicas terminológicas, se sostiene que una teoría del Derecho emprendida desde la filosofía ha de situarse en un punto equidistante entre la ontología iusnaturalista y la dogmática positivista. En concreto, se comparte la perspectiva normativista, pero ésta no se considera incompatible con el estudio de los elementos empíricos que constituyen la base del sistema; es lo que se llama normativismo realista.

Finalmente, el trabajo se cierra con unas «Propuestas para una teoría de la justicia», que el autor reconoce como un arriesgado ejercicio de superación de las estrictas fronteras marcadas por el rigor analítico. Pese a ello, el objetivo parece irrenunciable, no sólo por una lealtad histórica a esa dimensión utópica que incorporó el Derecho natural, sino especialmente porque es aquí donde la filosofía del Derecho dirime su razón de ser como reflexión crítica sobre el orden jurídico positivo, como filosofía práctica. Tras recordar la saludable crítica de la falacia iusnaturalista y llamar la atención sobre la superficialidad de algunos planteamientos éticos, el autor adopta como punto de partida la conocida teoría de la justicia de Rawls, pero propugnando una mayor sensibilidad hacia lo histórico-concreto, en la línea de las aportaciones de las escuelas de Francfort y Budapest. 
PUIGPELAT MARTÍ, Francesca.

Sobre la filosofía jurídica marxista española.

Crítica jurídica, México, núm. 5, 1987, págs. 27-42.

La finalidad de estas páginas, dice la autora, es «examinar cuáles son las aportaciones españolas de orientación marxista en el ámbito de la filosofía del Derecho», entendiendo, a este respecto, que «en nuestro país, aun cuando algunos juristas puedan estar de acuerdo con el carácter ideológico del Derecho burgués, sólo en la obra de Juan Ramón Capella se vislumbra un intento de reconstrucción de una teoría del Derecho basada en su carácter clasista e ideológico».

El artículo se centra, pues, en la obra de este autor. En primer lugar, la autora realiza un bosquejo de la biografia académica e intelectual de Capella; a continuación, estudia críticamente el tratamiento que Capella hace de los dos siguientes temas: 1. El Derecho como instrumento del dominio de clase; 2. la crítica de la ideología jurídica.

1. El concepto de Derecho del que parte Capella prima el aspecto formal, es decir, el de norma. Capella entiende que el Derecho se compone de «aquellas normas refrendadas por una sanción consistente en el uso de la fuerza ejercida socialmente o socialmente aceptada». Ahora bien, el poder de coacción no lo detenta la sociedad como un todo, sino el poder político, separado de la sociedad. Acepta este autor la tesis de que en la etapa de transición a la sociedad sin clases «es necesario el Derecho para acabar con el Derecho». Este Derecho será, en su opinión, todavía desigual, puesto que servirá para distribuir proporcionalmente el producto social. La distribución ha de utilizar como criterio de medida el trabajo, pero sólo en la medida en que facilita la creación de las condiciones requeridas para un modo de distribución según las necesidades y corregido de manera que todos los miembros de la sociedad reciban aquella parte del producto social que permita satisfacer sus necesidades mínimas no alienadas.

También se ocupa Capella de mostrar por qué la socialización de los medios de producción en la URSS no ha acabado con la explotación clasista, considerando que la manera de evitar el surgimiento de una clase de burócratas se encuentra en la socialización del saber, es decir, de los medios de producción estrictamente intelectuales -alfabeto, saber organizativo...-, siendo insuficiente la socialización de los medios de producción materiales.

La autora informa también de los temas que interesan en la actualidad a Capella -los movimientos alternativos no vinculados necesariamente al marxismo: pacifismo, feminismo, ecologismo...-, entendiendo que el análisis de estos nuevos temas obligará al autor a replantearse algunas de las cuestiones anteriores, que se detallan en el texto.

2. Según Capella, los destinatarios del Derecho perciben el Derecho como el consenso voluntario de todos, lo que ocurre porque el Derecho responde, en líneas generales, a la lógica del sistema económico de la sociedad que organiza. No obstante «el Derecho no es una mera consecuencia de las relaciones económicas, puesto que éste emerge, precisamente, cuando la lógica de las relaciones económicas no es suficiente para el mantenimiento de la relación social». Por otro lado, el discurso de los juristas es también ideológico, porque considera al Derecho meramente desde el punto de vista interno y porque se convierte en un discurso de poder, y no meramente descriptivo, a través de la 
interpretación jurídica. A esto se añade la creación de tópicos, como el de validez de la norma.

Actualmente, Capella «intenta llevar a cabo una reflexión política alternativa» que parta de la constatación de la posibilidad de que la acción del propio hombre destruya la Humanidad.

(Daniel González Lagier)

PUY, Francisco.

El tópico de los «derechos humanos».

Revista General de Legislación y Jurisprudencia, Madrid, núm. 95, 1987, págs. 199-218.

Constituye el concepto de los derechos humanos uno de los conceptos con más largo tratamiento teórico en los últimos cuarenta años, mientras que el mismo tópico apenas ha merecido estudio retórico. Ante esta situación, el autor realiza tres reflexiones sumarias:

a) Todas las definiciones conceptuales llevan escondida la trampa tópica.

b) La existencia de la función tópica se suele reconocer como un hecho lamentable.

c) Empieza a verse ahora reconocido y valorado positivamente el tópico por su función retórica como arma dialéctica en favor de la causa androdikea.

Los dikeos actúan, cuando hay que interpretar los preceptos constitucionales o instrumentales que los positivizan, como simples tópicos que en cada caso se van eligiendo en función de los contenidos de ambas variables: el problema real a resolver, y el dikeo concreto de que se trate. Y esto que ya se reconoce, constituye un hecho positivo para la praxis, aunque complique la construcción teórica. Pero, a la larga, ésta también se ve enriquecida por los desarrollos retóricos.

Por tanto, parece ser lo más oportuno la colaboración entre ambas perspectivas metodológicas; o sea, entre el análisis conceptual, en sede teórica, y la praxis tópica, en sede retórica.

Por cuatro vías se muestran así, según el autor, las posibilidades de una cooperación más dulce y fructífera, entre la teoría y la tópica dikea, a saber:

a) La afinación del método propio de los dikeólogos.

b) La definición y clasificación de los dikeos.

c) La justificación (defensiva o agresiva) de los dikeos.

d) Y la lucha por la realización y efectividad de los dikeos.

De las consideraciones correspondientes a esos análisis, el autor concluye que la evanescencia del concepto teórico de los derechos humanos se puede deber al hecho de que es un tópico enormemente fluido y lubrificante, por el incré́ble juego de siete variables, que se pueden recoger numeradas en la siguiente hipótesis de definición conceptual (obtenida por método tópico, y no teórico, y por eso tan distinta de las que se alcanzan por la vía usual):

Los derechos humanos son el discurso (1) del esclavo (2) para ante el señor (3) con una súplica (4) de conservación (5) y una amenaza (6) de suicidio (7).

Las definiciones teóricas sólo suelen hacer sustituciones para cada uno de esos siete valores, creando la ilusión de que lo que se define tiene un valor universal e intemporal, que es sólo eso, una ilusión convictiva de valor retórico. 
PUY, Francisco.

Guía da Filosofía do Dereito.

Imprenta Paredes, Santiago de Compostela, 1987, 52 págs.

El libro comprende un prólogo, un programa de Derecho natural, otro de filosofía del Derecho y una guía de la jurisprudencia doctrinal gallega.

En el prólogo se explicitan los cambios realizados sobre la edición anterior, a saber: supresión de los apartados referentes a los cursos de doctorado, a los seminarios y a las reglas para las evaluaciones; y la modificación de los tres apartados que permanecen.

El programa de Derecho natural se concentra en la temática de los derechos humanos, de la que se ofrece una panorámica en elenco, siguiendo el orden de los derechos económicos, los culturales, los sociales, los civiles y los políticos. Contiene una bibliografía puesta al día.

El programa de filosofía del Derecho se especifica como una Tópica Jurídica, alrededor de cinco series de tópicos: lógicos, físicos, metafísicos, antropológicos y políticos. También contiene una bibliografía actualizada sobre tópica y retórica jurídica.

La parte más enriquecida es la correspondiente a la jurisprudencia gallega. Contiene cuatro epígrafes: introducción a la jurisprudencia gallega; cuestionario fundamental para la realización de los informes escritos sobre cada jurisprudente; instrucciones para la operación del cuestionario; y bibliografía actualizada sobre historia del pensamiento gallego en general y en particular sobre el social y jurídico. Las instrucciones constituyen una detallada normativa metodológica perfectamente extensible a cualquier otra investigación de campo con dificultades de localización de manuscritos, ediciones raras y consiguientes problemas de ordenación de datos y depuración de errores, repeticiones, etc.

PUY, Francisco.

Las fórmulas del principio de igualdad.

Anuario de Filosofía del Derecho, Madrid, núm. 4 (Nueva Época), 1987, págs. 89-110.

Una análisis de las fórmulas del principio de igualdad que pueden encontrarse en la normación, en la jurisdicción y en la jurisprudencia, arroja un saldo de 124, suficientemente distintas entre sí, como para no poderse considerar iguales.

El autor considera más representativas las siete siguientes:

$1 .^{\text {a) }}$ El goce de los derechos humanos y de las libertades fundamentales ha de ser asegurado a todos sin distinción (instrumentos).

2. $\left.{ }^{a}\right)$ Toda forma de discriminación en los derechos fundamentales de la persona debe ser vencida y eliminada (doctrina social católica).

3. ${ }^{\mathrm{a}}$ ) Los poderes públicos promoverán las condiciones para que la libertad y la igualdad del individuo y de los grupos en que se integra sean reales y efectivas y removerán los obstáculos que lo 
impidan o dificulten su plenitud (ley fundamental española).

4. $\left.{ }^{\mathrm{a}}\right)$ Se protegerá contra toda discriminación a aquellas personas que se encuentran en una situación análoga (tribunal europeo de derechos humanos).

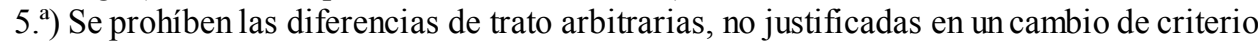
que pueda reconocerse como tal criterio (tribunal constitucional español).

6. $\left.{ }^{a}\right)$ A menos que exista una razón reconocida como suficiente por algún criterio identificable, un ser humano no debe ser preferido a otro (jurisprudencia extranjera).

7. $\left.{ }^{\mathrm{a}}\right)$ Trata igualmente a todos aquellos sobre los que no puedas establecer distinciones justificadas (jurisprudencia española).

El autor, por su parte, imagina otras tres fórmulas posibles, siguiendo tres modelos tradicionales, a saber:

8. ${ }^{\text {a }) ~ O b r a ~ d e ~ t a l ~ m a n e r a ~ q u e ~ t u ~ t r a t o ~ t i e n d a ~ a ~ n i v e l a r ~ a ~ l o s ~ i n f e r i o r e s ~ p o r ~ e l ~ r a s ~ d e ~ l o s ~}$ superiores (patrón imperativo categórico).

9..$^{\text {) }}$ Trata a todos de la misma manera (modelo tria praecepta iuris).

10. $\left.{ }^{a}\right)$ No discriminarás (modelo decálogo).

Finalmente, el autor afirma que el principio de igualdad, además de un concepto científico-jurídico, es un tópico filosófico-jurídico. Así que la noción de igualdad es, además de un concepto científico, un tópico especulativo. Pero el principio de igualdad, por ser un principio, o regla o norma, además de una proposición lógica, es un tópico práctico. Y como todos los tópicos prácticos consiste en una regla prejudicialmente aceptada, acríticamente admitida, que motiva, sin discusión u objeción previa, al que lo escucha a la ejecución de lo que se le manda en su nombre, y/o a la aceptación de lo que los otros hacen en su virtud, aunque una u otra cosa conlleve perjuicios o molestias para el sometido a su influencia. Y así es como, por la vigencia sociológica del principio de igualdad, se produce el milagro de que el prepotente ceda parte de su potencia al impotente, y éste deje de serlo. El trabajo termina con un análisis de las razones que explican la causa de tan insólito efecto.

PUY, Francisco.

Perspectivas actuales de la filosofía del Derecho.

Anuario del Centro Asociado de la UNED de Málaga, Málaga, núm. 1, 1987, págs. 193-202.

La filosofía del Derecho de ahora mismo, ¿cómo se entiende? Pues bien, todo el que pregunta a un iusfilósofo -viva voce o buceando sus escritos- busca la aclaración de un concepto jurídico, del que conoce un aspecto, pero ignora otros, cuando necesita una visión global. Global en el tiempo. Por tanto, también en su decurso histórico. Global en el espacio. Por tanto, también foránea a la propia cultura nacional. Y también, y sobre todo, global en el sistema. Y por ende, común a las diversas ramas teóricas de las ciencias jurídicas. De ahí que la filosofía del Derecho haya sido, sobre todo, en la modernidad, intento de realización de un sistema filosófico, o sea, teoría general.

Tal intento ha dado magníficos resultados y siempre los seguirá proporcionando. Pero desde Kelsen ha perdido su mayor interés. Su teoría pura del Derecho ha agotado, puede decirse, el método teórico sistemático en el puro logicismo o en la disputación intraescolar. Por eso no me interesa ya apenas y 
prefiero hacer menos teoría del Derecho, haciendo en su lugar retórica o tópica jurídica. En esta opción supongo que hay algo de interno irracional y de influencia céltica ambiental. Pero hay también una convicción fruto de la propia experiencia didáctica y heurística.

La experiencia en cuestión es percatarme de que el que pregunta al filósofo del Derecho por un concepto, parece que sólo está preguntándole por un concepto, pero en realidad hace otra cosa. Pregunta por un tópico. Y no es lo mismo. Porque el jurista que acude al iusfilósofo lo que busca es argumentos para sacar adelante la interpretación que conviene a los intereses -propios o de su cliente-, cuya defensa le ocupa, del término cuya intelección parece indagar con angelical curiosidad. No hay tal. Los juristas no tienen nunca (como juristas) curiosidad teórica. Tienen urgencias prácticas. Les trae sin cuidado la teoría general del Derecho y en ella sólo buscan munición o armamento retórico. O sea, tópicos con los que convencer al juez, al jurado, al árbitro... al decisor en suma.

El jurista que acude al templo de la iusfilosofía a orar, no busca la teoría general del Derecho por sus conceptos brillantes e inútiles. (Salvo el caso del jurista que ora ante el patrono pagano virginalmente novato). El jurista que ora ante el patrono pagano Iuppiter Stator o ante el patrono cristiano Jacobus Magnus quiere tópicos, retórica jurídica, para sus discursos retóricos o para sus combates dialécticos...

Por ello, y en lo que al contenido de la iusfilosofía se refiere, lo que conviene hacer hoy día es retórica jurídica más que teoría general del Derecho. Porque los juristas no necesitan de los filósofos para que les suministren conceptos -para eso ya tienen a los científicos-; sino para que les alimenten con argumentos extraídos de la historia filológica, de la historia sociológica, de la historia natural y de la historia sagrada. 
PUY, Francisco.

Santiago abogado en el «Calixtino» (1160).

Atti del Convegno Internazionale di Studi Pistoia e il Cammino di Santiago. Una dimensione europea nella Toscana medioevale. Pistoia, 28-29-30 settembre 1948. Edizione Scientifiche Italiane, Universitá di Perugia, 1987, págs. 57-92.

Un análisis de siete lugares en que Emerico Picouto, en su Calixtino de c.1160, invoca a Santiago como advocatus, y otras invocaciones paralelas, trata de contestar cinco cuestiones principales, a saber:

1. Santiago, abogado, ¿de quién?

2. Santiago, abogado, ¿contra quién?

3. Santiago, abogado, ¿en qué causa?

4. Santiago, abogado, ¿ante qué juez?

5. Santiago, abogado, ¿bajo qué forma?

La respuesta a esas cinco preguntas aclara algo, a su vez, lo que significa llamar «abogado» a Santiago en la Galicia del siglo XII. El autor sostiene, en resumen, las siguientes respuestas:

1. Los clientes de Santiago son los «gallegos», los «españoles» y los «occidentales», según los casos, y sólo ellos.

2. Santiago defiende a sus clientes frente a los demonios.

3. La causa de este abogado es siempre el juicio final individual de sus clientes, o el final general de sus pueblos.

4. El juez es la Trinidad en el juicio individual, y Cristo en el juicio final.

5. La normativa en fin está constituida por la ley cristiana, pero en una edición muy especial: la ley evangélica jacobea, que se expresa como luz de las costumbres de las Españas (Yspanias lux morum, dice el famoso himno Ultreya).

El autor subraya al final del trabajo algunas conclusiones, entre las que destacan las siguientes:

1. a) El Calixtino llama abogado a Santiago en un sentido jurídico riguroso y pleno (y no en un sentido metafórico o poético).

2.) El camino de Santiago lo han hecho siempre los gallegos, los españoles y los occidentales para tener asegurados los servicios de Santiago como abogado en el juicio final, contra el dominio, y así ganar la reivindicatoria del reino de los cielos.

3. a) El uso de invocar a Santiago como abogado, que refleja el Calixtino, tenía ya un par de siglos de antigüedad, como lo acredita la invocación como ahogada a Santa María en la oración de la Salve, compuesta por el obispo compostelano Pedro de Mezonzo (San Pedro de Mezonzo, santo por aclamación popular, que no por proceso técnico), el día terrible 12 de agosto del 997, mientras Almazor incendiaba y destruía la ciudad de Santiago... 
Los principios generales del Derecho en la jurisprudencia del Tribunal Supremo.

Ed. Dykinson, Madrid, 1987, 379 págs.

La presente investigación pretende mostrar, desde un punto de vista histórico, el proceso de generalización y aplicación de los principios del Derecho Romano desde su origen, referidos al caso concreto, hasta su canonización como regla jurisprudencial. El autor estudia la formación de los principios generales del Derecho en el Derecho Romano (el método romano de elaboración jurisprudencia de las máximas, reglas y axiomas, su casuismo, el sentido de las definitiones, distinctiones y divisiones, la analogía, la universalidad, etc.), las regulae iuris en la tradición jurídica española del «Derecho intermedio» y la etapa de la codificación, para desembocar en la redacción actual del Título Preliminar del Código Civil de 1974.

En opinión del autor, la ya vieja polémica acerca de si los principios generales del Derecho proceden del Derecho natural, del Derecho Romano o del espíritu de la propia ley escrita, resulta ociosa. En ella «se ha venido incurriendo en un constante error, que surge al intentar contemplarse esta cuestión desde una perspectiva general supranacional, y no individualizándola, en cada Estado». Al hablar de los principios generales del Derecho «nos movemos en el ámbito del Derecho positivo, donde no caben generalizaciones que traspasen la vigencia de los ordenamientos jurídicos en donde aparecen». Estos principios, según el autor, no son algo abstracto, que sirve de hilo conductor en la interpretación del sistema jurídico pero carentes de sustantividad positiva propia. «El que hoy, al menos en España, posean sustantividad propia, es algo que resulta evidente», pues desempeñan diversas funciones de Derecho positivo. Lo que sí puede indagarse es la procedencia de los principios generales del Derecho español, para lo cual «hemos de acudir a la jurisprudencia, que es su vehículo de expresión», trasladándose así el problema «desde la órbita teórica a otra sustancialmente práctica, y en la medida que es práctica lo es también objetiva». El autor se entregará, pues, a un minucioso estudio de numerosísimas sentencias del Tribunal Supremo posteriores a la promulgación del Código Civil, tras el que declara haber encontrado «una cantidad importante de principios que poseen una clara procedencia romana». «Este dato -afirma el autor- no hace más que evidenciar que el Derecho Romano es, y sigue siendo, Derecho positivo.»

En estas sentencias, por otra parte, «se observa que el principio actúa, en muchos casos, como norma imperativa, y no tan sólo como simple indicación o elemento interpretativo (...). De todas formas, hemos constatado que las reglas romanas se desenvuelven en su actuación positiva de varias y distintas maneras:

1. Mandatos u órdenes que se dan al juez para que los cumpla, como si de artículos del Código se tratase.

2. Principios que desarrollan su actividad en el campo de la interpretación y de la exégesis (entre los que cabe distinguir aquellos que pueden operar al aplicar cualquier precepto -porque de ellos parte todo el ordenamiento- y los que sólo sirven para interpretar casos concretos).

3. Principios a los que el Tribunal Supremo acude para justificar la creación de una doctrina en manifiesto contraste con la ley.

4. Por último, principios romanos «que poseen una gran carga de lógica deóntica y que permiten el permanente cotejo entre dos mundos, no siempre bien diferenciados: el ser jurídico y el deber ser jurídico»».

El autor también se ocupa de las condiciones para la aplicación de los principios, distinguiendo los 
requisitos exigidos por la ley (que el principio no contradiga a la ley; que sea susceptible de aplicación al caso; y que pueda considerarse como tal principio a la luz del Derecho Romano o de la tradición jurídica, o pueda ser deducido de la letra o del espíritu de la ley) y los que exige la jurisprudencia (un requisito de carácter material: que el principio haya sido reconocido en sentencias del Tribunal Supremo; y otro de carácter procesal: citar las sentencias que recogen tal principio).

El autor concibe el sentido de los principios generales del Derecho como «un freno de los fenómenos sociales reprensibles». «Los principios generales del Derecho conforman no sólo los cimientos, sino también la estructura tipo de un sistema jurídico dado, de manera que sus normas concretas obtendrán coherencia a la sombra de los principios sobre los que se construyen.»

(Juan Antonio Pérez Lledó)

RODRÍGUEZ PANIAGUA, José María.

Métodos para el conocimiento del Derecho.

Ed. Universidad Complutense, Madrid, 1987, 96 págs.

Se trata de una reedición parcial del libro Ley y Derecho, Madrid (Tecnos), 1976. Como los capítulos que se han suprimido son todos referentes a «conceptos fundamentales», el propósito básico, que se expresaba en el subtítulo, Interpretación e integración de la ley, sigue siendo el mismo. En concreto, los capítulos que se mantienen son: «Las lagunas del ordenamiento jurídico estatal», «Interpretación y aplicación de la ley», «La analogía jurídica», «Los principios generales del Derecho», «Las normas sociales como medio de integración de la ley» y «Las estructuras óntico-lógicas y la realidad en general como elementos de integración de la ley»».

En cada uno de ellos se expone lo que puede ser interesante para cualquier jurista, empezando por los alumnos de la licenciatura de Derecho, que son los que primordialmente se tiene en cuenta.

No se intenta, pues, llevar a cabo investigaciones personales, sino exponer doctrinas que se consideran ya aceptadas en un grado más o menos amplio. Es decir, no se trata de defender una determinada postura, ni tampoco de admitir en bloque determinadas teorías o escuelas, sino de recoger de las más conocidas lo que, a la vista de su aceptación y de los análisis más obvios, parece razonable.

Esta perspectiva es la que permite que se puedan considerar igualmente válidas estas páginas de un libro publicado once años antes.

Los autores más citados son: Bobbio, Engisch, Esser, Kelsen, Klug, Perelman, Welzel.

RODRÍGUEZ PANIAGUA, José M.

Rudolf von Ihering.

Anuario de Filosofía del Derecho, Madrid, núm. 4 (Nueva Época), 1987, págs. 249-270. 
El autor en el presente texto estudia el pensamiento de Ihering y, con este fin, se interesa por las siguientes obras:

1. El espíritu del Derecho Romano en las diversas fases de su desarrollo, en cuatro volúmenes, 1852, 1854,1858 y 1865.

2. La lucha por el Derecho, 1872.

3. El fin en el Derecho, en dos volúmenes, 1877 y 1883.

4. Jurisprudencia en broma y en serio, 1884.

Ihering, partiendo del concepto de Derecho como producto histórico, estudia la evolución del Derecho Romano con el fin de encontrar la esencia del Derecho («separar lo pasajero y puramente romano, de lo permanente y general»). Fruto de esto es la comprensión del origen del Derecho por medio de la idea de fuerza física, del poder. Junto a la fuerza física encontramos el poder moral y el sentido de la utilidad, cuyo motor es el egoísmo, como elementos configuradores del Derecho. Es la transformación del egoísmo individual en egoísmo colectivo lo que permite la transformación del poder físico en poder moral y entender la formación del Derecho. Dicho esto, desarrolla la idea de la libertad en el sistema romano.

Prosigue considerando como dato previo la independencia formal que adquiere el Derecho con el cambio de su forma de manifestarse: de usos sociales (forma no específica del Derecho) a la ley (manifestación específica del Derecho), con el estudio de los conceptos y del sistema. Ihering trata de definir los conceptos por su estructura, con intención de poder interrelacionarlos y formar un sistema («el árbol genealógico de los conceptos»). Pretende con esto una simplificación cualitativa y cuantitativa del Derecho.

Tras la crítica que el propio Ihering hace posteriormente a esta construcción logicista del Derecho, orienta su obra hacia la teleología, es decir, el estudio del fin en el Derecho.

Esta orientación se pone de manifiesto en su definición de derechos subjetivos como «intereses jurídicamente protegidos».

Ihering considera que «el fin es el creador de todo el Derecho». Intenta explicar, por tanto, el origen del Derecho por el fin que persigue. Entiende por fin las necesidades que intenta satisfacer la inteligencia humana, y aquéllas que son creadas a medida que se satisfacen las necesidades anteriores. Así, de lo que se trata es de «una explicación histórico-racional de la evolución del mundo moral». En este sentido se estudia la sociedad, el Derecho y la moral.

Sala Puche)

(Juan 
ROJO SANZ, José María.

Apuntes sobre el imperativo categórico y los derechos humanos (a propósito de recientes interpretaciones de Kant).

Anuario de Filosofía del Derecho, núm. 4 (Nueva Época), 1987, págs. 697-709.

La influencia del filósofo de Königsberg en la filosofía del Derecho actual es indudable, constituyéndose en muchos casos incluso como una «ideología popular» $\mathrm{y}$, en este estudio, la segunda formulación del imperativo categórico convierte el kantismo, como se ha afirmado entre nosotros, en una «incitación a ir más allá de él, al mismo tiempo que supone una conquista irrenunciable».

Este trabajo intenta desarrollar el valor de la dignidad humana y su necesaria consideración al referirnos a los derechos humanos como puntos centrales de la filosofía moral y jurídica de Kant, analizando los textos principales de la Eileutung in der Metaphysik der Sitten y de la Metaphysik der Sitten. Entre los autores citados destaca el estudio de Cattaneo, Dignità umana e pena nella filosofia di Kant.

Por otra parte, la Ilustración política es de una extraordinaria importancia cara a la positivación de los derechos humanos y su entrelazamiento con las ideas de libertad, igualdad y fraternidad.

La dignidad humana se expresaría a través de la consideración libre del otro, lo cual exige a su vez la consideración del respeto a la gravedad y al cuidado, permitiendo reconocer al otro ontológicamente libre e igual a uno mismo y no como un mero objeto in commercium. En efecto, la moralidad es entendida por Kant como sinónimo de libertad, al considerar como persona a aquel sujeto cuyas acciones son susceptibles de imputación. La personalidad moral no es, pues, sino la libertad de un ser racional bajo leyes morales. Frente al «precio» de las cosas, aparece la «dignidad» del hombre y la segunda formulación del imperativo categórico sienta las bases para poder rechazar cualquier atentado contra la vida e integridad humana. Incluso la segunda formulación del imperativo categórico se salvaría de la acusación de formalismo al hacer referencia a contenidos de preceptos morales: el respeto de la dignidad del hombre con la idea de fin como elemento central de su contenido, al tomar al hombre como fin en sí mismo. Parecería como si Kant comprendiese que la mera forma de ley no es suficiente para determinar actos conforme a la moralidad. Las aspiraciones jurídicas del hombre se derivarían de la existencia del hombre corporal en la multiplicidad de sus implicaciones mundanales e incluso en la limitación de la situación histórica de la época.

El artículo termina con un estudio de la coacción externa, la pena de muerte y la pena en general y sus implicaciones en relación con los derechos humanos.

ROJO SANZ, José María.

Libertad personal y libertad política en el pensamiento de Julián Marías.

Quaderns de Filosofia i Ciència, núm. 12, 1987, págs. 77-86. 
Este estudio consta de una introducción y un apartado titulado «Libertad personal y libertad política». En ellos se analiza el pensamiento de Julián Marías, en el contexto de toda su obra, respecto a las relaciones entre persona y Estado. Este es, para Marías, instrumento y función de la sociedad y debe «hacer posible la vida», sin decidir sobre su calidad y sentido último. En la constante amenaza hacia la disolución, reside la necesidad del Estado. Por ello, la misión auténtica del Estado residiría en ser el instrumento rector y ejecutor de la pretensión auténtica de la sociedad, teniendo que descansar aquél sobre la realidad social en sentido estricto, sobre las vigencias sociales: el repertorio de usos, creencias, ideas, estimaciones colectivas, proyectos compartidos, etc... que constituyen una sociedad. Sin embargo, la asunción por el Estado de funciones que corresponden normalmente al juego de «las fuerzas sociales», conduce al debilitamiento de estas fuerzas y a la decadencia de la sociedad, situación que tampoco favorecerla al Estado, pues conduce al debilitamiento de aquellas fuerzas y a la decadencia, convirtiéndose en una sociedad «no viable», producto de los diversos totalitarismos. Por otra parte, Marías, como es sabido, considera la vida humana como vida en libertad y ésta se da cuando se respeta la realidad, cuando no se la fuerza ni suplanta, cuando no se va más allá de lo que las cosas son. El ejercicio de la libertad vendría ayudado también por los materiales de la memoria, interpretados por la imaginación proyectivamente.

Por último, Marías explica cómo no basta con proclamar que el hombre es libre, sino que sólo es posible si existe una libertad política en sentido riguroso de democracia liberal, en el sentido que dicho autor confiere a estos términos. Hace falta, por ello, crear las «condiciones circunstanciales» de la libertad para que ésta sea efectivamente posible en una sociedad. La respuesta a una serie de preguntas que Marías se hace en su España real, serviría para dar una imagen bastante certera de qué libertad existe en una sociedad y de cómo se tratan los derechos humanos.

El artículo va acompañado de una exhaustiva nota crítica bibliográfica del autor con numerosas referencias para poder ampliar los conceptos clave acerca de este tema. 
ROMERO MOERNO, José Manuel.

Derechos fundamentales y relaciones entre particulares.

GARCÍA TORRES, Jesús, y JIMÉNEZ BLANCO, Antonio.

Réplica a José Manuel Romero.

Anuario de Filosofía del Derecho, Madrid, núm. 4 (Nueva Época), 1987, págs. 675-682.

Estos artículos recogen una polémica entre sus autores acerca de la «Drittwirkung», es decir, de la incidencia de los derechos fundamentales en el Derecho privado y en las relaciones jurídicas privadas. El origen de la polémica es la tesis sostenida por García Torres y Jiménez Blanco en su obra Derechos fundamentales y relaciones entre particulares, tesis a la que Romero Moreno critica $a$ ) en lo relativo a las consideraciones que hace al respecto de la orientación del Tribunal Constitucional sobre esta cuestión, $b$ ) en relación con la doctrina de la imputación a los órganos jurisdiccionales de la violación de los derechos fundamentales por deficiente protección, y $c$ ) en relación con el presupuesto ideológico que comporta la Drittwirkung.

El primer desacuerdo, señala Romero Moreno, es ya el punto de partida de los autores de que la autonomía de la voluntad y el libre desarrollo de la personalidad son conceptos opuestos a la Drittwirkung (para el primero «no puede haber real autonomía de la voluntad sin profundo respeto y protección de los derechos fundamentales en las relaciones particulares precisamente para evitar la insuperable primacía de la autonomía de la voluntad del más fuerte») y su «alineación» en la postura extrema de no admitir la Drittwirkung.

a) Por lo que respecta a la posición del Tribunal Constitucional, según Romero, los autores, que «se inclinan en principio por una posición muy abierta», acuden después a la jurisprudencia constitucional para «infiltrar la idea de que no todo derecho fundamental tiene Drittwirkung», cuando en su opinión «lo que en realidad hace la doctrina jurisprudencial alegada es matizar que existen aspectos o momentos de las declaraciones de derechos que no atribuyen derechos subjetivos a los ciudadanos. Pero esta característica juega no sólo en las relaciones entre particulares, sino también frente a los poderes públicos».

b) En relación con la doctrina de la imputación de la violación a los órganos jurisdiccionales se critica a los autores el que parecen no sólo estar disconformes con «la accionabilidad en amparo constitucional contra las violaciones de los derechos fundamentales en las relaciones jurídicas entre particulares», sino también e incluso en vía ordinaria, motivados por una «pulsión secreta» «en un sentido muy claro: es peligroso que los derechos fundamentales sean moldes de la sociedad, puesto que su papel es el ser solamente límites del poder político y que en relaciones jurídicas entre particulares la incidencia de los derechos fundamentales debe ser «obra del legislador, no del juez». c) Por último, cabe destacar de la crítica de Romero Moreno la afirmación de que la conclusión final de García Torres y Jiménez Blanco («no es posible amparo judicial ni constitucional de las violaciones de los derechos fundamentales de los ciudadanos producidos por otros ciudadanos en las relaciones jurídicas privadas; porque los derechos fundamentales sólo inciden en tales relaciones a través de la traducción normativa ordinaria del legislador») «no es el fruto de un irreprochable juicio 
técnico-jurídico o de política procesal de mantenimiento de las relaciones jurídicas», sino más bien de los presupuestos ideológicos de los que se ha partido, por lo que «se puede y a mi entender se debe partir de una hipótesis diferente y seguir un proceso dialéctico igualmente irreprochable que contuviera los mismos elementos positivos que el analizado, pero llegando a una posición y conclusión diferente». Esa hipótesis diferente sería la de que «los derechos fundamentales inciden en todas las situaciones y relaciones jurídicas por ser inspiradores del sistema jurídico total».

En su réplica, García Torres y Jiménez Blanco insisten, como idea central, en que pretender utilizar los derechos fundamentales como «troquel de las relaciones sociales es olvidar sus fundamentos y sus funciones $\mathrm{y}$, sobre todo, despreciar otros instrumentos de los que los poderes públicos pueden valerse y de hecho se valen para tender a "una distribución de la renta regional y personal más equitativa", como dice la propia Constitución».

(Daniel

González Lagier)

ROSS, Alf.

Autobiografía intelectual. (Introducción y comentarios de Rafael Hernández Marín.)

Anuario de Filosofía del Derecho, Madrid, núm. 4 (Nueva Época), 1987, págs. 273-277.

R. Hernández Marín nos presenta (conabundantes anotaciones explicativas y complementarias) el texto de una carta inédita fechada en 1976, en la que Ross, en respuesta a algunas cuestiones que Hernández Marín le había planteado, ofrece una visión muy resumida de la evolución de su propio pensamiento. Su primera obra relevante, Theorie der Rechtsquellen (1929), está claramente influenciada por el pensamiento jurídico de Kelsen, aunque Ross ya subraya las dificultades de Kelsen a la hora de explicar las relaciones entre la norma (idea) y la vida jurídica como hecho sociológico (realidad). Ante el rechazo de esta obra (en su versión original en danés) para la obtención del doctorado en Derecho por la Universidad de Copenhague, Ross se trasladó a Uppsala, donde Hägerström se convirtió en su segundo maestro, y obtuvo el doctorado en Filosofía con la traducción alemana de la obra anterior. Dedicado en estos años exclusivamente a la filosofía, Ross escribió, bajo la influencia de la teoría moral no cognoscitivista de Hägerström, Krtitik der sogenannten praktischen Erkenntnis (1933). En Virkelighed of Gyldighed i Retslaeren (1934) (traducción inglesa: Towards a Realistic Jurisprudence, 1946), Ross retomó los temas de los que se había ocupado en su primer trabajo y en su anterior obra filosófica (Kritik...), obteniendo el doctorado en Derecho por la Universidad de Copenhague. En dicha Universidad, ya como catedrático desde 1938, se dedicó durante los años siguientes a la docencia y a la investigación en Derecho Internacional y en Derecho Constitucional. Como profesor también de «General Jurisprudence», Ross escribió On Law and Justice (1953; versión inglesa: 1958), obra concebida como un manual para estudiantes, y también inspirada en las ideas de su Kritik... Su principal contribución al estudio del Derecho danés es su obra en dos volúmenes Dansk Statsforfatningsret (Derecho Constitucional Danés). Una vez retirado en 1969, Ross se ha ocupado principalmente de filosofía del Derecho penal, publicando, entre otras obras, On Guilt, Responsibility and Punishment (1975). 
Después de escribir On Law and Justice, y sobre todo, a partir de Directives and Norms, Ross recibe la influencia filosófica del grupo de Oxford (especialmente de Hare) y abandona la teoría emotivista de Hägerström. Sin embargo -según explica Hernández Marín en una de sus anotaciones-, aunque en conjunto Directives and Norms está inspirada en el prescriptivismo de Hare, conserva, a pesar de todo, residuos de la antigua teoría emotivista. Ello concuerda con la opinión del propio Ross cuando declara, a modo de conclusión: «Yo nunca he experimentado «conversión» alguna, sino que he sentido las diferentes fases de mi pensamiento como sucesivos pasos de una evolución continua.»

(Juan Antonio Pérez Lledó)

RUBIO CARRACEDO, José.

Democracia y legitimación del poder en Rousseau.

Revista de estudios políticos, Madrid, núm. 58, 1987, págs. 215-242.

El autor comienza el artículo situándonos en el contexto neocontractualista en el que se va a analizar el planteamiento legitimista por excelencia de Rousseau.

La primera parte («La construcción del Estado. De la ley natural a la razón normativa») constituye un análisis del constructivismo de Rousseau a través de la distinción de tres conductos normativos: «el hombre natural», «el hombre civilizado», $\mathrm{y}$ «el contrato social». El paso del primer modelo a alguno de los otros dos es obligado debido a su insuficiencia. El segundo modelo representa al contrato social abusivo frente al tercero, que es el modelo positivo, en el que se establecen «los principios del Derecho político». Planteado el contrato social como génesis normativa, ha de formularse procedimentalmente en estos términos: «Hay que encontrar una forma de asociación que defienda y proteja con toda la fuerza común la persona y los bienes de cada asociado, y por la que cada uno, al unirse a todos, no obedezca, sin embargo, más que a sí mismo y permanezca tan libre como antes.» En la segunda parte («Rousseau y la legitimación del poder»), el enfoque legitimista se expresa a través de dos ejes mayores: la dialéctica soberanía-gobierno y la crítica de la representación política. El objetivo en ambos es el mismo: «velar por la soberanía política de los ciudadanos y prevenir los abusos de poder». Respecto al carácter autoritario o romántico del modelo político de Rousseau, el autor sostiene que la clave reside en la interpretación del concepto de «voluntad general» como voluntad racional que excluye tanto el cognitivismo extremo como el voluntarismo estricto.

En la tercera parte («La interpretación kantiana de Rousseau») se exponen los principales aspectos de la relación Rousseau-Kant, así como las discrepancias, poniendo de manifiesto cómo «el ginebrino despertó a Kant a los nuevos problemas y enfoques, mientras que el regiomontano supo darles una respuesta original que, entre otros efectos, universalizó a través del idealismo alemán algunos aspectos básicos de su pensamiento moral y político».

En la cuarta y última parte ( «La crisis de la democracia representativa. Rousseau y la demanda de una democracia avanzada») se exponen distintas perspectivas actuales de crítica al sistema demoliberal, concluyendo que el problema no radica en el sistema democrático, sino en su insuficiente o desviada institucionalización. Asimismo, el sistema de partidos políticos resulta indispensable, pero urge su reforma y sobre todo institucionalizar políticamente otras asociaciones y facilitar realmente la 
información y la opinión pública.

(Ángeles Ródenas Calatayud) 
RUIZ MIGUEL, Alfonso.

Sobre la conexión entre ética y metaética. (A propósito de la Teoría de la Justicia de Norberto Bobbio.)

Revista de Ciencias Sociales, Valparaíso, núm. 30, 1987, págs. 97-118.

Este artículo pretende desarrollar algunos problemas sólo esbozados o anunciados en el libro del autor, Filosofía y Derecho en Norberto Bobbio, Madrid, Centro de Estudios Constitucionales, 1983, esp. cap. IV, $\S 22$.

De las dos partes en que puede diferenciarse la teoría de la justicia, la metodológica y la ético-normativa, Bobbio se ha ejercitado en una y otra. Ello, por un lado, aunque no haya construido una teoría acabada y sistemática, al estilo de la de Rawls, sino una aportación al modo de Kelsen, Ross o Hart; y, por otro lado, aunque tal aportación presuponga un concepto amplio de justicia, en conexión con la política, que es por lo demás el sentido en que hacen teoría de la justicia Rawls o Dworkin: por ello, en cuanto aportación ético-normativa, la teoría de la justicia de Bobbio ha de buscarse en su filosofía política.

La metateoría de la justicia bobbiana procede de una tajante dicotomización entre los juicios de hecho y los juicios de valor y una remisión de los juicios de valor últimos a emociones. Este no cognoscitivismo emotivista no ha conducido a Bobbio al decisionismo, al irracionalismo ético, sino que se ha apartado del emotivismo radical de un Pareto o un Ross, aceptando tanto la introducción de la razón deductiva para la derivación de juicios de valor secundarios (Hare) como el valor de la argumentación retórica (Perelman). No obstante, éstas son limitaciones a un emotivismo ético básico que en el campo jurídico se ha manifestado en una crítica decidida a toda forma de iusnaturalismo.

La teoría normativa de la justicia de Bobio se enuclea sin variación a lo largo de su obra en torno a la defensa de la democracia liberal, en el marco de una concepción socialista liberal, opuesta tanto al totalitarismo fascista como al comunista. La defensa de la democracia liberal como método frente a la teoría política marxista se basa en la dicotomía democracia-dictadura, entre las que no existe camino intermedio o tercera vía. En las relaciones internacionales, por su parte, Bobbio ha destacado el cambio cualitativo de las armas nucleares, sugiriendo la necesidad de una autoridad internacional. La metateoría no cognoscitivista y una teoría normativa de la justicia como la de Bobbio parecen no casar. Con independencia del plano pragmático, hay una incoherencia lógica, pues no se puede ser a la vez escéptico en ética y creyente en la superioridad del valor de la tolerancia y la libertad. Podría pensarse que la posición de Bobbio (como la de Kelsen o Russell) no es por completo escéptica, moviéndose entre el racionalismo y el arracionalismo, sino sólo relativamente escéptica. Pero eso no resuelve, ni intenta hacerlo, la tensión constante entre su metaética y su ética, como la han pretendido resolver muchos autores de la analítica anglosajona desde finales de los cincuenta mediante un relativo acercamiento, a modo de analogía, entre ciencia y ética, bien destacando los presupuestos dogmáticos y convencionales de la primera, bien atribuyendo un especial papel a la razón en la segunda. Este es un camino prometedor para superar el contraste entre ética y metaética: frente a algunas sólidas razones del escepticismo no cognoscitivista, que es una hipótesis, se puede alentar también la hipótesis de que el acuerdo ético es siempre posible mediante el razonamiento y el diálogo. Al menos, ésa es la hipótesis que parece más coherente para quien, como Bobbio, habla éticamente y desea un mundo más 
verdaderamente humano.

RUBIO CASTRO, Ana.

Teoría del Derecho y Derecho subjetivo en Alf Ross.

Anuario de Filosofía del Derecho, Madrid, núm. 4 (Nueva Época), 1987, págs. 279-302.

El presente estudio de la teoría jurídica de Ross parte de sus presupuestos filosóficos: el realismo de Hägerström, cercano al neopositivismo lógico. Respecto del problema de la posibilidad del conocimiento, «Hägerström se propone demostrar el error del subjetivismo epistemológico, el carácter lógico de la realidad sensible y la imposibilidad de la metafísica (...). Su tesis central es la independencia entre el acto de conocer y el objeto conocido». Para Hägerström, lo real es objetivo, determinado y lógico (el principio de no contradicción es una ley no sólo del pensamiento, sino también de la realidad). Afirmar de algo que es real significa afirmar que pertenece al contexto de la experiencia espacio-temporal, cuya realidad, a su vez, es un presupuesto que no admite prueba. De aquí interesan dos conclusiones: a) no tiene sentido lógico hablar de una realidad espiritual, ya que no puede ser conocida; $b$ ) los valores no son propiedades reales de los objetos, sino expresión de simples sentimientos. Desde esta reducción empirista, el realismo escandinavo pretende aportar una visión renovada de la realidad jurídica, frente a iusnaturalistas y positivistas: las normas jurídicas no tienen más existencia que la de operar, en un grupo social, como pautas de conducta generalmente admitidas como obligatorias (su realidad viene determinada por su efectividad).

A continuación, la autora expone las bases de la teoría jurídica de Ross, situándola en el contexto de las distintas etapas del realismo escandinavo. Ross pretende llevar hasta sus últimas consecuencias, en el ámbito jurídico, las tesis empiristas, tanto desde el punto de vista metodológico (sometiendo el conocimiento del Derecho a los patrones de observación y verificación de la ciencia empírica) como analítico (interpretando los conceptos jurídicos como modos de comprender el comportamiento del hombre en la sociedad). La autora resume aquí el concepto rossiano de Derecho válido (determinado por la conjunción de un elemento externo, su aplicación efectiva por los jueces, y otro interno o psicológico, que la norma sea sentida por el juez como socialmente obligatoria) y de ciencia jurídica (ciencia empírica constituida por aserciones que predicen que ciertas directivas son Derecho válido). Por lo que se refiere específicamente al derecho subjetivo, Ross lo concibe como «la realidad objetiva del Derecho, considerado de acuerdo a su alcance en cuanto a las posibilidades de conducta individual». Frente al dualismo del pensamiento jurídico anterior (el Derecho pertenece a la vez al mundo de los hechos empíricos y al metaempírico de las ideas externas de validez), Ross muestra el paralelismo entre el concepto de Derecho y el derecho subjetivo. El dualismo ha de ser disuelto mediante un análisis realista, reinterpretando el concepto de validez no como noción abstracta, sino como «vivencias de validez», racionalizaciones de ciertas experiencias emocionales pertenecientes al mundo de los hechos. Depurados de residuos metafísicos, los conceptos jurídicos fundamentales pueden recuperarse para la teoría y la práctica jurídicas. Así, en $T \hat{u}-T \hat{u}$, Ross asigna al derecho subjetivo una útil función sistemática de presentación de situaciones jurídicas complejas, aunque por sí mismo no represente ninguna realidad. Y en Sobre el Derecho y la justicia explicita las situaciones 
en que puede emplearse correctamente esta herramienta. Desde esta perspectiva, Ross rechaza la discusión tradicional entre la teoría del interés (Ihering) y la de la voluntad (Windscheid), así como la forma en que se ha trazado la distinción entre derechos in rem y derechos in personam.

El artículo concluye con algunas reflexiones críticas. La autora alude aquí, entre otras, a las críticas de Hart (imposibilidad de distinguir conductas regulares en el orden social de conductas reguladas por reglas; la distinción entre aspecto interno y externo no se cifra en la diferencia conducta/sentimiento, sino que alude a dos perspectivas para conocer el Derecho), pero sobre todo destaca que Ross debía haber profundizado en la función ideológica del derecho subjetivo, conectando las formas jurídicas con la realidad socio-política. «Los límites más importantes de la teoría jurídica de Ross proceden de su punto de partida, su empirismo, un empirismo corto de miras, hoy suficientemente superado, para quien la sociedad son individuos y relaciones individuales, la historia mera sucesión del tiempo y las luchas por el poder no adoptan ninguna forma determinada.»

(Juan Antonio Pérez Lledó)

RUS RUFINO, Salvador.

El problema de la fundamentación del Derecho. La aportación de la sofística griega a la polémica entre naturaleza y ley.

Universidad de Valladolid, Secretariado de Publicaciones, Valladolid, 1987, 236 págs.

El presente libro está dedicado a la dualidad entre physis y nómos en la sofística griega, dualidad que, según el autor, se agrava con sus teorías filosófico-jurídicas y políticas.

«En la primera sección ("physis") -escribe el autor en el prólogo- se propone una hipótesis sobre el significado de la physis en los primeros filósofos griegos. Dado que esta noción es inseparable de la aparición de la filosofía, se ha justificado la hipótesis a partir de la determinación del filosofar por contraste con otras modalidades sapienciales. El enfoque se ha mostrado útil en orden a la mejor caracterización de la sofística. Por otra parte, he intentado precisar la denominada crisis de la filosofía presocrática. La physis que puede considerarse el descubrimiento inaugural de la Filosofía Griega, después de Parménides se convierte en una noción problemática. Esta problematicidad consiste en el paso desde su captación a nivel abstracto a su formulación proposicional. Gorgias -como he demostrado en un artículo publicado- es un testimonio privilegiado de este problema. El punto de partida para la precisión del significado de la physis lo he encontrado en la propuesta epistemológica del Prof. Leonardo Polo, según la cual las operaciones mentales son plurales. En esta pluralidad el primer lugar corresponde a la abstracción, que es seguida de la conceptuación y finalmente del juicio de la abstracción. El paso da otro tipo de operaciones es la clave de las vacilaciones de la Filosofía Griega, así como de pasajes centrales del despliegue de la filosofía de Platón y de la reposición de las cuestiones en Aristóteles.»

«En la segunda sección ("nómos”) -continúa explicando el autor- estudio un tema proteico y a la vez vinculado de forma constante a la experiencia jurídica, moral y política de Grecia: el nómos. Expongo las variantes del asunto en tres grupos de sofistas. Como prueba de la opinión sobre la necesidad de contextualización de la sofística en el ámbito griego de su tiempo, se aducen textos literarios y algunos 
pasajes de Tucídides.»

En el último capítulo («La filosofía política de Platón y de Aristóteles»), el autor intenta responder a la siguiente pregunta: «¿Hasta qué punto determina la sofística la filosofía jurídica y política de Platón y de Aristóteles?». «El planteamiento sofístico de la razón práctica -señala el autor entre sus conclusiones- plantea a los grandes socráticos varias dificultades que se esforzaron en resolver»; entre ellas el autor destaca dos: «lograr que el gobernante no gobierne en provecho propio» (dificultad planteada por Trasímaco) y «averiguar las peculiaridades del lenguaje práctico de manera tal que la incomunicación del mundo humano con la razón teórica pueda ser superada» (cuestión que arranca de Gorgias). «Se trata, en suma, de lograr una auténtica filosofia práctica.» La primera aporía conduce a Platón al estudio de la naturaleza del gobernante, para perfilar un tipo humano del que quepa excluir por principio el abuso del poder. «Tal tipo de hombre es el filósofo, pues la contemplación de las Ideas libera de las apetencias cuya satisfacción se logra mediante la explotación de los gobernados.» En cuanto a la segunda cuestión, el autor señala que en Platón «la práctica ha de fundarse en la ontología, pues de otra manera el proyecto socrático de encontrar la verdad no puede llevarse a cabo.» Aristóteles, por su parte, responde a la primera aporía con el régimen mixto, la politeia: si todos participan en el poder, se logra al menos un equilibrio que impide la unilateralidad del gobierno que hace posible su abuso. Y por lo que se refiere a la otra dificultad, «Aristóteles establece el significado filosófico del lenguaje práctico a partir de la distinción entre el poder despótico y el político. Esta distinción permite entender que la ejecución de las instrucciones contenidas en una orden revierte sobre ella corrigiéndola. La razón práctica política es la razón correcta». Aristóteles entiende la prudencia como la virtud correctora que salva la incomunicación entre el lógos teórico y el lógos práctico; y «la clasificación de los regímenes políticos se puede entender de acuerdo con su adecuación o no con la razón práctica así formulada, y a la vez, con un criterio ético. Salvo el régimen mixto, las demás formas de gobierno son incapaces de las correcciones oportunas y, por tanto, son inestables.»

(Juan Antonio Pérez Lledó) 
SAAVEDRA LÓPEZ, Modesto.

La libertad de expresión en el Estado de Derecho. Entre la utopía y la realidad.

Ed. Ariel, Barcelona, 1987, 200 págs.

En las doctrinas jurídico-constitucionales sobre el Estado de Derecho, la libertad de expresión aparece como uno de los soportes fundamentales del ejercicio del poder. Según la lógica de tales doctrinas, la realización de esa libertad a través de los medios de comunicación de masas contribuye a formar una opinión pública plural e informada, una instancia a partir de la cual el gobierno y las instituciones obtienen un reconocimiento crítico, es decir, logran la legitimidad necesaria para el ejercicio de sus funciones. En la información sobre el entorno y el debate entre los ciudadanos, que sólo unos medios libres hacen posible, se ha querido ver tradicionalmente la mejor garantía que permite al poder exigir acatamiento a sus decisiones.

El libro analiza en toda su complejidad los desarrollos más importantes que desde el liberalismo ha experimentado la doctrina sobre la libertad de los medios, comparando sus postulados normativos con la realidad social de su funcionamiento. Con un planteamiento metodológico inspirado en el modelo de la crítica de la ideología, se ponen al descubierto las contradicciones que se dan entre lo pretendido por la doctrina y lo efectivamente conseguido en cuanto a información y comunicación social.

La conclusión es que, en el estadio actual de desarrollo de los medios y de la sociedad, y en virtud de la lógica que gobierna su funcionamiento, aquéllos tienden a ser más divertidos y espectaculares que informativos y críticos, más seductores que ilustradores de la conciencia de los ciudadanos. Con independencia relativa de su regulación jurídica (pública o privada, liberal o intervencionista), los medios no contribuyen a la formación de una opinión pública ilustrada y reflexiva, en contra de lo que las teorías liberal-democráticas sostienen para justificar la libertad y el pluralismo en su organización, sino que contribuyen más bien a la gratificación psico-lógica de las audiencias y al mantenimiento de la capacidad de sugestión de los mensajes, único elemento capaz en nuestros días de asegurar su recepción. De esta forma, los medios traicionan la función legitimadora a la que están objetivamente llamados y que reiteradamente se invoca para defender su constitución jurídica liberal. Finalmente, si la democracia requiere una información lo más completa y significativa posible para los que participan en ella, se hacen necesarias para aumentar su autenticidad otras instancias y prácticas que contrarresten la acción objetivamente manipuladora de los medios. No obstante, y por lo que respecta a estos últimos, es inexcusable para la supervivencia de una democracia legitimadora potenciar unos medios de comunicación que, sin plegarse a las influencias del poder, estén tan libres como sea posible de las determinaciones del mercado.

SALCEDO MEGALES, Damián.

La fundamentación normativa de un principio igualitarista.

Anuario de Filosofía del Derecho, Madrid, núm. 4 (Nueva Época), 1987, págs. 193-215. 
Este trabajo está estructurado en tres partes: la primera constituye una «presentación y defensa del principio igualitarista desarrollado en el último decenio y conocido con el nombre "leximín"»; la segunda recoge las críticas formuladas por Rawls en contra de la concepción de la justicia que encarna este principio; y la tercera es una reformulación del principio «leximín» elaborada de manera que evite los inconvenientes denunciados por Rawls.

El principio «leximín» ofrece «una ponderación especial a los individuos o sectores de la sociedad peor situados a la hora de evaluar estados, acciones o políticas sociales alternativas. Se trata de un principio consecuencialista y "welfarista" como los principios utilitaristas; pero a diferencia de ellos, no es aditivista, en ello radica su ventaja». Este principio ha sido objeto de la crítica de Rawls. El autor se adhiere a la critica rawlsiana de una manera matizada, aceptando que la concepción moral de la persona no es respetada por el principio «leximín». «Más bien éste trata a los individuos como si no poseyeran lo que tienen de más característico, a saber, un valor de diferencia expresado en una concepción personal del bien inconmensurable.» Para el autor, sin embargo, es posible acomodar la concepción moral de la persona tal y como la presenta Rawls con la regla «leximín». Por ello defiende una concepción del bienestar personal que identifica éste no con la posesión de bienes ni con la utilidad que la posesión produce, sino con la capacidad de aprovecharse de los mismos. «Dicha concepción de bienestar nos permite reconciliar las exigencias de la concepción moral de la persona con las exigencias de la estructura de las comparaciones interpersonales. De este modo, la versión del principio «leximín» que defendemos sigue siendo consecuencialista. Otros valores distintos a la simple maximización de la utilidad personal pueden intervenir en la apreciación de los estados sociales a través del concepto de libertad para elegir qué cosas hacer con los bienes y propiedades.»

(Francisco López Ruiz)

SÁNCHEZ DE LA TORRE, Ángel.

\section{El Derecho en la aventura europea de la libertad.}

Ed. Reus, Madrid, 1987, 264 págs.

«La experiencia contemporánea del Derecho -escribe el autor- desemboca en una diversidad de modalidades institucionales en que, aparentemente, se difumina una visión capaz de atender coherentemente todas las realidades jurídicas en presencia. El orden normativo descuella como dimensión instrumentalista en las teorías institucionalistas, realistas y positivistas.»»

En este horizonte de problemas, el autor pretende con este ensayo «recuperar la perspectiva de los orígenes de las estructuras sociales y normativas que pueden haberse desplegado, dentro de una evolución homogénea, en un espacio culturalmente determinado para un concreto ordenamiento histórico. Tal investigación ayudaría a la comprensión del sistema normativo denominado "Derecho", asumiendo los caracteres que históricamente ha ofrecido en la confrontación dialógica entre el conjunto de normas y el espacio en que las mismas actúan, dentro de un escenario cultural denominado "Europa", en cuya historia el despliegue del orden jurídico constituye uno de sus perfiles más definidos».

El presente estudio se dirige, pues, a «la mostración de las conexiones básicas entre sociedad y orden 
normativo, y de la productividad que desde ambos polos dialógicos externos alcanza la coexistencia humana merced a la acción que los mismos acondicionan para la presencia del protagonismo de la cultura, entendida como empresa histórica de la libertad».

La obra se estructura en cuatro partes: En la primera, el autor analiza el «desarrollo de la raíz occidental de la libertad»: la conexión entre libertad y orden jurídico, las raíces culturales de la noción europea de libertad, los límites de la libertad en los mitos europeos, el sentido y los objetivos de la libertad en la cultura europea, la libertad en el desarrollo de la ciencia europea, la libertad en el marco socio-político de la convivencia europea, la filosofía y la teología de la existencia social en la tradición europea, las características de la persona como sujeto de la libertad y, finalmente, la «apertura de la ley natural hacia el protagonismo de la libertad humana». De todo ello, el autor extrae «una confirmación: el interés que representa examinar el orden jurídico, sus instituciones, sus normas y sus sanciones, en la perspectiva de su instrumentación al servicio de la libertad humana». Según el autor, ello podría manifestarse, como objeto de investigación, en tres planos, que serán desarrollados en cada una de las restantes tres partes de esta obra:

Primeramente (Parte III: «Elementos integrantes del orden jurídico en la tradición Europea»), el autor estudia «el concepto más usual y aceptado de orden jurídico, o sea, cuáles son los elementos reales que componen esa compleja realización sociopolítica que denominamos Derecho».

En segundo lugar (Parte III: «Definición del Derecho»), expone «los principios estructuradores del orden jurídico que pudieran coincidir con los grandes criterios normativos que el conjunto del orden jurídico trata de establecer institucionalmente en el seno de la organización común de la convivencia social, interpretados también en su conexión con las condiciones necesarias para la libertad humana». $\mathrm{Y}$ en tercer lugar (Parte IV: «Instituciones básicas del orden jurídico»), el autor centra su atención «en las más importantes instituciones jurídicas, tanto en sus estadios históricos como en su significación y formas actuales, para verificar si dentro de sus planteamientos obtiene la libertad humana el lugar, la ocasión y las oportunidades que le resulten adecuadas conforme a lo examinado anteriormente. Para ello aparece en primer lugar la más directa estructura institucional de la libertad, que es la figura de los derechos subjetivos. A continuación aquellas otras instituciones que dependen directamente de los sujetos, desde las más íntimamente conectadas con ellos, hasta las más alejadas». Así, el autor examina dichas instituciones por este orden: derecho subjetivo de la persona (su concepto y su significación cultural, y su caracterización como «forma de la libertad social objetiva»); derecho del contrato (como «forma de aventura y de riesgo de la creatividad social»); derecho de la propiedad (su sentido y función «como institución de la libertad»); derecho de la organización política (el Estado y las relaciones entre poder y libertad); y, por último, los derechos humanos (como «directrices personalizadas de la libertad»).

(Juan Antonio Pérez Lledó)

\section{SÁNCHEZ DE LA TORRE, Ángel.}

\section{Sociología del Derecho.}

Ed. Tecnos, Madrid, 2. ${ }^{\mathrm{a}}$ edición, 1987 (1. a edición, 1985), 249 págs.

Tratándose de un estudio de sociología jurídica, el autor parte de la consideración del Derecho como 
componente estructural y funcional de la sociedad. Según el autor, la sociedad ha de entenderse como un tipo característico de la realidad, no identificada con la suma de sus individuos, y se la puede captar como el conjunto de todos los sistemas de comunicación en un determinado ámbito de convivencia. Dentro de tal conjunto, el Derecho es aquel sistema de comunicación que transmite mensajes referidos a conductas tipológicamente caracterizadas como licitas o ilícitas, con la previsión de una coactividad organizada para promover aquéllas y disuadir de éstas.

El libro se ocupa de los siguientes temas:

En el capítulo I ( «Hacia una Sociología jurídica científica») trata del status epistemológico de una sociología del Derecho como auténtica ciencia, «en el sentido de abarcar complexivamente el conjunto de la fenomenología jurídica de la sociedad», y no simplemente una sociología «sobre materias jurídicas», sectorial, dedicada solamente al problema de la eficacia de las normas para auxiliar a juristas prácticos, legisladores y políticos. El autor se ocupa aquí de la delimitación y conexiones de la sociología del Derecho con la filosofía del Derecho y con la teoría general del Derecho, considerando a esta última -y no a la filosofía ni a la dogmática jurídicas- «la posición científico-jurídica exactamente complementaria con la sociología jurídica».

En el capítulo II ( «El ámbito jurídico») desarrolla su concepción antes aludida de la sociedad como conjunto de sistemas de comunicación, centrándose en los rasgos de la comunicación intersubjetiva y en «la ciudad» como modo de organización política que dio origen a la mayor parte de los actuales caracteres del orden jurídico».

En el capítulo III ( «La fuerza del Derecho») estudia las funciones del Derecho y la noción del Derecho como sistema de control social, analizando la dimensión sociológica de los conceptos de coacción y sanción.

En el capítulo IV («Cultura social y valores jurídicos») se ocupa de la legitimación del orden jurídico. El autor no relativiza la norma en su sociología del Derecho, pues la considera indisociable de un Topos, de un vinculum societatis humanae, que puede ser la naturaleza entendida como «principio normativo», lo cual no significa que no haya lugar para las «referencias culturales del Derecho». Estas referencias, en Occidente, se remontan a la tradición bíblica y grecorromana, y se centran en la noción de dignidad humana; aquí aparece un «componente espiritual», racional, que es la libertad y no la igualdad, pues esta última es concebida por el autor como un simple «standard hipotético»».

En el capítulo V ( «La estructura de la norma jurídica») el autor señala que la norma jurídica, como vehículo de la comunicación jurídica, ha de tener una estructura comunicante capaz de contener simultáneamente dos mensajes: cómo debe ser realizada la conducta jurídica (deber jurídico) y qué consecuencias se derivarían del hecho de haber cumplido o no el deber jurídico (sanción jurídica). En la norma la sociedad elabora conscientemente y expresa la validez de las conductas jurídicas.

En el capítulo VI ( «La estructura de la relación jurídica») el autor concibe la relación jurídica como el ámbito social afectado por la existencia de una norma jurídica. La estructura de dicha relación ha de identificar a los sujetos cuyos intereses resultan afectados por la regulación jurídica, atendiendo a su adscripción, aseguramiento o transmisión.

Por último, en el capítulo VII («Sociología de las transformaciones jurídicas en la sociedad europea») analiza los rasgos de la sociedad de masas en la Europa actual: la democracia socio-política, la comunicación informática y los órdenes jurídicos supraestatales.

En suma, el autor quiere desarrollar en este libro una propuesta teórica convergente con los conceptos generales elaborados, en la vertiente del conocimiento de los juristas dogmáticos, por la teoría general 
del Derecho, sometiendo a ésta a una consideración «realista» desde varias perspectivas: empírica, antropológica, lingüística, etc., unificadas desde una visión del Derecho como «forma de la libertad en la existencia colectiva».

(Juan Antonio Pérez Lledó)

SAUQUILLO, Julián.

Poder político y sociedad normalizada en Michel Foucault.

Revista de Estudios Políticos, Madrid, núm. 56, abril-junio 1987, págs. 181-203.

En el actual debate en torno a la modernidad y su crisis, Michel Foucault muestra su incomodidad al ser catalogado dentro del «antimodernismo de los jóvenes conservadores», según la tipología habermasiana de los enemigos del proyecto ilustrado (antimodernismo, premodernismo y postmodernismo). Para el autor, el sentido del diagnóstico de la razón que posee la «analítica del poder» de Foucault (analizar la razón en la especificidad de sus continuas transformaciones, en vez de verla como un proceso a sustituir o superar) «no pretende ni una revocación total de racionalismo, ni una crítica del Aufklärung», sino superar «tanto la inimputabilidad de la razón como la exaltación de la irracionalidad». Foucault se reconoce heredero de la Ilustración, pero dentro de una corriente crítica, surgida en el siglo XIX, frente a los excesos de la razón ilustrada. Su tarea crítica, no obstante, presenta rasgos diferenciadores respecto de la escuela de Francfort: «no se trata de analizar la racionalidad política moderna, sino de estudiar el proceso de racionalización en diversos dominios de la experiencia -locura, enfermedad, crimen, sexualidad- desde momentos previos a la Ilustración». En esta «genealogía del poder», Foucault parte de la existencia de «un conjunto complejo de fuerzas que produce la realidad». Esas «relaciones y prácticas sociales que atraviesan el tejido social» en cada período histórico configuran diversas formas de racionalidad, «entre las cuales Foucault no establece ninguna perspectiva o vector de "progreso"». Así, la racionalidad de la moderna sociedad occidental «no está configurada por evidentes opiniones, principios teóricos o técnicas científicas en progresivo desarrollo, sino por relaciones de poder materializadas en prácticas institucionales, administrativas, psiquiátricas, judiciales, médicas o penales...». La filosofía ya no es reflexión sobre la totalidad, sino actividad fragmentaria, que Nietzsche entendió como «diagnóstico del subsuelo de nuestro presente»: ¿qué somos hoy?, ¿qué es el presente? Para Foucault ésta es la pregunta básica de la reflexión política e histórica desde el siglo XIX. Y, según el autor, esta misma búsqueda del «estatuto histórico-político de nuestra constitución como sujetos» es también el motor de los análisis arqueológicos y genealógicos de Foucault, cuyo «deseo final» es «ofrecer una historia de los procedimientos de subjetivación del individuo en nuestra cultura». En sus» primeros trabajos, Foucault expone diversas formas de subjetivación del individuo en relación con determinados saberes: como sujeto hablante, a través de la gramática y la filología; como sujeto productivo, a través de la economía; y como ser vivo, a través de la historia natural, la biología y la medicina. En Surveiller et punir, analiza críticamente «la producción política de la experiencia, como doble movimiento que integra al sano, al cuerdo y al obediente ciudadano, y extraña al enfermo, al loco y al criminal». A ello añade, en La volonté de savoir, la objetivación del individuo como sujeto sexual. Sus últimos escritos, 
en cambio, son «un intento de proteger su propio pensamiento de la vacuidad a la que nos relegan las relaciones de poder», proponiendo una ética concebida como estética, que «problematiza» la subjetividad y «abre la vida al arte».

Foucault invierte el análisis tradicional de la teoría política, tanto liberal como marxista, que coincidían en «una especie de gigantismo estatal», ya fuese como «monopolio público de la fuerza» o como «garantía institucional del intercambio económico desigual». El análisis genealógico, en cambio, indaga en «efectos mucho más diseminados del poder sobre el cuerpo social», en las técnicas de gobierno para «la organización racional de las necesidades de la "población"». Este poder individualizante actúa sobre «el entorno social básico del individuo, el núcleo constitutivo de sus necesidades, afectos e impresiones primarias, y no el de sus derechos». «Al localizar el soporte de la normalización del cuerpo social en la sociedad moderna, Foucault opta por subrayar el papel de los poderes médicos y técnico-sociales, en detrimento del prioritario papel normativo que se acostumbra conceder a la legislación». Foucault sugiere desligarse de algunos postulados de la teoría política (los de propiedad, localización, subordinación, modo de acción y legalidad), y propone «un modelo relacional de comprensión del poder, materializado en un campo de fuerzas sin finalidad identificable y donde sólo es posible un infinito combate».

(Juan Antonio Pérez Lledó)

SCHMILL O., Ulises.

El debate sobre Mitilene. Una interpretación.

Doxa, Alicante, núm. 4, 1987, págs. 203-245.

«Este trabajo -señala el autor- tiene por objeto exponer, en primer lugar, de la manera más fiel posible, los temas abordados en el famoso debate ateniense sobre el destino de los mitilenios, relativos a la justificación de las penas. En dicho debate pueden verse, in statu nascendi, muchas de las concepciones que los tiempos subsecuentes han utilizado para justificar las sanciones que el hombre impone al hombre. En el fondo se trata del análisis de lo que el hombre ha pensado para legitimar el uso de la fuerza contra otros hombres y otorgar un sentido a la creación positiva del dolor en el mundo. Estas concepciones legitimadas constituyen, adicionalmente, el fundamento de múltiples concepciones del Derecho penal contemporáneo».

En el año 428 a. C. la ciudad-estado de Mitilene se alzó contra los atenienses. Sofocaron éstos la rebelión y, en sus indignación y arrebato, decidieron no sólo matar a los prisioneros, sino también a los mitilenios mayores de edad y vender como esclavos a los niños y mujeres. Pero se arrepintieron de una tan precipitada actuación: después de dictada aquella sentencia, Cleón y Diódoto arengaron al pueblo ateniense, reunido en asamblea, sobre la justicia o la conveniencia de la decisión mortal adoptada contra los mitilenios.

Los discursos de Cleón y Diódoto -cuyo texto íntegro se reproduce en el apéndice a este trabajorepresentan, respectivamente, una «actitud normativa» y una «actitud explicativa», que son, en opinión del autor, «dos tendencias generales observables en la conducta humana». La primera parte de la afirmación del libre albedrío y aspira, así, a la retribución por el daño causado cuando no exista 
constancia de que el infractor no pudo actuar de otro modo. La segunda pretende explicar el comportamiento delictivo y asume que éste, como cualquier otro, se encuentra condicionado por hechos o circunstancias antecedentes. De este modo, el sujeto no pudo haber actuado de manera distinta y, por ello, «la conducta del sujeto titular de facultad punitiva tiene que variar sustancialmente, como aparece en el debate que analizamos».

(Antonio Doval Pais) 
SERRANO, José Luis.

Algunas hipótesis sobre los principios rectores de la política social y económica.

Revista de Estudios Políticos, Madrid, núm. 56, 1987, págs. 95-119.

Este texto se puede resumir en los siguientes puntos: 1. «Los principios rectores de la política social y económica, como concreción de la idea de Estado social del artículo 1, funcionan. Ello metodológicamente implica que sólo desde la pregunta por su función en el contexto jurídico y/o socioeconómico es posible tener claro cuál es el sentido y alcance de dichos principios.» 2. «Es exacto hablar de que esa función de los principios rectores de la política social y económica es "correctiva" en el sentido de que proporcionan al poder público una serie de instrumentos capaces de evitar que el costo social de los desequilibrios inherentes al sistema social capitalista sea demasiado alto. Pero (...) la completa subordinación de estos principios a una serie de necesidades de índole política hace que su función no necesariamente deba ser correctiva.» 3. «Los principios rectores de la política social y económica participan indudablemente de la condición jurídica de toda la Constitución», pero tienen carácter de normas jurídicas no independientes o de principios coactivos. 4. «La Constitución en su conjunto ha tenido entrada en el ordenamiento jurídico no sólo como pirámide de principios de éste, sino también como norma jurídica directamente aplicable a la resolución de conflictos. Los órganos constitucionalmente encargados de delimitar el alcance de la innovación que supuso la promulgación de la Constitución lo han hecho en el sentido del «nuevo modelo de Constitución». 5. «Si toda la Constitución tiene naturaleza de norma jurídica, entonces los criterios de división de materias entre los capítulos II y III del título I de la Constitución... obedecen necesariamente a criterios materiales, políticos, funcionales o, simplemente, a la ausencia de criterios.»

(Ángeles Ródenas Calatayud)

\section{SERRANO GONZÁLEZ, A.}

Michel Foucault. Sujeto, Derecho, poder.

Ed. Universidad de Zaragoza, Zaragoza, 1987, 157 págs.

Concebido el Derecho como un complejo en el que operan instituciones y destinatarios considerados en un sentido amplio, el autor pretende en este libro «complicar en la medida de lo posible una visión cómoda que suelen tener los juristas del objeto de su atención», con la finalidad de descubrir la procedencia de los «propios juegos de la verdad jurídica», sirviéndose, para ello, de la metodología y el instrumental proporcionados por la obra de Foucault.

En el primer capítulo («La obra de Michel Foucault: una historia de la verdad»), se realiza una sintética exposición de las principales obras del filósofo francés, en las que se trata de encontrar los puntos principales de su preocupación intelectual en torno a los discursos del saber y del poder en relación con el Derecho. 
En el segundo y tercer capítulos («Saber e Historia (I): el método» y «Saber e Historia (II): La nueva relevancia de las formas y prácticas jurídicas»), es expuesto el llamado «método arqueológico», que facilita el estudio de la distribución de lo verdadero y lo falso en el Derecho mediante la observación de una realidad, resultante de la conjunción de técnicas jurídicas, códigos morales y condiciones económicas, mediante la remisión a la genealogía de los circuitos de creación, alimentación y regeneración de un Derecho inserto en un entramado social.

Se ocupa, a continuación, en el capítulo cuarto («Los tipos de normatividad (I): la acción normalizadora»), de las manifestaciones o relaciones del poder -«los tipos de normatividad»-, refiriéndose, concretamente, a las ciencias del hombre -medicina, psiquiatría y psicología, particularmente- como creadoras de unos discursos del saber que habría aprovechado el Derecho como medio de legitimación de sus instituciones. El análisis se centra, partiendo de la obra de Foucault fundamentalmente, de la Historia de la locura-, en el tema de la enajenación y se advierte la conexión existente entre el crimen y la locura, como paradigma de lo expuesto.

El capítulo quinto («los tipos de normatividad (II): la sociedad disciplinaria») recoge las consideraciones que la obra foucaultiana sugiere respecto a la práctica de la punición, donde el poder -de castigar- toma su máxima expresión. La cárcel, particularmente el Panóptico de Bentham, cumple la función disciplinaria de normalización y se presenta, desde el liberalismo, como el instrumento específico que gestiona y explota los ilegalismos que la ley penal distribuye según criterios de clase. Los ilegalismos de bienes, cometidos por las masas, son severamente reprimidos, a diferencia de los ilegalismos de derechos, cuya ejecución es más propia de los burgueses, generalmente tolerados o poco perseguidos.

Finalmente, el capítulo sexto («Del poder sin rey al poder pastoral») recoge unas reflexiones que inciden en la importancia de la obra de Foucault en cuanto que desvela un poder entendido como «administración de conductas que produce formas de subjetividad». Revelar éstas será dar con la verdad del Derecho.

(Antonio Doval Pais)

SORIANO, Ramón.

¿Es iusnaturalista la constitución española de 1978?

Revista de las Cortes Generales, Madrid, 1987, págs. 109-159.

El autor pretende en este artículo «precisar cómo y hasta dónde es admisible defender la presencia del iusnaturalismo en nuestra Ley Fundamental», asomarse «a la proyección del Derecho natural en las constituciones europeas de la postguerra», indagar «la opinión de los constituyentes, los magistrados constitucionales y los juristas españoles en torno a este tema, es decir, el parecer de las fuentes más autorizadas para interpretar la hipotética profesión iusnaturalista de nuestra Constitución»y, finalmente, exponer su «opinión al respecto en una interpretación lógico-conceptual y sistemática de los preceptos de la Constitución española».

Respecto a todo esto el autor concluye que «constituyentes, jueces y juristas han preferido obviar una respuesta concreta sobre el tema del iusnaturalismo constitucional; cuando en contadas ocasiones se 
han visto obligados o han sentido la necesidad de pronunciarse sobre esta cuestión, han optado prudentemente por la constatación de una teoría de los valores o una ética material de los valores. No niegan la necesidad de una axiología o filosofía crítica de los preceptos de nuestra Constitución, pero rehuyen la opción por una interpretación expresamente iusnaturalista de la misma.

Quizá contribuya a aclarar esta posición -continúa el autor- la visión devaluada y cerrada que buena parte de los elaboradores e intérpretes de la Constitución presumiblemente tendrían del Derecho natural profesado en las Facultades de Derecho y demás centros docentes humanísticos: el Derecho natural escolástico católico, del que poco se separaban los fundamentos ideológicos del régimen de la dictadura. No cabe duda de que esta tradición docente debió de pesar significativamente en el ánimo de un número considerable de diputados y senadores; lo suficiente para soslayar la equiparación de los valores jurídicos constitucionales con cualquier especie de iusnaturalismo.

Por otra parte, una interpretación sistemática de los preceptos constitucionales, y significativamente aquellos más ladeados hacia una profesión de fe iusnaturalista -artículos 1.1 y $2 ; 2 ; 10.1 ; 53.1 ; 103.1$ de la Constitución-, admiten, a mi juicio, otras interpretaciones distintas a la propiamente iusnaturalista y más cercana a una teoría material de los valores, sin que este juicio prejuzgue de la falta absoluta de consistencia de las argumentaciones iusnaturalistas en este sentido, si el Derecho natural es concebido en una perspectiva abierta, como método epistemológico y valorativo de la realidad del ordenamiento jurídico, y no como una ontología jurídica supraconstitucional».

(Daniel González Lagier) 
SORIANO, Ramón.

La objeción de conciencia: significado, fundamentos jurídicos y positivación en el ordenamiento jurídico español.

Revista de Estudios Políticos, Madrid, núm. 58, octubre-diciembre 1987, págs. 61-110.

El primer objetivo de este trabajo consiste en determinar conceptualmente la objeción de conciencia, distinguiéndola de otras figuras jurídicas afines (en especial de la desobediencia civil) y analizando sus caracteres y los criterios que, desde una perspectiva fundamentalmente jurídica, pueden justificar no sólo su admisibilidad, sino también su consideración como un verdadero derecho de los ciudadanos. En opinión del autor, estos criterios son, por un lado, «el carácter relativo... del principio de derecho contravenido por los actos del objetor» (este principio sería el de generalidad de la norma) $\mathrm{y}$, por otro lado, el «juego de interrelaciones de derechos y deberes fundamentales en el seno de una sociedad y un ordenamiento constitucional democráticos»; este segundo argumento permite desplazar a un deber siempre que cumpla los siguientes requisitos: no ser un deber personalísimo y primario, admitir ser sustituido por otros deberes de semejante naturaleza y no afectar a bienes esenciales de la persona.

A partir de estos datos, el autor pasa a desarrollar su segundo objetivo, estudiar y enjuiciar la evolución de esta figura en la regulación jurídico-positiva española, centrándose fundamentalmente en la objeción de conciencia al servicio militar (única expresamente enunciada en la Constitución). El autor nos muestra como la objeción de conciencia era considerada, en el periodo pre-constitucional, como una conducta delictiva y reprochable. La Constitución de 1978 considera a la objeción como un derecho, pero lo regula de tal modo que parece tratarse de «una mera excepción de un deber fundamental, el deber de servir a la patria militarmente»; además, el lugar y la forma en que se constitucionaliza supone un obstáculo para su interpretación sistemática en el conjunto de los derechos y libertades de la persona; será la jurisprudencia constitucional la que lo defina como una manifestación de la libertad ideológica.

Las principales críticas que formula el autor a la vigente legislación sobre la objeción de conciencia (Ley de 26 de diciembre de 1984) se concretan en la «duración excesiva de la prestación del servicio social sustitutorio, parquedad en la regulación de la objeción sobrevenida, funciones fiscalizadoras del Consejo Nacional de Objeción de Conciencia...»; en particular, las atribuciones de este Consejo para indagar la veracidad de los motivos aducidos por el objetor entrarían en contradicción con los artículos 16 (libertad ideológica y prohibición de obligar a declarar sobre la ideología...) y 18 de la Constitución (intimidad personal y familiar). Entre las valoraciones positivas de la ley se encuentran la inclusión de una lista abierta de motivaciones expresas; también destaca el autor la importancia de que, de un modo expreso, se haya recogido el motivo filosófico (caracterizado por su amplitud).

A continuación el autor analiza los argumentos que basaban el recurso de inconstitucionalidad presentado por el Defensor del Pueblo contra determinados aspectos de esta ley (que coinciden, en gran medida, con las críticas del autor) y, finalmente, estudia la labor que, a partir de la publicación de esta ley, ha realizado la jurisprudencia constitucional en cuanto a su interpretación.

(Isabel Lifante Vidal) 
SORIANO, Ramón; HERRERA, Joaquín.

La sociología del Derecho española y los poderes públicos. Perspectivas de una futura y necesaria colaboración.

Anuario de Sociología y Psicología Jurídicas, Barcelona, núm. 13, 1987, págs. 43-64.

«Las páginas que siguen a continuación -explican los autores en la presentación de su artículo- son producto de la decepción provocada por la situación de la sociología del Derecho en los planes de estudios de las Universidades españolas.» «El panorama no puede ser más desolador, si se parte de la convicción de la necesidad de la sociología del Derecho como especialidad en la que se articula la valoración crítica de las ciencias del Derecho, la comprobación empírica de la virtualidad de las normas e instituciones jurídicas, y la orientación de la actividad desplegada por los poderes públicos en el proceso de la creación y la aplicación del Derecho».

En este sentido, el presente artículo intenta destacar el valor de los estudios sociológico-jurídicos, pretendiendo ser un manifiesto programático de la sociología del Derecho. Así, los autores se ocupan de las siguientes cuestiones:

1. Las ventajas del método empírico-sociológico frente al teórico-formal: mayor abarcabilidad del estado de las cuestiones planteadas, la pormenorización jerarquizada de los estados de opinión, la proporción de puntos de referencia y contraste respecto de datos obtenidos en un momento anterior o posterior, y la verificación de las tesis teóricas.

2. La caracterización de la sociología del Derecho (frente a sus críticos) como ciencia jurídica no paradigmática (por su juventud, sobre todo en la investigación empírica, lo cual no la convierte en un saber a-científico), autónoma (respecto de la dogmática jurídica, por adoptar aquélla una perspectiva externa, y respecto de la sociología general, pues la peculiaridad del elemento jurídico delimita un campo temático propio y al menos una forma particular de utilizar de los métodos sociológicos), y necesaria (como disciplina «desmitificadora de los sistemas de legitimidad históricos y críticamente valoradora del significado y alcance de los sistemas de legalidad en los distintos períodos históricos», que permitiría abordar mejor la crisis de la justicia frente a las limitaciones del positivismo formalista y del iusnaturalismo abstracto, ambos alejados de la realidad social).

3. La precaria situación de la sociología del Derecho en España y las razones de su marginación: el escaso desarrollo en España de las ciencias experimentales en general, y la marginación de la sociología jurídica de los planes de estudios por sus «potencialidades subvertidoras» frente a la ciencia jurídica dominante.

4. Los campos de investigación de una sociología del Derecho española en la actualidad: auspiciando la colaboración entre los sociólogos del Derecho y los poderes públicos en el proceso de creación y aplicación del Derecho, los autores presentan aquí un programa con los siguientes temas: legalidad normativa-legitimidad social (conocimiento sociológico de sus conexiones y desajustes, orientado al cambio legislativo); cambio legislativo y transformación de los órdenes normativos (detectar los criterios sociales que exigen la normatización o desnormatización jurídica); cambio legislativo y naturaleza cualitativa-cuantitativa del sector social regulado (la legislación distributiva de bienes ha de servirse de estudios sociológico-jurídicos para deslindar los grupos sociales 
beneficiados/recargados y para determinar el grado de beneficio/carga de cada uno); cambio legislativo-reglamentario y periodo de adaptación de nuevas normas (estudios a partir de experiencias-piloto previas a la introducción de reformas jurídicas); cambio legislativo y eficacia de las normas (detectar las causas de la posible ineficacia de normas ya vigentes); aplicación del Derecho y operadores jurídicos (examen de la función y problemas que encuentran jueces y abogados al aplicar el Derecho).

5. La deseable ubicación de la sociología de Derecho española en los planes de estudios: «dado el predominio que en esta asignatura tiene el elemento jurídico», su «lugar insoslayable» sería, según los autores, la Facultad de Derecho (desglosada entre el primer y el quinto curso), siendo también «conveniente» en los centros más conectados con los problemas jurídicos (Ciencias Sociales, Políticas, Económicas, Graduados Sociales...).

(Juan Antonio Pérez Lledó)

SQUELLA, Agustín.

Democracia e igualdad en América Latina.

Doxa, Alicante, núm. 4, 1987, págs. 367-379.

Dada la actual realidad de América del Sur se cuestiona en este artículo la posibilidad de que la democracia, entendida como el procedimiento que conduce a la toma de unas determinadas decisiones acordes a un proyecto de gobierno aprobado por la mayoría de un pueblo desde la libertad que es inherente a este sistema, pueda atenuar las desigualdades y la crisis económica imperantes hoy en Iberoamérica.

Tras señalar las relaciones entre democracia y libertad, por una parte, y, por otra, democracia e igualdad, concluye el autor que es factible y necesario caminar desde la libertad democrática hacia modalidades más igualitarias de convivencia, salvando y superando las tesis que sostienen la irreconciliabilidad entre los principios de libertad e igualdad. A través del ejercicio de la libertad, inspiradora y límite del gobierno de las mayorías que es toda democracia, se debe luchar por la atenuación de las desigualdades existentes en estas colectividades, que demandan urgentemente un sistema de gobierno tendente a una salida digna dentro de los cauces de libertad e igualdad esenciales al hombre.

(Angélica Such) 
TORRES LÓPEZ, Juan.

Análisis económico del Derecho.

Ed. Tecnos, Madrid, 1987, 108 págs.

«En las páginas que siguen -comenta el autor- se encontrará el lector con lo que pretende ser una visión panorámica del estado doctrinal actual del análisis económico del Derecho, de sus planteamientos, de su alcance epistemológico y de algunos de sus resultados. Y en la medida en que se trata de ofrecer una visión general de un cuerpo de conocimientos novedoso, lo más sintética y resumida posible, he preferido optar por una presentación del trabajo donde prime la máxima divulgación de los contenidos del análisis económico del Derecho aun a costa de renunciar en la mayoría de los casos a profundizar sobre los componentes analíticos del mismo.»

«He optado por estructurar el libro -continúa- en tres grandes contenidos. El primero de ellos se corresponde con el capítulo I, y en él se sintetizan las fases teórico-doctrinales que han sido necesarias para conformar el panorama actual del análisis económico del Derecho. Trato en este capítulo de reflejar los diferentes momentos que culminan en su auténtica formación epistemológica.

El segundo gran contenido, correspondiente al capítulo II, hace referencia al intento de presentar coherentemente y como un todo los propios presupuestos teóricos y metodológicos de la disciplina, generalmente dispersos, como digo, en toda la literatura.

Por último, y sobre la base de los diversos desarrollos efectuados de dichos presupuestos, los capítulos III y IV sistematizan las diversas concepciones apreciables actualmente en el análisis económico del Derecho.

En el capítulo III se recogen los componentes esenciales de la corriente actualmente mayoritaria y que se nuclea en torno a la lectura más literal del paradigma neoclásico, tomando como sistema de decisión al mercado y a la eficiencia como objetivo principal y único de la actividad económica y de la asignación de recursos.

El capítulo IV, por último, está dedicado a sistematizar las aportaciones doctrinales cuyos fundamentos resultan opuestos o críticos respecto de la corriente mayoritaria o eficientista.»

(Daniel González Lagier)

VERNENGO, Roberto J.

Relativismo ético y justificaciones morales.

Doxa, Alicante, núm. 4, 1987, págs. 247-255.

Este artículo constituye una réplica a las afirmaciones vertidas por Ernesto Garzón en torno a la fundamentación de toda acción política en principios morales. Para ello, en primer lugar, se denuncia la imposibilidad del positivismo ideológico para justificar moralmente, mediante la invocación de las normas, las acciones que se realizan de acuerdo con ellas. A partir de aquí, el autor sostiene que son 
principios morales «las razones últimas de justificación de las acciones». El siguiente paso en este discurso parte de las críticas al relativismo ético contenidas en un estudio de Hedenius para concluir en una necesaria depuración del concepto de relativismo ético o axiológico como principio metaético que reviste distintas formas. La conclusión de todo ello es clara, en palabras de Vernengo: «La actitud reciente de muchos pensadores (...), en que aparece un repudio ante el relativismo axiológico y la pretensión de buscar razones últimas, fundamentos últimos para los conjuntos de normas sociales positivas -fundamentos que se buscan en supuestos hechos morales o en principios que aspiran a ser instancia final de justificación de las acciones- constituyen manifestaciones de aquel nihilismo que Nietzsche apuntara (...). La racionalidad se identifica con el nihilismo, en cuanto la verdad es vista como un mero valor».

(Ángeles Ródenas Calatayud)

VILAJOSANA, RUBIO, Josep. M.

El aparato conceptual de C. B. Macpherson: Poder y propiedad.

Anuario de Filosofía del Derecho, Madrid, núm. 4 (Nueva Época), 1987, págs. 449-475.

Para el autor los conceptos de «poder» y «propiedad» son «las categorías fundamentales del aparato conceptual utilizado por Macpherson». Este artículo se divide en dos apartados que tratan de analizar, respectivamente, los conceptos de «poder» y «propiedad» en el pensamiento del que fue profesor de Ciencias Políticas en la Universidad de Toronto.

En el primero de estos apartados -El concepto de poder-, tras advertir que el término power aparece en los escrito de este autor con distintos usos semánticos y señalar algunos de ellos, se trata acerca de la dimensión ética en la discusión sobre el poder. En este sentido, Macpherson sostiene que la democracia liberal es un sistema doble de poder, porque añade a la posibilidad del ejercicio de la coerción por parte del Estado el mantenimiento de unas relaciones entre individuos y grupos sociales que son verdaderas relaciones de poder. Macpherson llama relaciones de poder a aquellas relaciones en las que se produce una «cesión de poder», es decir, a aquéllas en las que se produce una enajenación de la energía y de las capacidades de unos en beneficio de otros. En toda la argumentación de este autor se advierte una noción subyacente de libertad como la posibilidad de desarrollo de las capacidades y las potencialidades humanas mediante un fin consciente, por lo que, si tomamos esta noción de libertad como postulado inicial, la situación que genera el sistema de la democracia liberal es ilógica, además de ser injusta.

Se aborda también en este primer apartado el aspecto cuantitativo del poder. Se trata de cuantificar el poder de un hombre -y la cesión de poder-, lo que según Macpherson puede hacerse en términos de ausencia de impedimentos: en concreto estos impedimentos serían: falta de medios de vida, carencia de medios de trabajo (medios de producción) y ausencia de protección contra la invasión de otros. Esto hay que ponerlo en relación con la opinión de este autor de que la finalidad de una teoría democrática actual debe ser maximizar los «poderes humanos».

Otro aspecto tratado es «el pretendido marxismo de C. B. Macpherson. El autor de este artículo sostiene que aunque existen, en efecto, puntos de conexión entre el marxismo y el pensamiento y el 
método de Macpherson, existen también otros muchos puntos que pueden ser considerados claves en la tradición marxista que no se hallan en sus escritos. Prefiere, por tanto, considerar a este profesor como «un pensador liberal crítico con su tradición». Uno de estos puntos divergentes es el modo como se debe producir el paso de la sociedad actual a una sociedad igualitaria. Para Macpherson hay que partir de las instituciones presentes y de la ideología que las sustenta; se trata de hacer desaparecer el «poder extractivo» de una sociedad maximizando las capacidades de desarrollo de las personas, lo que según este autor puede hacerse a través de su igualación en los accesos a los medios de vida y de trabajo.

El segundo de los apartados de este artículo (El derecho de propiedad) recoge la teoría política de la propiedad de Macpherson, destacando los cambios que, según este autor, ha experimentado el concepto de propiedad, que se contempla desde mediados del siglo XX más como un rédito, como un derecho a obtener un ingreso, que como un derecho sobre cosas materiales. Esta concepción del derecho de propiedad puede favorecer la visión de la propiedad como «el derecho de acceso a los medios de producción existentes, es decir, a algunos de los recursos productivos acumulados por el conjunto de la sociedad». Pero Macpherson va más allá y amplía el concepto de propiedad hasta incluir, en palabras suyas, «el derecho a una parte del poder político e, incluso, un derecho a un tipo de sociedad o conjunto de relaciones de poder que posibilita al individuo vivir una vida plenamente humana».

El artículo termina con algunas apreciaciones críticas y conclusiones sugeridas por la teoría política de este autor.

(Daniel González Lagier) 


\section{ZAPATERO GÓMEZ, Virgilio.}

Tres visiones sobre el Estado de bienestar.

Sistema, Madrid, núms. 80-81, noviembre 1987, págs. 23-37.

En la introducción, que es a la vez síntesis de todo el artículo, su autor escribe: «El siglo XX, en especial tras la segunda guerra mundial, ha visto cómo conservadores, liberales y socialistas compartían, en sus líneas básicas, una idéntica estrategia frente al paro, la falta de viviendas, la inseguridad que provoca la vejez, la ignorancia y la enfermedad. Las tres orientaciones ideológicas más importantes de nuestro siglo llegaron a la conclusión de que el David que mejor podía vencer a este Goliat de cinco cabezas era un orden social basado en la democracia, por un lado, y en una combinación proporcionada, por otro, de mercado y Estado, de lo público y lo privado. Estaban, pues, entonces de acuerdo -pese a que hoy algunos de ellos no lo recuerden, o no lo sepan, o simplemente renieguen de ello- en consolidar el denominado Estado de Bienestar.

Ello no quiere decir que compartieran razones y objetivos. Desde el punto de vista teórico y estratégico, el Estado de Bienestar era considerado, por unos y otros, al mismo tiempo como:

-Un engranaje necesario para el buen funcionamiento del sistema.

-Una fase superior en el desarrollo de la idea de ciudadanía.

-Un valioso instrumento de redistribución de la riqueza, de obtener mayor igualdad.

Seguridad, libertad e igualdad fueron los objetivos que perseguían conservadores, liberales y socialistas y que constituyeron el núcleo axiológico del llamado (R. Dahrendorf) "consenso socialdemócrata", base del Estado de Bienestar.»

El artículo realiza un breve recorrido a través del «peculiar y curiosamente convergente camino hacia el Welfare State de unos y otros».

"Yo me inclino a pensar -concluye el autor, después de analizar las "respuestas" conservadora, liberal y socialista y ver "cómo ha sido posible una convergencia tan feliz"- que fue la astucia de la razón la que, por caminos insospechados, condujo a conservadores, liberales y socialistas a formular el gran contrato social del siglo XX: un orden social, económico y político, comúnmente conocido como Estado de Bienestar, que ha dado a Europa las más altas cotas históricas de seguridad, libertad e igualdad.

Parece que el consenso se halla hoy roto y amenaza el futuro del Estado de Bienestar. Hasta qué punto es cierta y, en su caso, definitiva dicha ruptura no está claro. Como tampoco está tan claro el orden social alternativo que pudiera, en su caso, alcanzar similares y/o mayores cotas de progreso. Nuevamente habrá que confiar en que la astucia de la razón se abra camino entre tanto ruido y alumbre un nuevo pacto social que garantice aquello que constituye el objetivo último de las políticas de bienestar: la libertad y la igualdad para todos.»

(Juan Antonio Pérez Lledó)

ZULETA PUCEIRO, Enrique. 


\section{Teoría del Derecho. Una introducción crítica.}

Ed. Depalma, Buenos Aires, 1987, 164 págs.

Este libro se compone de seis capítulos que conforman un conjunto «de enfoques parciales, de conclusiones y balances provisorios, que buscan la forma cristalizada del libro al sólo efecto de contar con una base desde la cual trabajar con un poco más de firmeza».

El primero de estos capítulos (La teoría del Derecho como problema) aborda, en primer lugar, la visión de la filosofía del Derecho como concepto histórico que, como tal, aparece vinculada a «una estructura histórica y cultural determinada» y refleja los cambios que se han producido en ella desde finales del siglo XVIII y principios del XX. A continuación relaciona la filosofía del Derecho con la teoría general del Derecho, entendiendo que «las diferencias (de la teoría general del Derecho) con la filosofia del Derecho son, sin embargo, no sustanciales, y prueba de ello es el hecho de que buena parte de la abundante literatura reciente, sobre la asignatura, transita caminos paralelos alternativamente situados entre teoría general del Derecho y filosofía del Derecho». Por último comenta la posibilidad y las dificultades con las que tropieza «el empeño por una Big Theory en el ámbito del Derecho, ya sea bajo la forma tradicional de la filosofía del Derecho, o bien bajo la aparentemente más rigurosa estructura de la teoría general del Derecho, acuñada por el positivismo -tanto en sus variantes realistas como analíticas-»).

El capítulo II (Teoría jurídica y nueva filosofía de la ciencia) trata los interrogantes planteados por la proyección al campo del Derecho de los nuevos enfoques sugeridos por la filosofía de la ciencia y las perspectivas que ésta ofrece. Para ello se centra en la cuestión del progreso científico en relación con la teoría del Derecho (tomando como concepto esencial para este enfoque la noción de paradigma, expresión que alude a los marcos dominantes o estilos de pensamiento que predominan y otorgan unidad a una disciplina consolidada) y en la consideración de la teoría del Derecho como saber multiparadigmático.

El capítulo III (Teoría crítica e ideología) se ocupa de algunas corrientes críticas dentro de la teoría jurídica contemporánea, realizando una sumaria esquematización de algunos de sus contenidos y aventurando «un análisis de las líneas de confluencia posible con orientaciones críticas nacidas ya no del ámbito de la crítica ideológica jurídica, sino del eco en el ámbito jurídico de las transformaciones experimentadas por la epistemología y la filosofía de la ciencia también a partir de los años 70». El capítulo IV es un replanteamiento de las relaciones entre justicia, equidad y seguridad jurídica «en el contexto de las transformaciones actuales del Derecho», prestando una atención especial al problema de la decisión judicial, que «debe trascender el nivel del control procedimental y asumir la compleja problemática filosófico-política y práctica de la igualdad».

El capítulo V (Fuentes del Derecho) estudia la evolución de la noción de «fuentes del Derecho» en el modelo del Derecho común, en la codificación y en los actuales fenómenos de la legislación, es decir, en lo que el autor llama el modelo de la decodificación, observando «hasta qué punto la tradición romanista ofrece una línea evolutiva dentro de la cual es dable advertir modelos normativos y teorías de las fuentes distintos y aún opuestos»».

Por último, el capítulo VI (Derecho y orden social) analiza los cambios en el Derecho producidos por el Estado social y la crisis de legitimación.

(Daniel González Lagier) 